\title{
Induction of Cytotoxicity in Pyridine Analogues of the Antimetastatic Ru(III) Complex NAMI-A by Ferrocene Functionalization
}

Changhua Mu,${ }^{\dagger}$ Stephanie W. Chang, ${ }^{\dagger}$ Kathleen E. Prosser, ${ }^{\dagger}$ Ada W. Y. Leung ${ }^{\S}$, Stephanie Santacruz, ${ }^{\dagger, \dagger}$ Thalia Jang, ${ }^{\dagger}$ John R. Thompson, ${ }^{\dagger}$ Donald T. T. Yapp, ${ }^{\S}$ Jeffrey J. Warren, ${ }^{\dagger}$ Marcel B. Bally, ${ }^{\S}$ Timothy V. Beischlag, ${ }^{\ddagger}$ and Charles J. Walsby, ${ }^{\dagger}{ }^{\dagger}$

${ }^{\dagger}$ Department of Chemistry, Simon Fraser University, 8888 University Drive, Burnaby, BC, Canada, V5A 1S6

${ }^{\ddagger}$ Faculty of Health Sciences, Simon Fraser University, 8888 University Drive, Burnaby, BC, Canada, V5A 1S6

${ }^{\S}$ Department of Experimental Therapeutics, BC Cancer Agency, 675 West 10th Ave, Vancouver, BC, Canada, V5Z 4E6

\section{Supporting Information}

Table of Contents

1. Synthetic procedures for selected ligands and complexes. .53

- $\quad$ Synthetic procedure for 4-Ferrocenyl(vinyl)pyridine (4-FcVinylPyr)

- Synthetic procedure for [H(4-FcPyr)][trans-Ru(DMSO-S)(4-FcPyr)Cl $\left.{ }_{4}\right]$ (Ru-4FcPyr/H(4-FcPyr))

- Synthetic procedure for $[\mathrm{H}(3-\mathrm{FcPyr})]\left[\right.$ trans-Ru(DMSO-S)(3-FcPyr)Cl $\left.{ }_{4}\right](\mathbf{R u}-3-$ FcPyr/H(3-FcPyr))

- Synthetic procedure for [PPN][trans-Ru(DMSO) $\left.)_{2} \mathrm{Cl}_{4}\right]$

- Synthetic procedure for [PPN][trans-Ru(DMSO-S)(4-FcEtPyr)Cl 4 ( Ru-4-FcEtPyr/PPN)

2. Crystal structure determination

- Table S1. Crystal data and details of data collection and refinement.

- Table S2. Selected bond lengths from X-ray crystal structures.

3. Nuclear magnetic resonance spectroscopy .S7

- Figure S1(a-d). ${ }^{1} \mathrm{H}$ NMR spectra of all synthesized ferrocenyl ligands.

4. Optical Spectroscopy

- Figure S2(a-c). UV-vis spectra for the solution behavior of complexes.

- Figure S3(a-d). UV-vis spectra of ligands. 
- Figure S4(a-d). Deconvolution of EPR spectra of complexes in PBS.

- Table S3. g values and line widths used in the simulations of the EPR spectra from the complexes in PBS.

- Figure S5(a-d). Deconvolution of EPR spectra of complexes with hsA in PBS.

- Table S4. g values and line widths used in the simulations of the EPR spectra from the complexes in PBS with hsA.

6. Electrochemistry

- Figure S6(a-f). Cyclic voltammetry of complexes in DMF.

- Figure S7(a-e). Cyclic voltammetry of complexes in PBS.

- Figure S8. Differential pulse voltammetry of Ru-4-FcEtPyr in PBS.

7. Density functional theory calculations

- Figure S9(a-e). DFT optimized structures of complexes.

- Table S6(a-e). DFT optimized structure coordinates of complexes.

- Table S7(a-e). DFT optimized structure bond lengths of complexes.

- Table S8(a-e). DFT optimized structure bond angles of complexes.

- Table S9(a-e). DFT Mulliken atomic spin densities of complexes. 


\section{Synthetic procedures for selected ligands and complexes}

\section{Synthetic procedure for 4-ferrocenyl(vinyl)pyridine (4-FcVinylPyr)}

4-FcVinylPyr was synthesized following the literature procedure reported by Bhadbhade et $^{\text {al }}{ }^{1}$ with slight modification. To a solution of lithium diisopropylamide $\left(\operatorname{Li}\left[\mathrm{NPr}_{2}{ }_{2}\right], 1.1 \mathrm{~mL}, 2.2 \mathrm{mmol}\right)$ in tetrahydrofuran (THF, distilled, same below) $(12 \mathrm{~mL})$ at $-78{ }^{\circ} \mathrm{C}$ under $\mathrm{N}_{2}$, 4-picoline (195 $\mu \mathrm{L}, 2.0$ mmol) in THF ( $8 \mathrm{~mL})$ was added, and the resulting solution was stirred for 1 hour. A solution of ferrocenecarboxaldehyde $(0.428 \mathrm{~g}, 2.0 \mathrm{mmol})$ in THF $(10 \mathrm{~mL})$ was then added dropwise, and the mixture was stirred overnight at room temperature and quenched with $5 \mathrm{~mL}$ of water. The mixture was extracted several times into dichloromethane. The organic layers were combined, washed with brine, dried over $\mathrm{MgSO}_{4}$, and the solvent was removed under vacuum. The resulting residue was dissolved in dry pyridine $(6 \mathrm{~mL})$ and a solution of $\mathrm{POCl}_{3}(466 \mu \mathrm{L}, 5 \mathrm{mmol})$ in pyridine $(4 \mathrm{~mL})$ was added dropwise under $\mathrm{N}_{2}$. After stirring for 3 hours, ice was added to quench the reaction. A dark gum was obtained when solvent was removed under vacuum. Water $(30 \mathrm{~mL})$ was added followed by $\mathrm{NaOH}$ solution $(4.0 \mathrm{M})$ to adjust the $\mathrm{pH}$ value of the solution to between 8 and 9. The suspension was extracted several times into dichloromethane and dried over $\mathrm{MgSO}_{4}$. Solvent was then removed under vacuum to yield a dark solid. The crude product was isolated by column chromatography on alumina, eluting with dichloromethane/hexanes $(1: 1, \mathrm{v} / \mathrm{v})$. The first reddish band was collected and solvent was removed under vacuum to obtain a dark red solid. Purification was carried out by eluting the resulting material on a silica gel column with a mixture of dichloromethane/hexanes $(9: 1, \mathrm{v} / \mathrm{v})$, which flushed out two orange bands. Subsequently, the eluent was changed to a mixture of dichloromethane/methanol $(9: 1, \mathrm{v} / \mathrm{v})$, allowing collection of third dark red fraction. Solvent was

removed under vacuum to yield 4-Ferrocenyl(vinyl)pyridine as a bright red solid. Yield: $47 \%$. ${ }^{1} \mathrm{H}$ NMR shown in Figure S1(c).

\section{Synthetic procedure for $[\mathrm{H}(4-\mathrm{FcPyr})][$ trans-Ru(DMSO-S)(4-FcPyr)Cl $]$ (Ru-4-FcPyr/H(4- FcPyr))}

To a suspension of $\left[(\mathbf{D M S O})_{2} \mathbf{H}\right]\left[\right.$ trans $\left.-\mathbf{R u}(\mathbf{D M S O})_{2} \mathbf{C l}_{4}\right] \quad(0.556 \mathrm{~g}, 1.0 \mathrm{mmol})$ in acetone $(10 \mathrm{~mL})$, 4.0 equivalents of $\mathbf{4 - F c P y r}(1.052 \mathrm{~g}, 4.0 \mathrm{mmol})$ was added. After the resulting mixture was stirred at room temperature for 6 hours, the color of suspended solid changed from orange to brown. The solution was filtered and washed with cool acetone $(3 \times 2 \mathrm{~mL})$ and diethyl ether $(3 \times 2 \mathrm{~mL})$. The solid was collected and dried under vacuum to afford the pure target compound. Yield: $86 \%$. EA: $\mathrm{C}_{32} \mathrm{H}_{33} \mathrm{Cl}_{4} \mathrm{~N}_{2} \mathrm{SOFe}_{2} \mathrm{Ru}$ Calc. C 45.31, H 3.92, N 3.30. Found C 45.52, H 4.04, N 3.46. Melting point: 218-220 ${ }^{\circ} \mathrm{C}$ (decomp.) Crystals suitable for X-ray diffraction were obtained by dissolving the compound in a mixture of acetone and diethyl ether $(8: 2, \mathrm{v} / \mathrm{v})$ at room temperature followed by cooling at $-18^{\circ} \mathrm{C}$ for 2 weeks.

\section{Synthetic procedure for [H(3-FcPyr)][trans-Ru(DMSO-S)(3-FcPyr)Cl 4 (Ru-3-FcPyr/H(3- FcPyr))}

The procedure was as described above for Ru-4-FcPyr/4-FcPyr. Yield: 88\% EA: $\mathrm{C}_{32} \mathrm{H}_{33} \mathrm{Cl}_{4} \mathrm{~N}_{2} \mathrm{SOFe}_{2} \mathrm{Ru}$ Calc. C 45.31, H 3.92, N 3.30. Found C 45.18, H 3.88, N 3.35. Melting point: 
176-178 ${ }^{\circ} \mathrm{C}$ (decomp.). Crystals suitable for X-ray diffraction were obtained by dissolving the compound in a mixture of acetone and diethyl ether $(8: 2, \mathrm{v} / \mathrm{v})$ at room temperature followed by cooling at $-18^{\circ} \mathrm{C}$ for 2 weeks.

\section{Synthetic procedure for $[\mathrm{PPN}]\left[\right.$ trans $\left.-\mathrm{Ru}(\mathrm{DMSO})_{2} \mathrm{Cl}_{4}\right]$}

To a suspension of $\left[(\mathbf{D M S O})_{\mathbf{2}} \mathbf{H}\right]\left[\right.$ trans $\left.-\mathbf{R u}(\mathbf{D M S O})_{2} \mathbf{C l}_{4}\right](0.100 \mathrm{~g}, 0.18 \mathrm{mmol})$ in acetone $(3 \mathrm{~mL})$, 1.5 equivalents of bis(triphenylphosphoranylidene)ammonium chloride (PPNCl) (0.155 g, 0.27 mmol) was added. Dichloromethane was added dropwise to the mixture under stirring until the solid was totally dissolved. The resulting solution was stirred for $30 \mathrm{~min}$ at room temperature before half of the solvent was removed under vacuum. Sufficient diethyl ether was added to precipitate the product, which was filtered, washed with diethyl ether, and dried in air. The product was used as a starting material in the following reaction without further purification.

\section{Synthetic procedure for [PPN][trans-Ru(DMSO-S)(4-FcVinylPyr)Cl 4 (Ru-4-FcVinylPyr/PPN)}

To a solution of [PPN][trans-Ru(DMSO $\left.)_{2} \mathbf{C l}_{4}\right](0.094 \mathrm{~g}, 0.1 \mathrm{mmol})$ in dichloromethane $(10 \mathrm{~mL})$, 2.5 equivalents of 4-FcVinylPyr $(0.072 \mathrm{~g}, 0.25 \mathrm{mmol})$ was added. After the resulting mixture was stirred at room temperature for 6 hours, hexanes $(20 \mathrm{~mL})$ was added to precipitate the product. The product was purified through recrystallization and crystals suitable for X-ray diffraction were obtained by dissolving the compound in a mixture of dichloromethane and hexanes (7:3, v/v), and allowing the solvents to evaporate slowly at room temperature for 4 days. EA: $\mathrm{C}_{55} \mathrm{H}_{51} \mathrm{Cl}_{4} \mathrm{FeN}_{2} \mathrm{OP}_{2} \mathrm{RuS} \cdot 2 \mathrm{CH}_{2} \mathrm{Cl}_{2}$ Calc. C 51.92, H 4.20, N 2.12, S 2.43. Found C 51.56, H 4.56, N 2.38, S 2.14. Melting point: $178-180^{\circ} \mathrm{C}$ (decomp.)

\section{Synthetic procedure for [PPN][trans-Ru(DMSO-S)(4-FcEtPyr)Cl 4 (Ru-4-FcEtPyr/PPN)}

The procedure was as described for Ru-4-FcVinylPyr/PPN. Crystals suitable for X-ray diffraction were obtained by dissolving the compound in a mixture of dichloromethane and hexanes (7:3, v/v) at room temperature followed by cooling at $-18{ }^{\circ} \mathrm{C}$ for 1 week. The yield of crystals was too low to carry out other characterization.

(1) Bhadbhade, M. M.; Das, A.; Jeffery, J. C.; McCleverty, J. A.; Navas Badiola, J. A.; Ward, M. D., J. Chem. Soc., Dalton Trans. 1995, 2769-77. 


\section{Crystallographic Structure Determination}

Table S1. Crystal data and details of data collection and refinement.

\begin{tabular}{|c|c|c|c|c|}
\hline & Ru-4-FcPyr/H(4-FcPyr) & Ru-3-FcPyr/H(3-FcPyr) & Ru-4-FcVinylPyr/PPN & Ru-4-FcEtPyr/PPN \\
\hline Empirical formula & $\mathrm{C}_{34} \mathrm{H}_{37} \mathrm{Cl}_{8} \mathrm{Fe}_{2} \mathrm{~N}_{2} \mathrm{ORuS}$ & $\mathrm{C}_{32} \mathrm{H}_{33} \mathrm{Cl}_{4} \mathrm{Fe}_{2} \mathrm{~N}_{2} \mathrm{ORuS}$ & $\mathrm{C}_{60} \mathrm{H}_{62} \mathrm{Cl}_{8} \mathrm{FeN}_{2} \mathrm{OP}_{2} \mathrm{RuS}$ & $\mathrm{C}_{60} \mathrm{H}_{64} \mathrm{Cl}_{8} \mathrm{FeN}_{2} \mathrm{OP}_{2} \mathrm{RuS}$ \\
\hline$M\left(\mathrm{~g} \mathrm{~mol}^{-1}\right)$ & 1018.08 & 848.23 & 1361.63 & 1363.65 \\
\hline Space group & Monoclinic P 21/c & Triclinic P -1 & Triclinic P -1 & Triclinic P -1 \\
\hline$a(\AA)$ & $7.7643(2)$ & $8.3753(2)$ & $11.9811(5)$ & $12.0000(3)$ \\
\hline$b(\AA)$ & $20.1554(5)$ & $11.7218(3)$ & $15.3443(7)$ & $15.4153(4)$ \\
\hline$c(\AA)$ & $25.7405(6)$ & $18.1258(5)$ & $17.5295(8)$ & $17.4911(4)$ \\
\hline$\alpha(\operatorname{deg})$ & 90 & $76.440(19)$ & $84.6680(10)$ & $84.476(2)$ \\
\hline$\beta(\operatorname{deg})$ & $94.1860(12)$ & $76.946(2)$ & $75.1510(10)$ & $75.3370(10)$ \\
\hline$\gamma(\operatorname{deg})$ & 90 & $89.137(2)$ & $83.2460(10)$ & $84.049(2)$ \\
\hline$V\left(\AA^{3}\right)$ & 4017.45(17) & $1683.82(8)$ & $3086.8(2)$ & $3105.07(13)$ \\
\hline $\mathrm{Z}$ & 4 & 2 & 2 & 2 \\
\hline$\rho_{\text {calc }}\left(\mathrm{g} \mathrm{cm}^{-3}\right)$ & 1.683 & 1.673 & 1.419 & 1.412 \\
\hline$\mu\left(\mathrm{mm}^{-1}\right)$ & 14.349 & 14.132 & 0.953 & 8.131 \\
\hline$\lambda(\AA)$ & 1.54178 & 1.54178 & 0.71073 & 1.54178 \\
\hline$T(\mathrm{~K})$ & 296 & 296 & 150 & 296 \\
\hline Goodness of fit & 1.061 & 1.012 & 0.994 & 1.013 \\
\hline$R_{1}$ & 0.0534 & 0.0398 & 0.0322 & 0.0481 \\
\hline$w R_{2}$ & 0.1479 & 0.1016 & 0.0932 & 0.1409 \\
\hline
\end{tabular}


Table S2. Selected bond lengths from X-ray crystal structures.

\begin{tabular}{|c|c|c|c|c|c|c|c|}
\hline \multicolumn{2}{|c|}{ Ru-4-FcPyr/H(4-FcPyr) } & \multicolumn{2}{|c|}{ Ru-3-FcPyr/H(3-FcPyr) } & \multicolumn{2}{|c|}{ Ru-4-FcVinylPyr/PPN } & \multicolumn{2}{|c|}{ Ru-4-FcEtPyr/PPN } \\
\hline Bond & $\begin{array}{c}\text { Bond Length } \\
\text { (^) }\end{array}$ & Bond & $\begin{array}{c}\text { Bond Length } \\
\text { (Å) }\end{array}$ & Bond & $\begin{array}{c}\text { Bond Length } \\
\text { (̊) }\end{array}$ & Bond & $\begin{array}{c}\text { Bond Length } \\
\text { (Å) }\end{array}$ \\
\hline \multicolumn{2}{|c|}{ Ru Center } & \multicolumn{2}{|c|}{ Ru Center } & \multicolumn{2}{|c|}{ Ru Center } & \multicolumn{2}{|c|}{ Ru Center } \\
\hline Ru1-S1 & $2.2927(16)$ & Ru1-S1 & $2.2942(12)$ & Ru1-S1 & $2.3048(7)$ & Ru1-S1 & $2.3030(10)$ \\
\hline Ru1-N1 & $2.126(5)$ & Ru1-N1 & $2.113(4)$ & Ru1-N1 & $2.110(2)$ & Ru1-N1 & $2.121(3)$ \\
\hline Ru1-Cl1 & $2.3599(16)$ & Ru1-Cl1 & $2.3467(11)$ & Ru1-Cl1 & $2.3568(7)$ & Ru1-Cl1 & $2.3719(11)$ \\
\hline $\mathrm{Ru} 1-\mathrm{Cl} 2$ & $2.3764(16)$ & $\mathrm{Ru} 1-\mathrm{Cl} 2$ & $2.3615(11)$ & $\mathrm{Ru} 1-\mathrm{Cl} 2$ & $2.3398(7)$ & $\mathrm{Ru} 1-\mathrm{Cl} 2$ & $2.3558(11)$ \\
\hline $\mathrm{Ru} 1-\mathrm{Cl} 3$ & $2.3328(16)$ & $\mathrm{Ru} 1-\mathrm{Cl} 3$ & $2.3528(11)$ & $\mathrm{Ru} 1-\mathrm{Cl} 3$ & $2.3467(7)$ & $\mathrm{Ru} 1-\mathrm{Cl} 3$ & $2.3400(10)$ \\
\hline $\mathrm{Ru} 1-\mathrm{Cl} 4$ & $2.3429(17)$ & $\mathrm{Ru} 1-\mathrm{Cl} 4$ & $2.3568(11)$ & $\mathrm{Ru} 1-\mathrm{Cl} 4$ & $2.3678(7)$ & $\mathrm{Ru} 1-\mathrm{Cl} 4$ & $2.3432(11)$ \\
\hline \multicolumn{2}{|c|}{ Fc: Sub-Cp } & \multicolumn{2}{|c|}{ Fc: Sub-Cp } & \multicolumn{2}{|c|}{ Fc: Sub-Cp } & \multicolumn{2}{|c|}{ Fc: Sub-Cp } \\
\hline $\mathrm{Fe} 1-\mathrm{C} 6$ & $2.025(7)$ & $\mathrm{Fe} 1-\mathrm{C} 6$ & $2.044(4)$ & $\mathrm{Fe} 1-\mathrm{C} 8$ & $2.038(3)$ & $\mathrm{Fe} 1-\mathrm{C} 8$ & $2.051(4)$ \\
\hline $\mathrm{Fe} 1-\mathrm{C} 7$ & $2.033(9)$ & $\mathrm{Fe} 1-\mathrm{C} 7$ & $2.029(4)$ & $\mathrm{Fe} 1-\mathrm{C} 9$ & $2.046(3)$ & Fe1-C9 & $2.045(5)$ \\
\hline $\mathrm{Fe} 1-\mathrm{C} 8$ & $2.038(9)$ & Fe1-C8 & $2.039(5)$ & $\mathrm{Fe} 1-\mathrm{C} 10$ & $2.048(3)$ & $\mathrm{Fe} 1-\mathrm{C} 10$ & $2.049(4)$ \\
\hline $\mathrm{Fe} 1-\mathrm{C} 9$ & $2.033(9)$ & $\mathrm{Fe} 1-\mathrm{C} 9$ & $2.053(5)$ & $\mathrm{Fe} 1-\mathrm{C} 11$ & $2.041(3)$ & $\mathrm{Fe} 1-\mathrm{C} 11$ & $2.030(5)$ \\
\hline $\mathrm{Fe} 1-\mathrm{C} 10$ & $2.013(8)$ & $\mathrm{Fe} 1-\mathrm{C} 10$ & $2.064(5)$ & $\mathrm{Fe} 1-\mathrm{C} 12$ & $2.042(3)$ & $\mathrm{Fe} 1-\mathrm{C} 12$ & $2.038(4)$ \\
\hline \multicolumn{2}{|c|}{ Fc: Cp } & \multicolumn{2}{|c|}{ Fc: Cp } & \multicolumn{2}{|c|}{ Fc: Cp } & \multicolumn{2}{|c|}{ Fc: Cp } \\
\hline Fe1-C11 & $2.018(11)$ & $\mathrm{Fe} 1-\mathrm{C} 11$ & $2.047(6)$ & $\mathrm{Fe} 1-\mathrm{C} 13$ & $2.030(3)$ & $\mathrm{Fe} 1-\mathrm{C} 13$ & $2.026(5)$ \\
\hline $\mathrm{Fe} 1-\mathrm{C} 12$ & $2.016(11)$ & $\mathrm{Fe} 1-\mathrm{C} 12$ & $2.033(6)$ & $\mathrm{Fe} 1-\mathrm{C} 14$ & $2.036(3)$ & $\mathrm{Fe} 1-\mathrm{C} 14$ & $2.050(5)$ \\
\hline $\mathrm{Fe} 1-\mathrm{C} 13$ & $1.998(15)$ & $\mathrm{Fe} 1-\mathrm{C} 13$ & $2.023(6)$ & $\mathrm{Fe} 1-\mathrm{C} 15$ & $2.047(3)$ & $\mathrm{Fe} 1-\mathrm{C} 15$ & $2.041(5)$ \\
\hline $\mathrm{Fe} 1-\mathrm{C} 14$ & $2.023(13)$ & $\mathrm{Fe} 1-\mathrm{C} 14$ & $2.047(6)$ & $\mathrm{Fe} 1-\mathrm{C} 16$ & $2.040(3)$ & Fe1-C16 & $2.047(5)$ \\
\hline $\mathrm{Fe} 1-\mathrm{C} 15$ & $2.009(14)$ & $\mathrm{Fe} 1-\mathrm{C} 15$ & $2.045(5)$ & $\mathrm{Fe} 1-\mathrm{C} 17$ & $2.034(3)$ & $\mathrm{Fe} 1-\mathrm{C} 17$ & $2.034(5)$ \\
\hline & & & & \multicolumn{2}{|c|}{ Linker } & \multicolumn{2}{|c|}{ Linker } \\
\hline & & & & C3-C6 & $1.459(4)$ & C3-C6 & $1.488(6)$ \\
\hline & & & & C6-C7 & $1.327(4)$ & C6-C7 & $1.501(6)$ \\
\hline & & & & C7-C8 & $1.450(4)$ & $\mathrm{C} 7-\mathrm{C} 8$ & $1.499(6)$ \\
\hline
\end{tabular}




\section{Nuclear magnetic resonance spectroscopy}

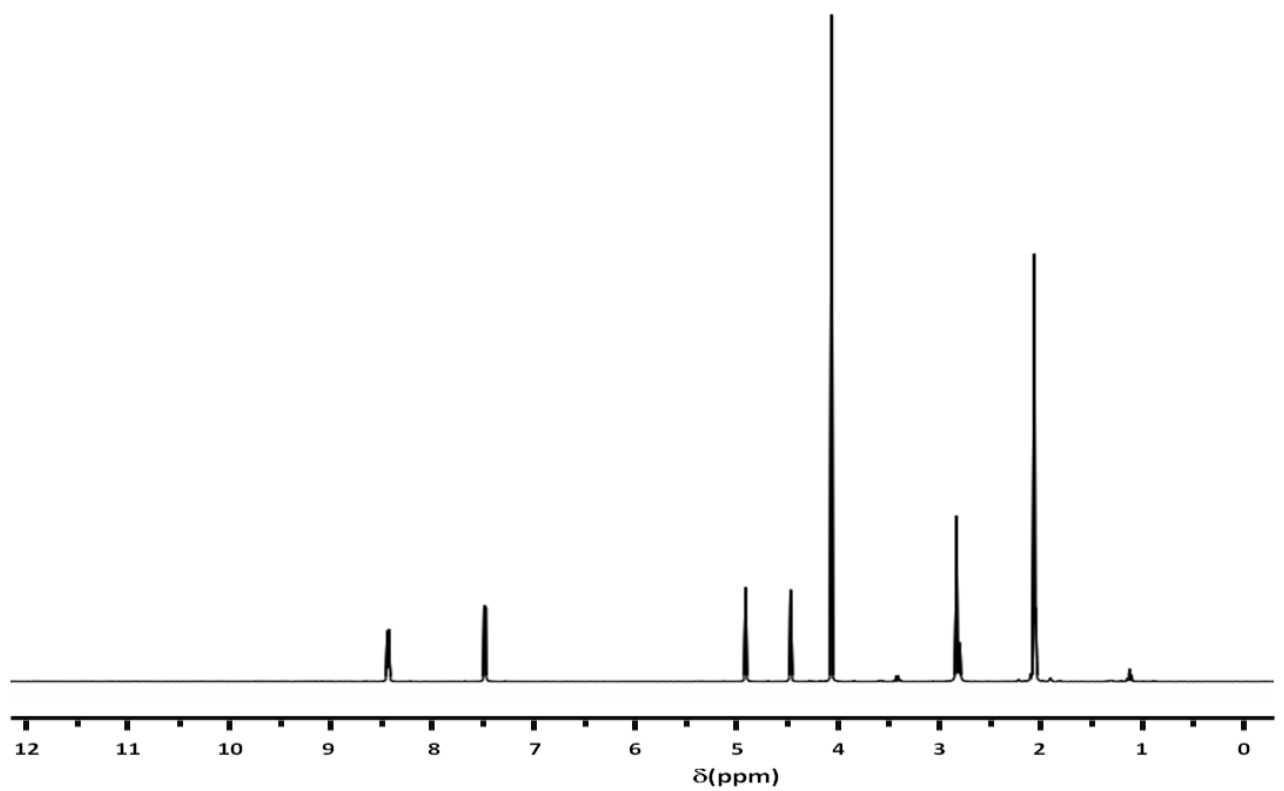

Figure S1(a). ${ }^{1} \mathrm{H}$ NMR spectrum for 4-FcPyr (400 MHz, acetone-d6, ppm): $\delta 8.44(\mathrm{dd}, J=4.3,1.7$ $\mathrm{Hz}, 2 \mathrm{H}$, pyridyl), 7.48 (dd, $J=4.3,1.7 \mathrm{~Hz}, 2 \mathrm{H}$, pyridyl), 4.91 (t, $J=1.9 \mathrm{~Hz}, 2 \mathrm{H}$, sub-Cp), 4.47 (t, $J=$ $1.9 \mathrm{~Hz}, 2 \mathrm{H}$, sub-Cp), 4.07 (s, 5H, Cp).

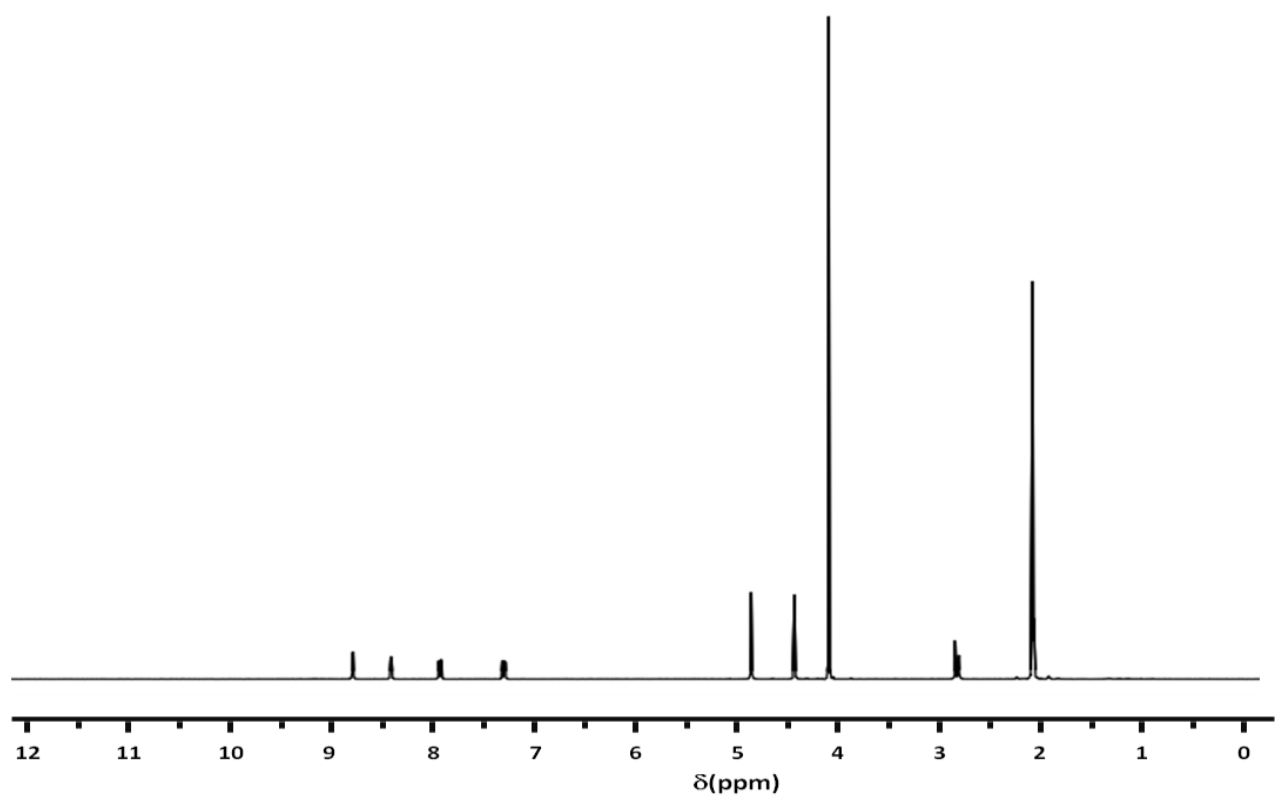

Figure S1(b). ${ }^{1} \mathrm{H}$ NMR spectrum for 3-FcPyr (400 MHz, acetone-d6, ppm): $\delta 8.78$ (dd, $J=2.4,0.9$ $\mathrm{Hz}, 1 \mathrm{H}$, pyridyl), 8.40 (dd, $J=4.7,1.6 \mathrm{~Hz}, 1 \mathrm{H}$, pyridyl), 7.92 (ddd, $J=8.0,2.4,1.6 \mathrm{~Hz}, 1 \mathrm{H}$, pyridyl), 7.28 (ddd, $J=7.9,4.7,0.9 \mathrm{~Hz}, 1 \mathrm{H}$, pyridyl), 4.84 (t, $J=1.9 \mathrm{~Hz}, 2 \mathrm{H}$, sub-Cp), 4.42 (t, $J=1.9 \mathrm{~Hz}, 2 \mathrm{H}$, sub-Cp), 4.08 (s, 5H, Cp). 


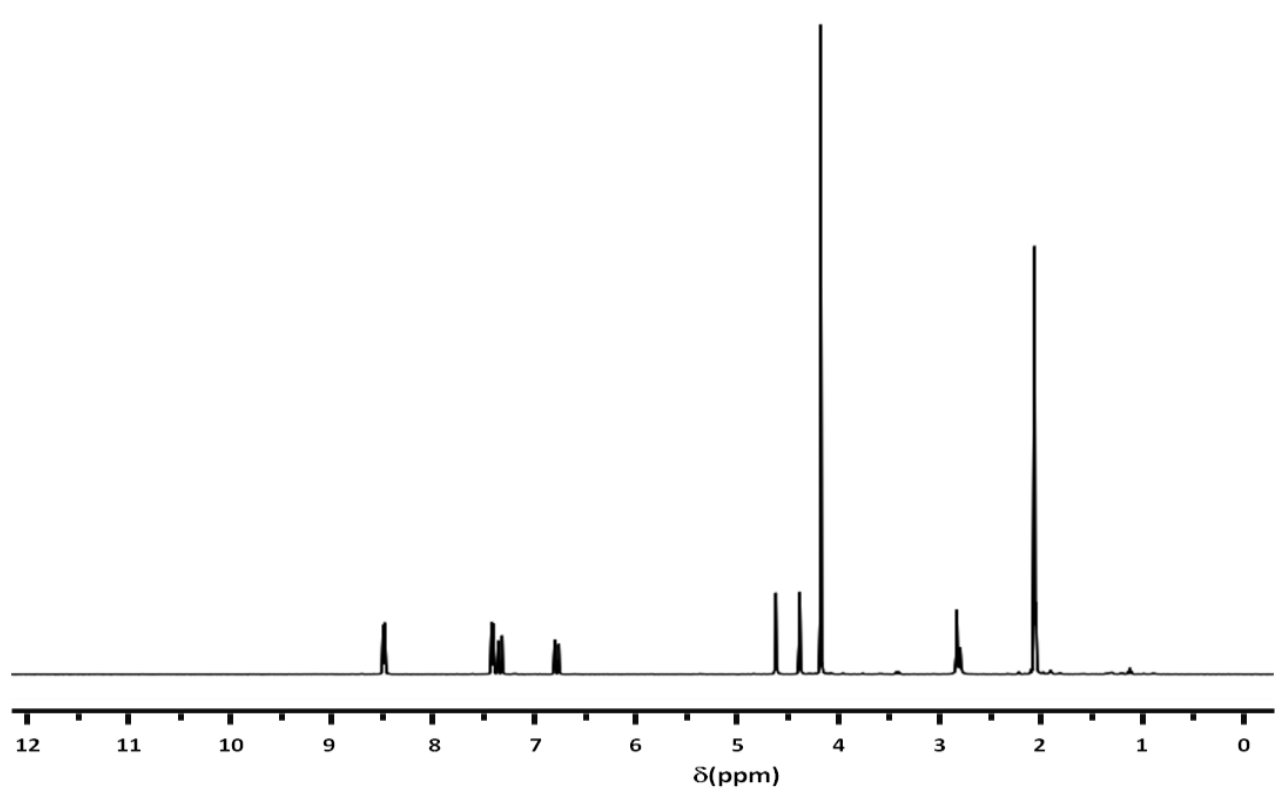

Figure S1(c). ${ }^{1} \mathrm{H}$ NMR spectrum for 4-FcVinylPyr (400 MHz, acetone-d6, ppm): $\delta 8.49$ (dd, $J=4.3$, $1.6 \mathrm{~Hz}, 2 \mathrm{H}$, pyridyl), 7.42 (ddd, $J=4.3,1.6,0.4 \mathrm{~Hz}, 2 \mathrm{H}$, pyridyl), 7.34 (d, $J=16.2 \mathrm{~Hz}, 1 \mathrm{H}$, Vinyllinker), 6.78 (d, $J=16.2,1 \mathrm{H}$, Vinyl-linker), 4.62 (t, $J=1.8,2 \mathrm{H}$, sub-Cp), 4.38 (t, $J=1.8,2 \mathrm{H}$, subCp), 4.18 (s, 5H, Cp).

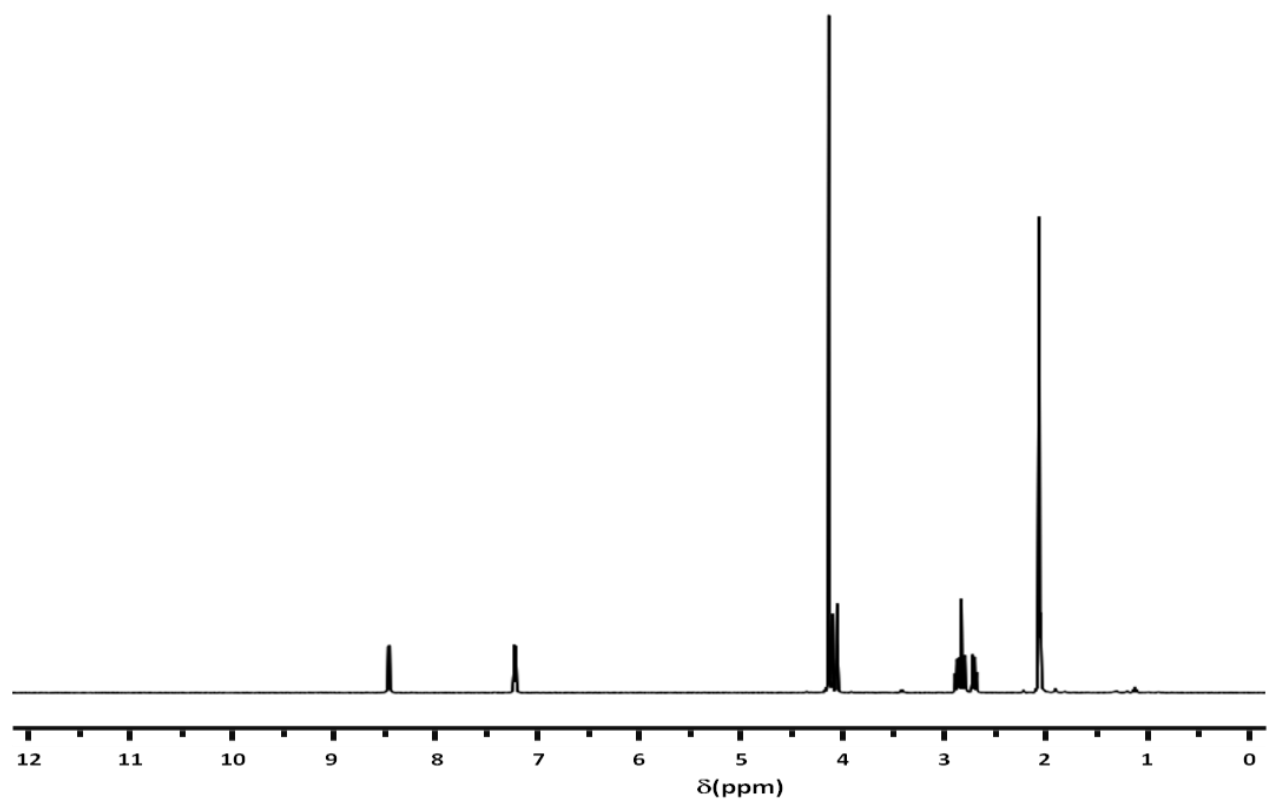

Figure S1(d). ${ }^{1} \mathrm{H}$ NMR spectrum for 4-FcEtPyr (400 MHz, acetone-d6, ppm): $\delta 8.46$ (dd, $J=4.4$, $1.6 \mathrm{~Hz}, 2 \mathrm{H}$, pyridyl), 7.22 (dd, $J=4.4,1.6 \mathrm{~Hz}, 2 \mathrm{H}$, pyridyl), 4.14 (s, 5H, Cp), 4.11 (t, $J=1.8,2 \mathrm{H}$, sub-Cp), 4.06 (t, $J=1.8,2 \mathrm{H}$, sub-Cp), 2.87 (dd, $J=9.5,6.5 \mathrm{~Hz}, 2 \mathrm{H}$, Et-linker), 2.71 (dd, $J=10.3$, $8.7 \mathrm{~Hz}, 2 \mathrm{H}$, Et-linker). 


\section{Optical Spectroscopy}

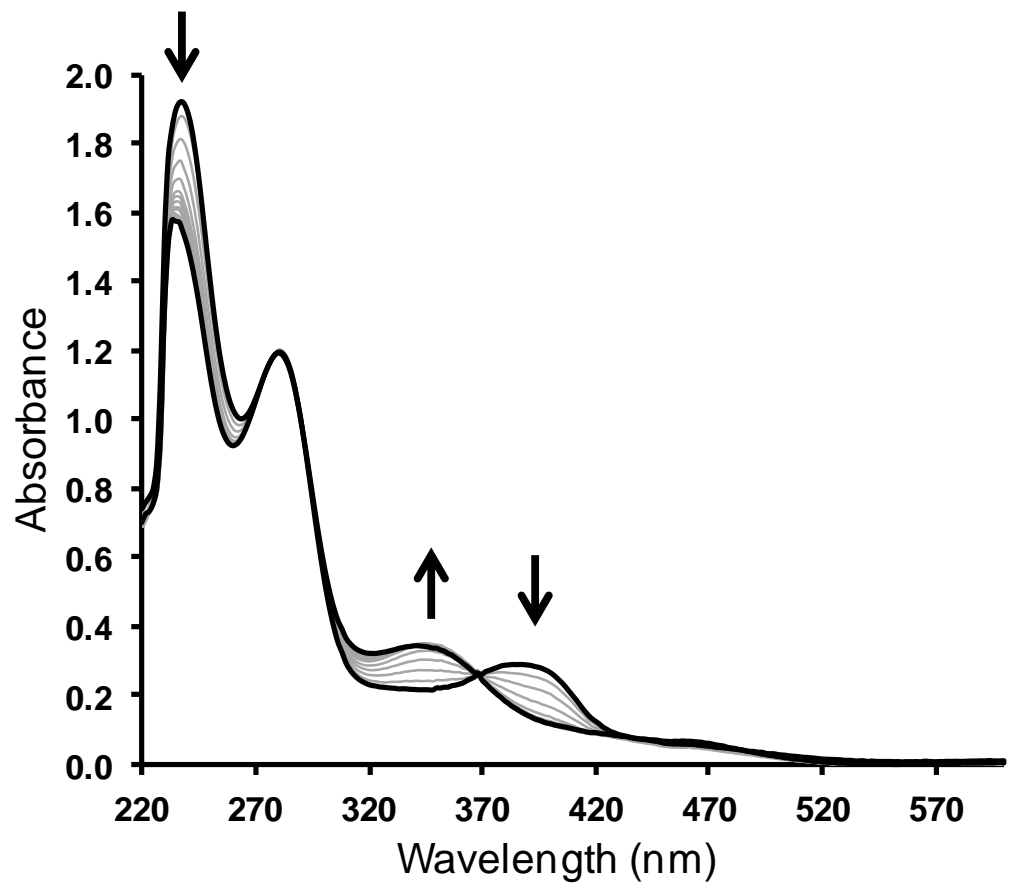

Figure S2(a). UV-vis spectra for the solution behavior of Ru-3-FcPyr in PBS $(80 \mu \mathrm{M})$ at $37{ }^{\circ} \mathrm{C}$ recorded at 1.5 minutes intervals over a period of $18 \mathrm{~min}$.

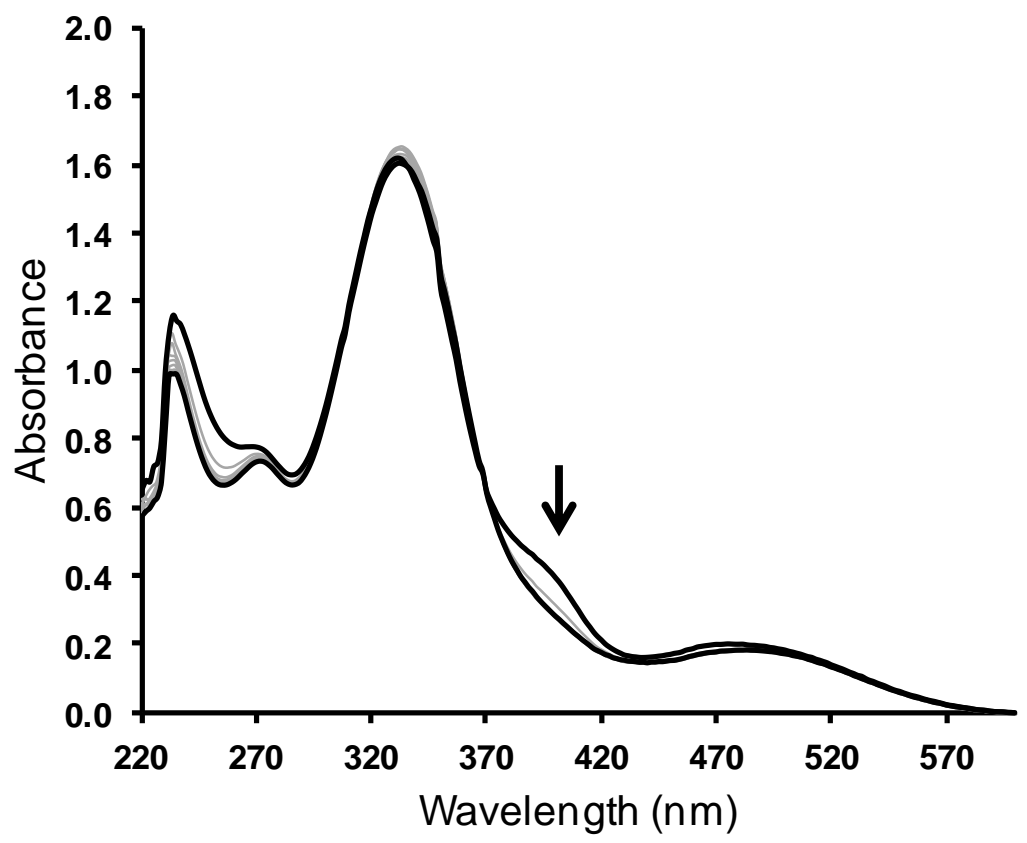

Figure S2(b). UV-vis spectra for the solution behavior of Ru-4-FcVinylPyr in PBS (40 $\mu \mathrm{M})$ at 37 ${ }^{\circ} \mathrm{C}$ recorded at 1.5 minutes intervals over a period of $12 \mathrm{~min}$. 


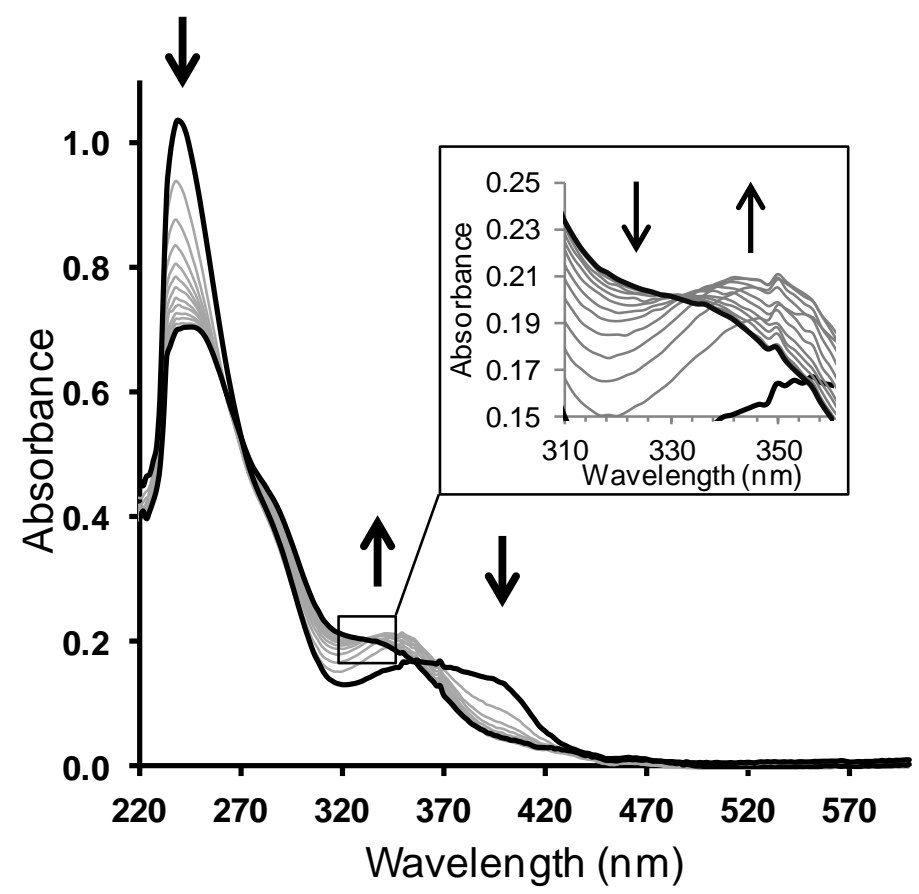

Figure S2(c). UV-vis spectra for the solution behavior of Ru-4-FcEtPyr in PBS $(160 \mu \mathrm{M})$ at $37{ }^{\circ} \mathrm{C}$ recorded at 1.5 minutes intervals over a period of $18 \mathrm{~min}$. 


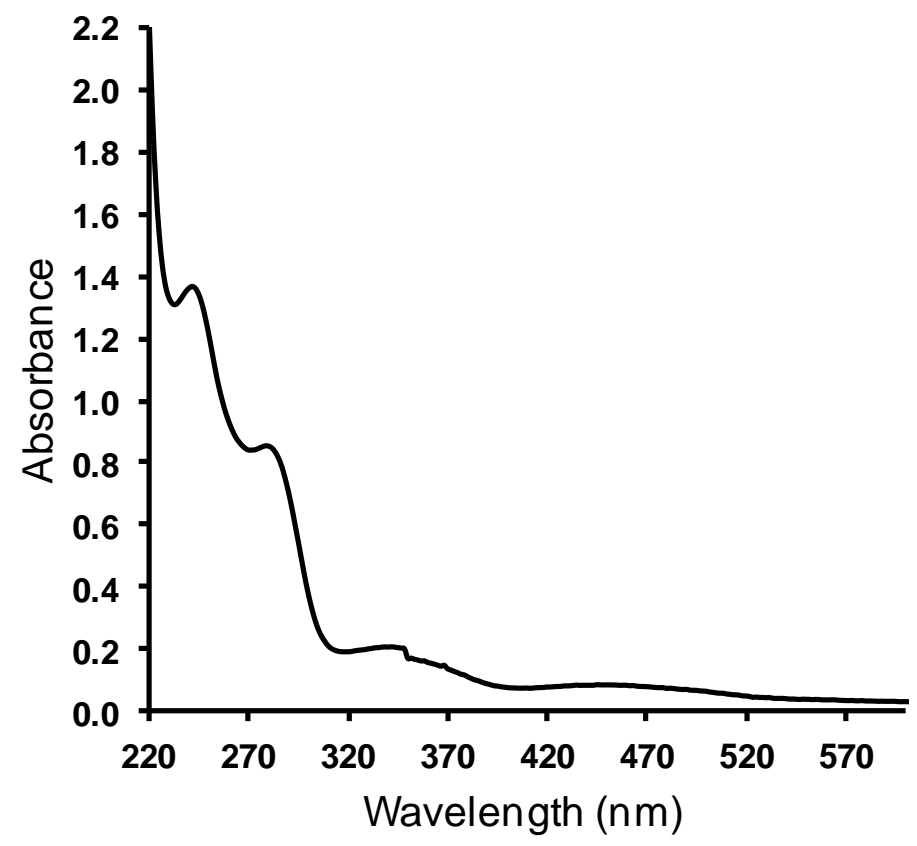

Figure S3(a). UV-vis spectrum for 4-FcPyr in ethanol (80 $\mu \mathrm{M})$.

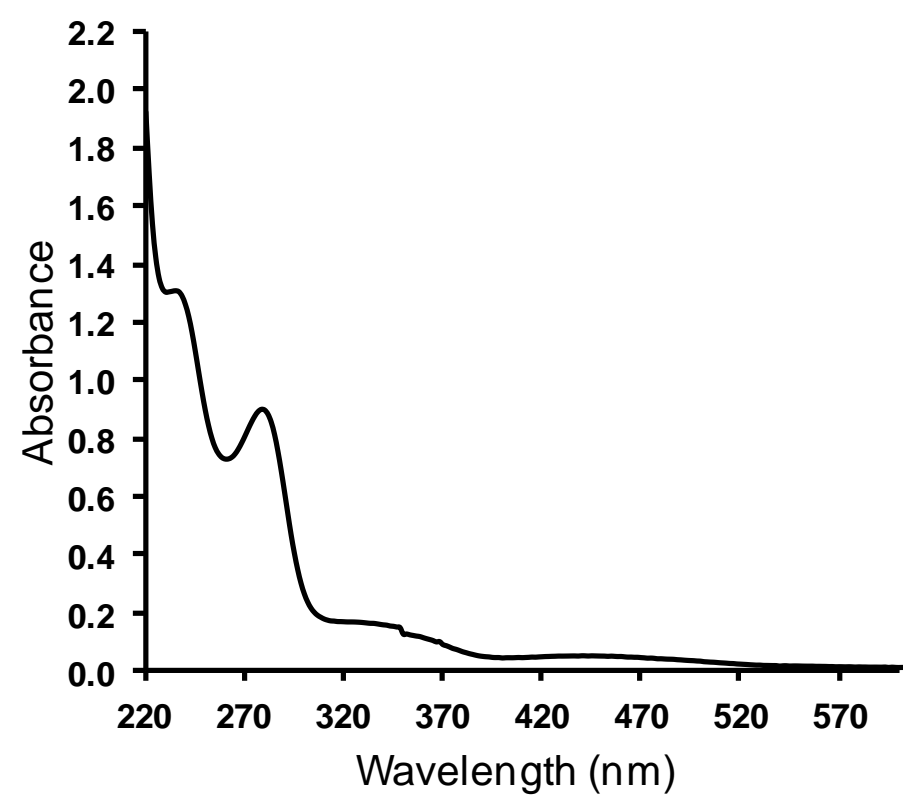

Figure S3(b). UV-vis spectrum for 3-FcPyr in ethanol $(80 \mu \mathrm{M})$. 


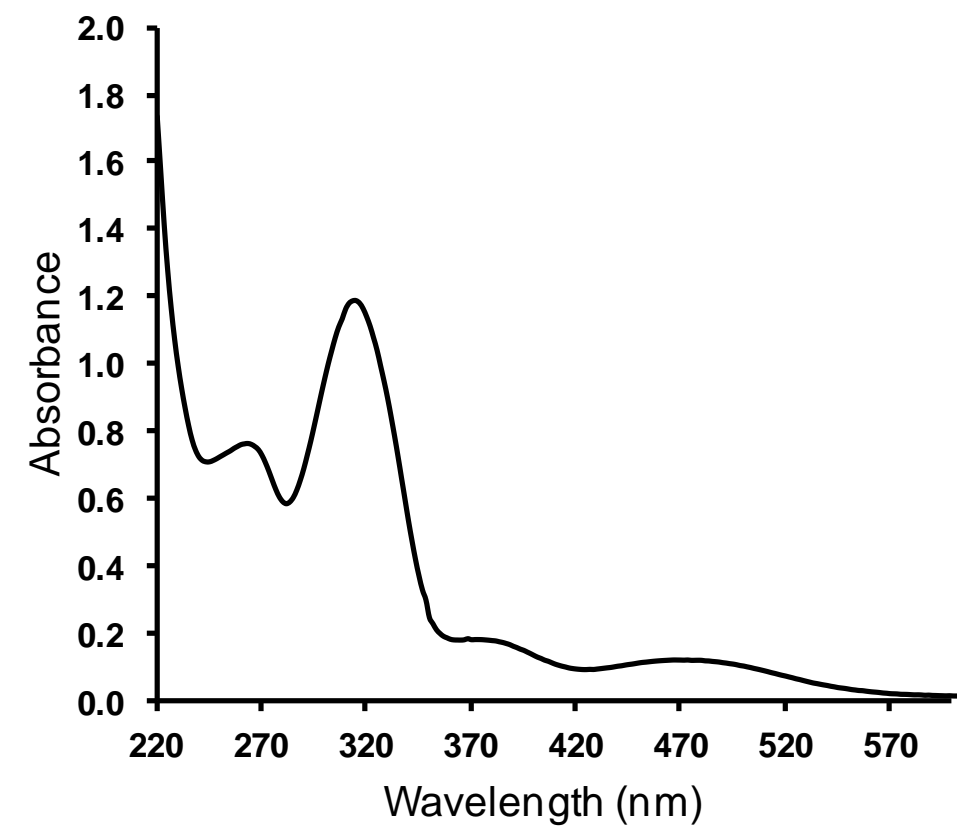

Figure S3(c). UV-vis spectrum for 4-FcVinylPyr in ethanol (40 $\mu \mathrm{M})$.

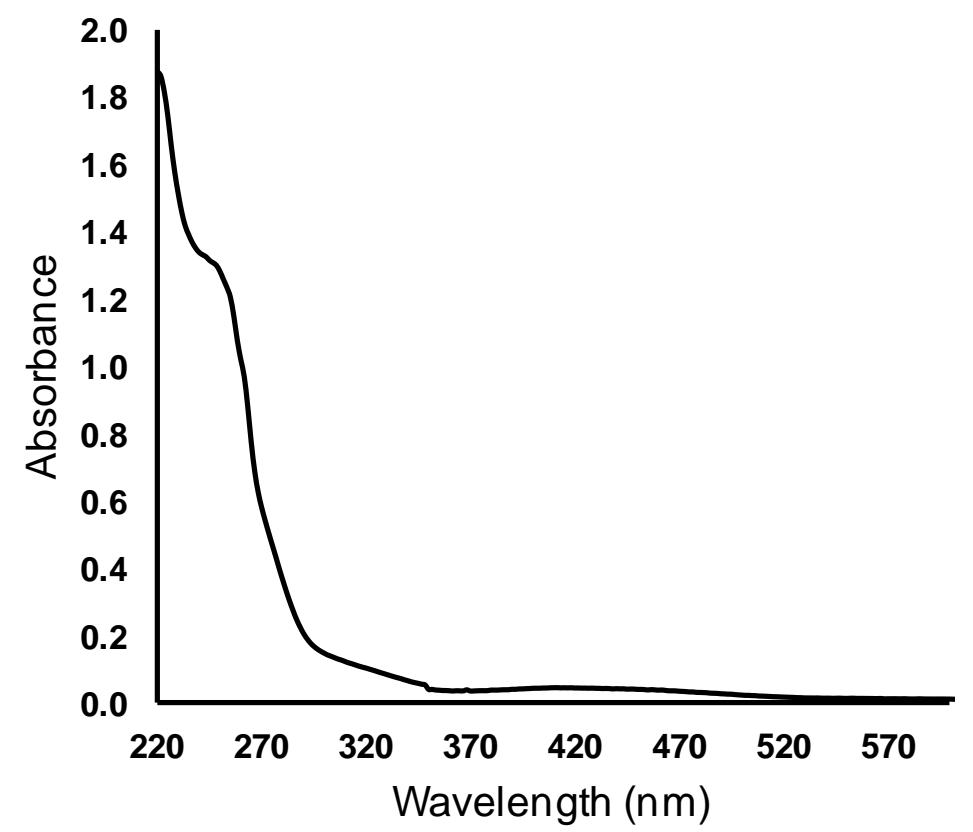

Figure S3(d). UV-vis spectrum for 4-FcEtPyr in ethanol $(160 \mu \mathrm{M})$. 


\section{EPR simulations}

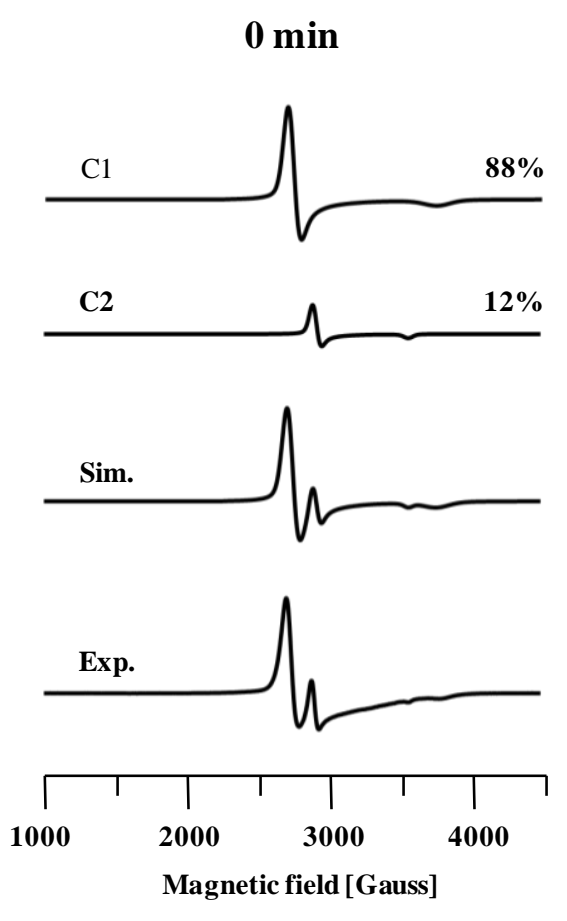

$30 \mathrm{~min}$

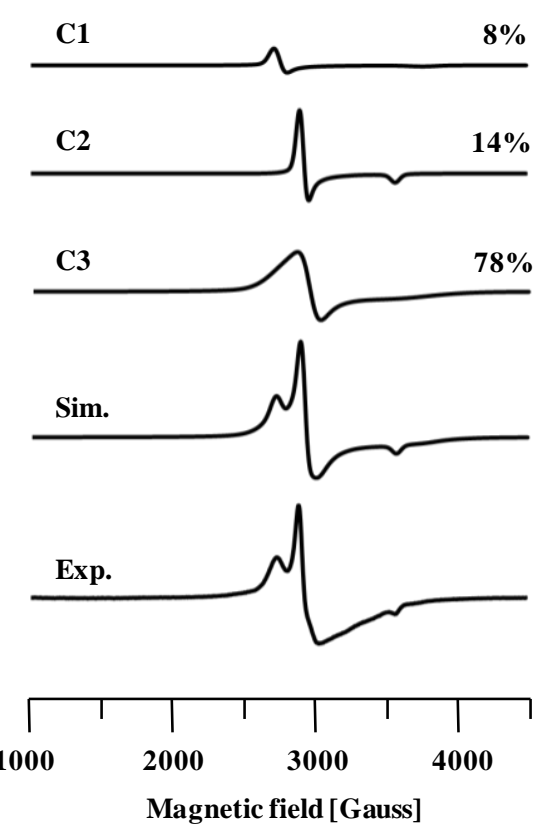

$10 \mathrm{~min}$
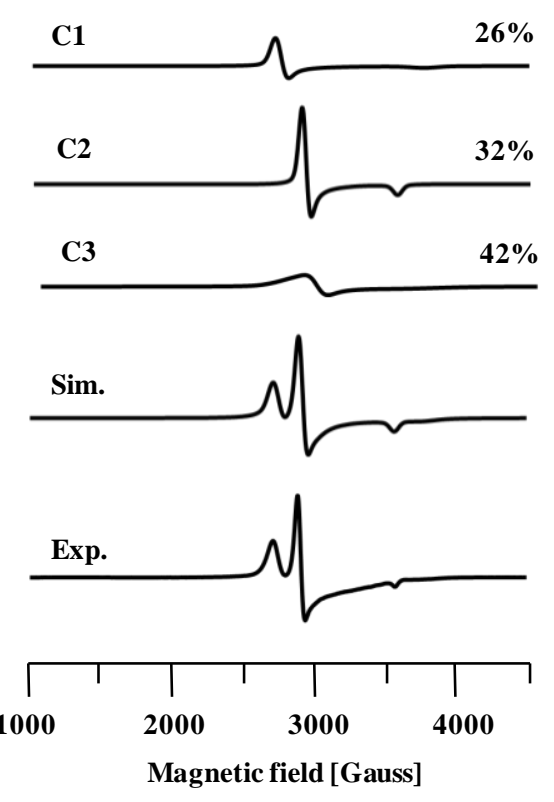

$60 \mathrm{~min}$
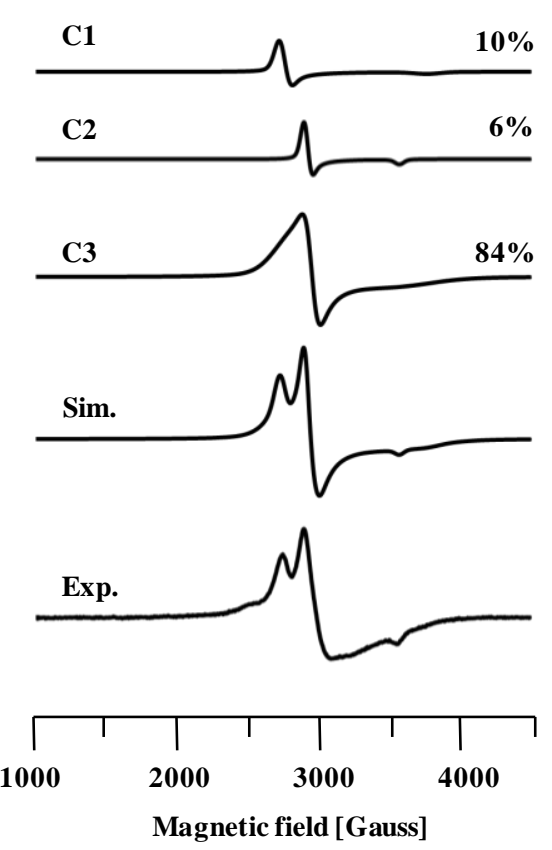

Figure S4(a). Deconvolution of EPR spectra of Ru-4-FcPyr in PBS after incubation for 0, 10, 30 and $60 \mathrm{~min}$ at $37{ }^{\circ} \mathrm{C}$. Experimental conditions: frequency $=9.38 \mathrm{GHz}$, microwave power $=2.0$ $\mathrm{mW}$, time constant $=40.96 \mathrm{~ms}$, modulation amplitude $=6 \mathrm{G}$, average of 5 scans of 2 minutes. Simulation parameters: See Table $\mathbf{S 3}$ for g values and line widths. Relative intensities used in the simulations are shown as percentages on the right of the spectra. 


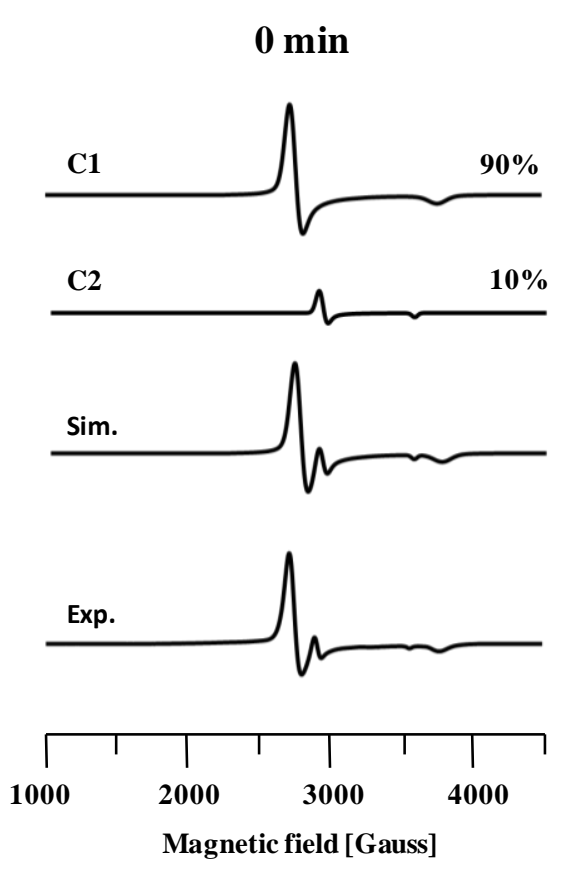

$30 \mathrm{~min}$
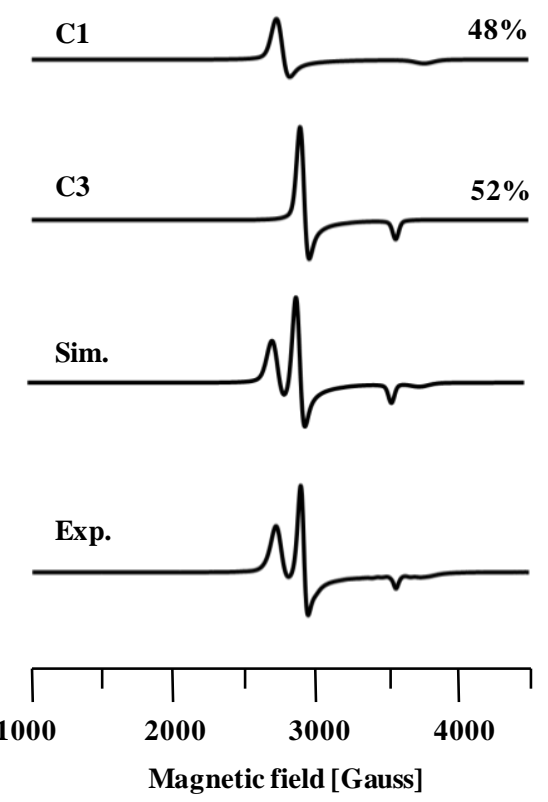

$10 \mathrm{~min}$
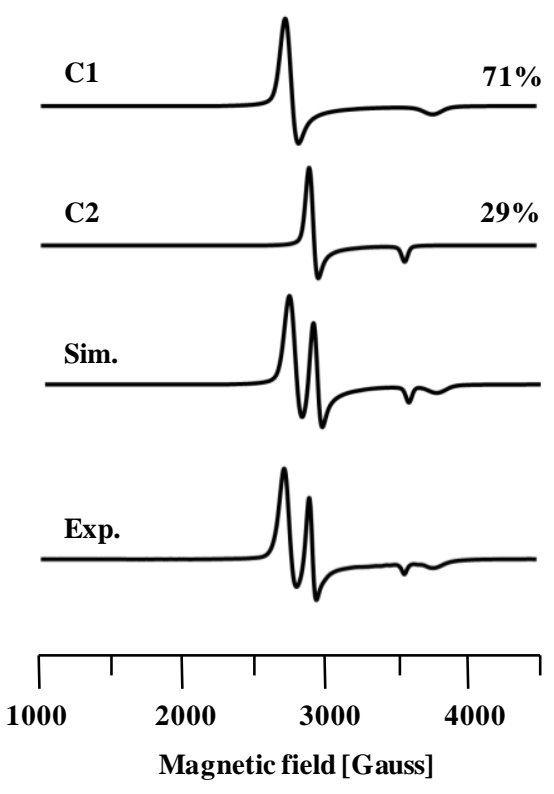

$60 \mathrm{~min}$
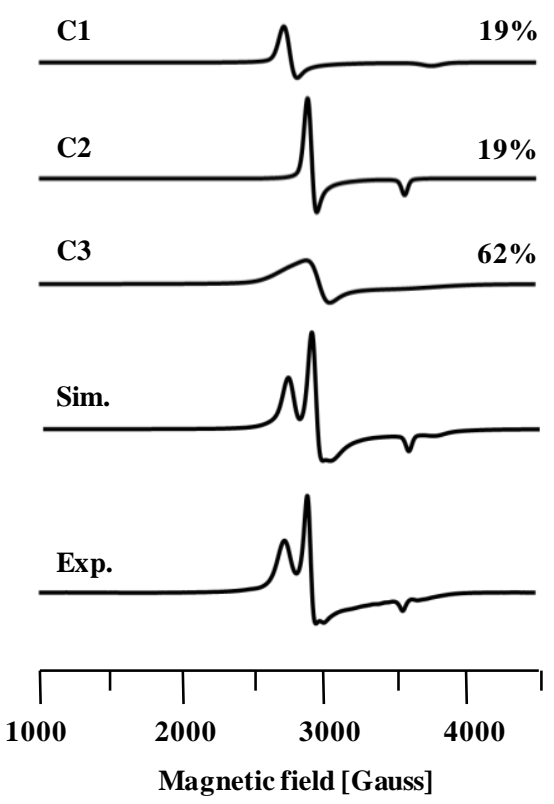

Figure S4(b). Deconvolution of EPR spectra of Ru-3-FcPyr in PBS after incubation for 0, 10, 30 and $60 \mathrm{~min}$ at $37{ }^{\circ} \mathrm{C}$. Experimental conditions: frequency $=9.38 \mathrm{GHz}$, microwave power $=2.0$ $\mathrm{mW}$, time constant $=40.96 \mathrm{~ms}$, modulation amplitude $=6 \mathrm{G}$, average of 5 scans of 2 minutes. Simulation parameters: See Table $\mathbf{S 3}$ for g values and line widths. Relative intensities used in the simulations are shown as percentages on the right of the spectra. 
0 min
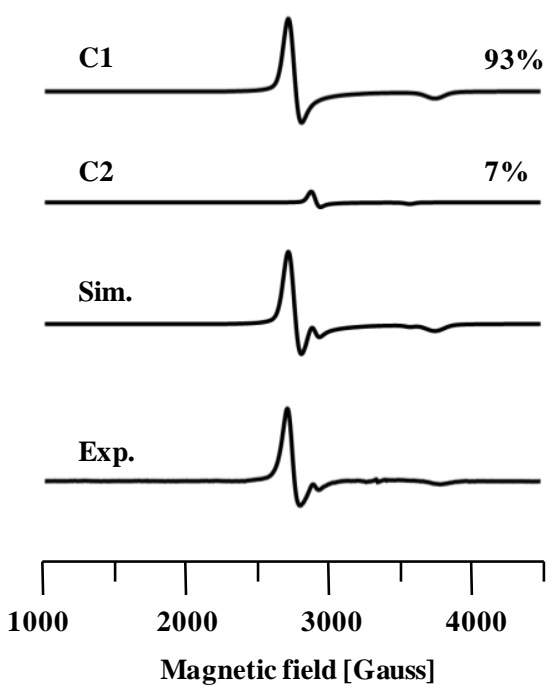

$30 \mathrm{~min}$
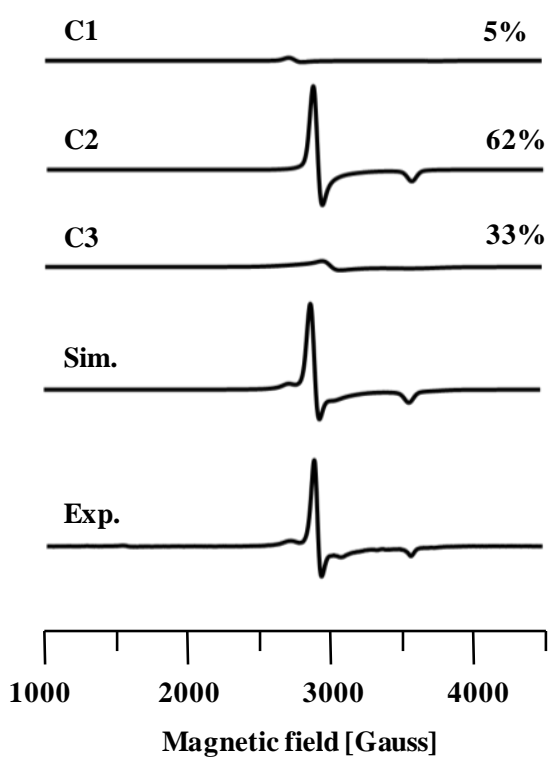

$10 \mathrm{~min}$
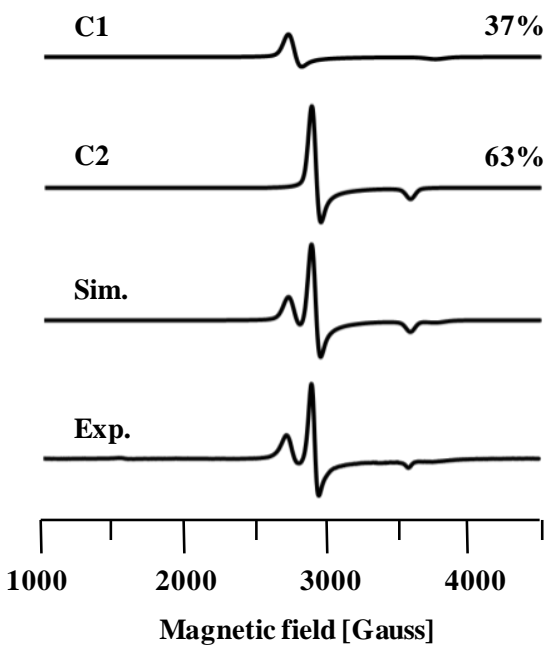

$60 \mathrm{~min}$
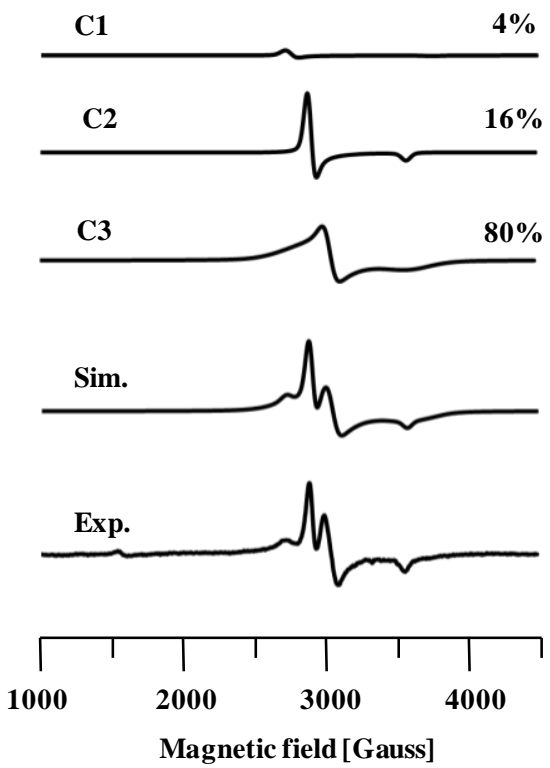

Figure S4(c). Deconvolution of EPR spectra of Ru-4-FcVinylPyr in PBS after incubation for 0, 10, 30 and $60 \mathrm{~min}$ at $37{ }^{\circ} \mathrm{C}$. Experimental conditions: frequency $=9.38 \mathrm{GHz}$, microwave power $=2.0$ $\mathrm{mW}$, time constant $=40.96 \mathrm{~ms}$, modulation amplitude $=6 \mathrm{G}$, average of 5 scans of 2 minutes. Simulation parameters: See Table S3 for g values and line widths. Relative intensities used in the simulations are shown as percentages on the right of the spectra. 
0 min
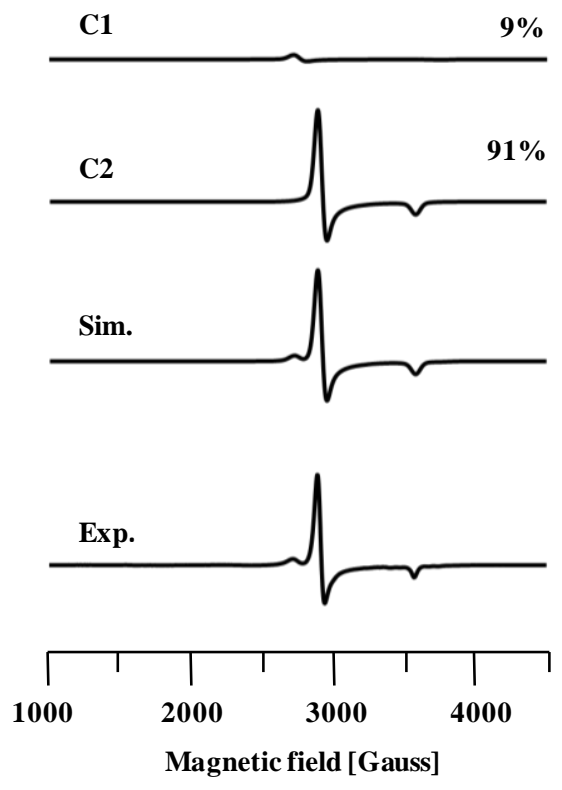

$30 \mathrm{~min}$
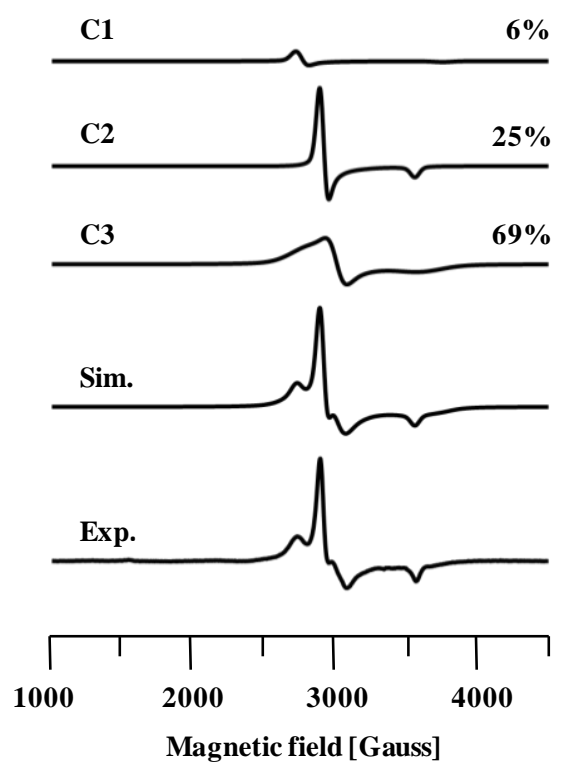

$10 \mathrm{~min}$
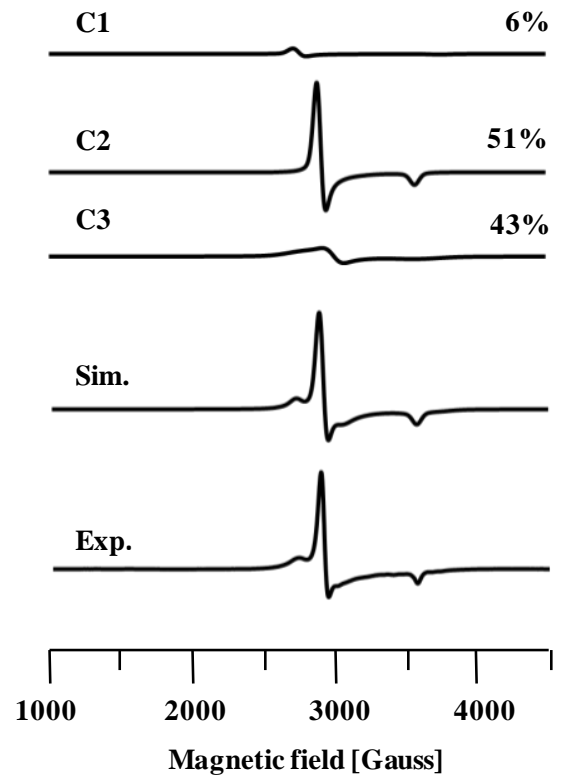

$60 \mathrm{~min}$
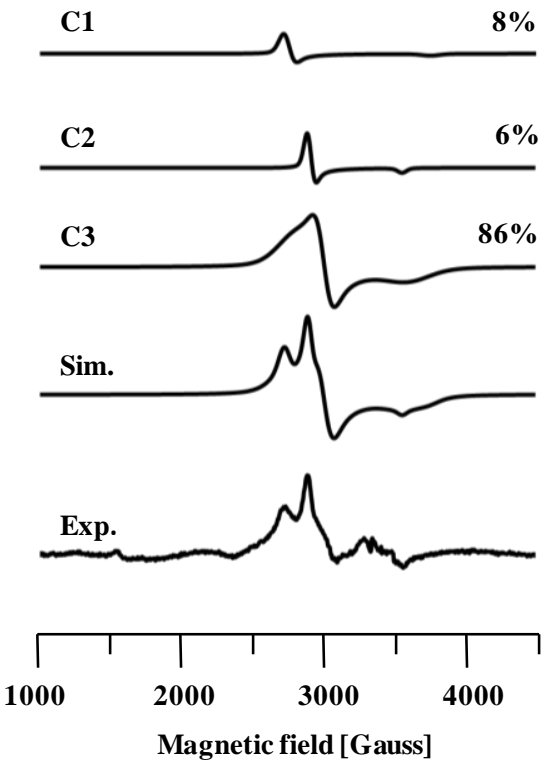

Figure S4(d). Deconvolution of EPR spectra of Ru-4-FcEtPyr in PBS after incubation for 0, 10, 30 and $60 \mathrm{~min}$ at $37{ }^{\circ} \mathrm{C}$. Experimental conditions: frequency $=9.38 \mathrm{GHz}$, microwave power $=2.0$ $\mathrm{mW}$, time constant $=40.96 \mathrm{~ms}$, modulation amplitude $=6 \mathrm{G}$, average of 5 scans of 2 minutes. Simulation parameters: See Table $\mathbf{S 3}$ for g values and line widths. Relative intensities used in the simulations are shown as percentages on the right of the spectra. 
Table S3. $g$ values and line widths used in the simulations of the EPR spectra from the complexes in PBS.

\begin{tabular}{|c|c|c|c|c|c|c|}
\hline \multirow[b]{2}{*}{ Ru(III) species } & \multicolumn{3}{|c|}{ g values } & \multicolumn{3}{|c|}{ Line widths } \\
\hline & $g_{1}$ & $g_{2}$ & $g_{3}$ & $L_{1}$ & $L_{2}$ & $L_{3}$ \\
\hline Ru-4-FcPy-C1 & 2.45 & 2.45 & 1.78 & 80 & 80 & 175 \\
\hline Ru-4-FcPy-C2 & 2.30 & 2.30 & 1.88 & 55 & 55 & 60 \\
\hline Ru-4-FcPy-C3 & 2.40 & 2.27 & 1.85 & 250 & 100 & 500 \\
\hline Ru-3-FcPyr-C1 & 2.435 & 2.44 & 1.78 & 80 & 80 & 120 \\
\hline Ru-3-FcPyr-C2 & 2.30 & 2.30 & 1.88 & 55 & 55 & 40 \\
\hline Ru-3-FcPyr-C3 & 2.40 & 2.25 & 1.85 & 350 & 100 & 500 \\
\hline Ru-4-FcVinylPyr-C1 & 2.44 & 2.44 & 1.78 & 80 & 80 & 120 \\
\hline Ru-4-FcVinylPyr-C2 & 2.31 & 2.31 & 1.87 & 55 & 55 & 60 \\
\hline Ru-4-FcVinylPyr-C3 & 2.36 & 2.23 & 1.85 & 350 & 75 & 300 \\
\hline Ru-4-FcEtPyr-C1 & 2.44 & 2.44 & 1.78 & 80 & 80 & 120 \\
\hline Ru-4-FcEtPyr-C2 & 2.31 & 2.31 & 1.88 & 55 & 55 & 60 \\
\hline Ru-4-FcEtPyr-C3 & 2.40 & 2.23 & 1.85 & 250 & 100 & 300 \\
\hline
\end{tabular}




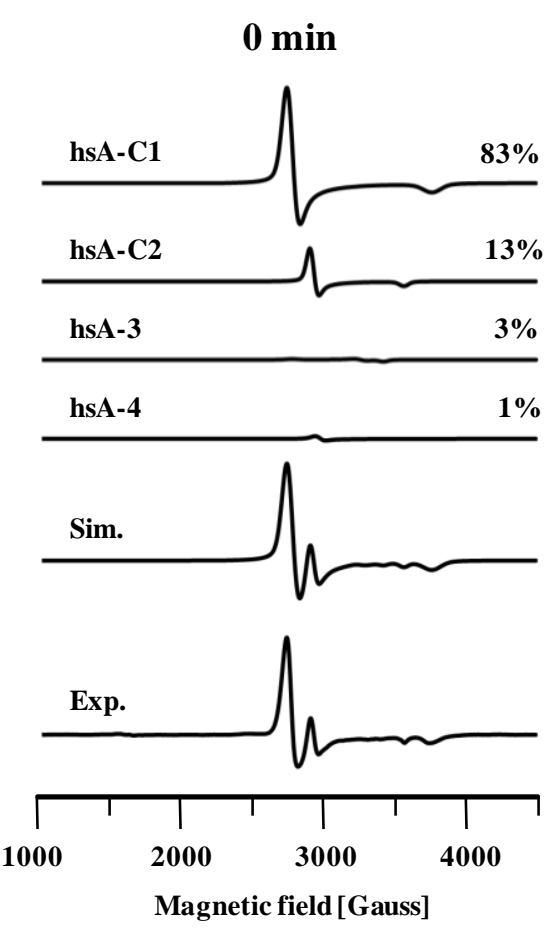

\section{$30 \mathrm{~min}$}

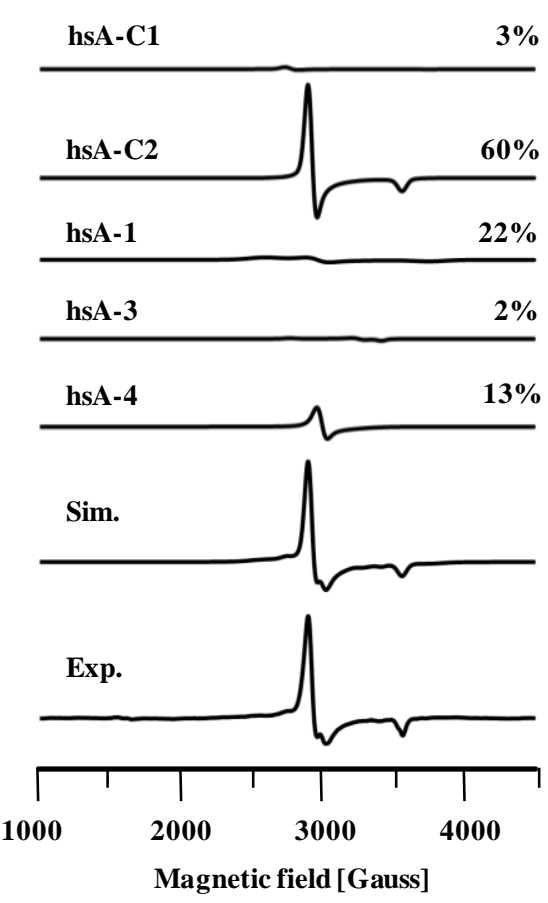

$10 \mathrm{~min}$
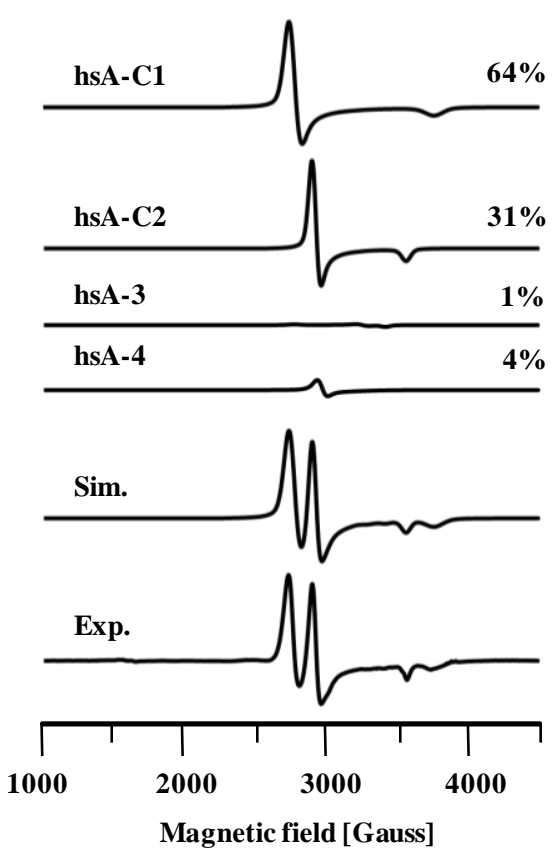

$60 \mathrm{~min}$

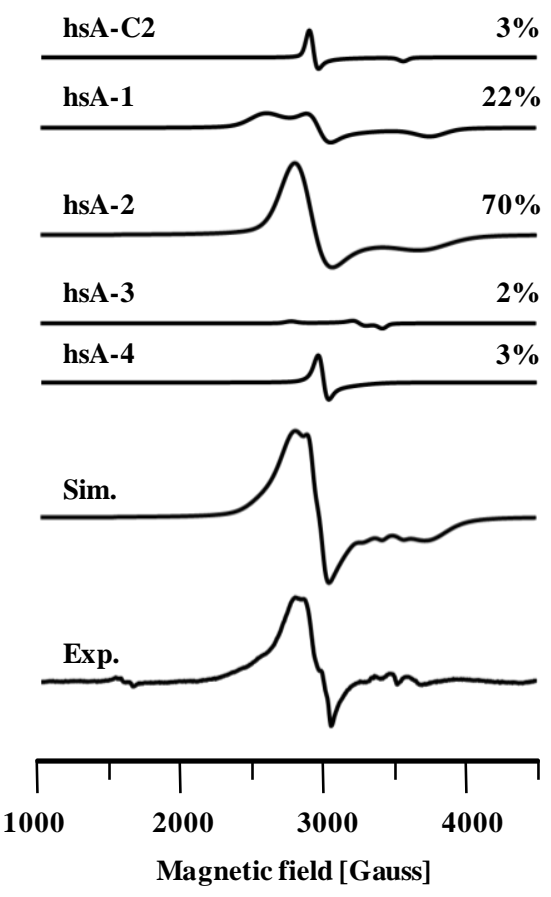

Figure S5(a). Deconvolution of EPR spectra of compound Ru-4-FcPyr in PBS with hsA after incubation for 0, 10, 30 and $60 \mathrm{~min}$ at $37{ }^{\circ} \mathrm{C}$. Experimental conditions: frequency $=9.38 \mathrm{GHz}$, microwave power $=2.0 \mathrm{~mW}$, time constant $=40.96 \mathrm{~ms}$, modulation amplitude $=6 \mathrm{G}$, average of 5 scans of 2 minutes. Simulation parameters: See Table S4 for g values and line widths. Relative intensities used in the simulations are shown as percentages on the right of the spectra. 
0 min

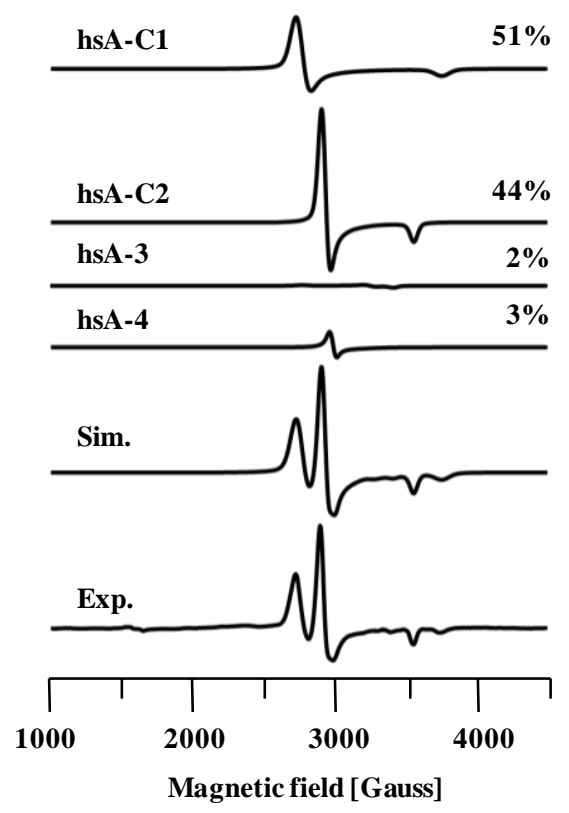

$30 \mathrm{~min}$

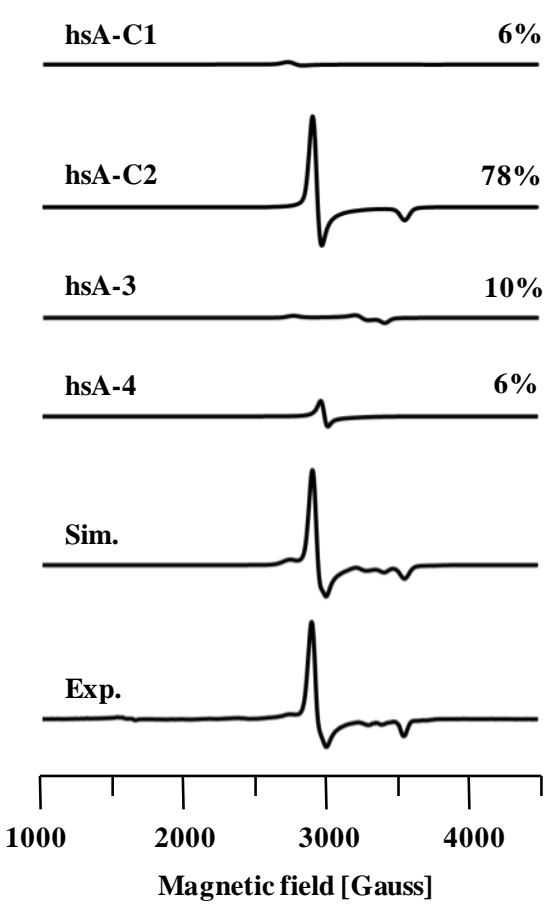

$10 \mathrm{~min}$

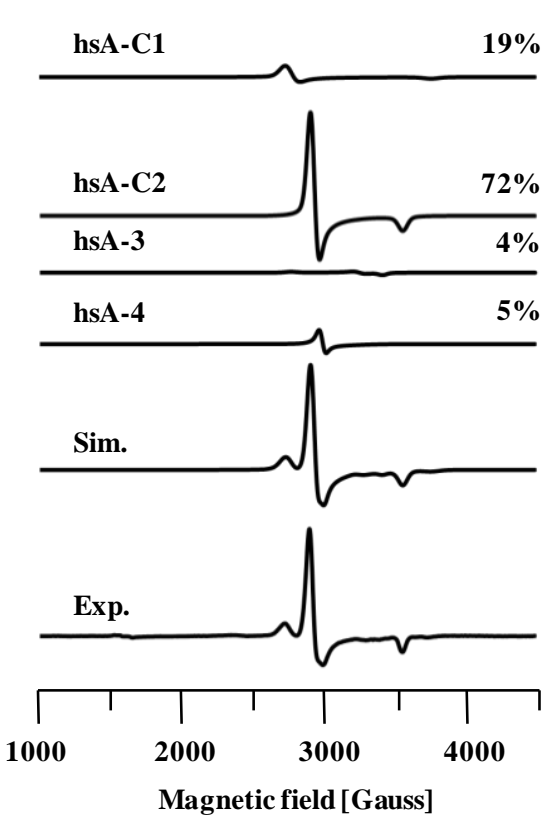

$60 \mathrm{~min}$

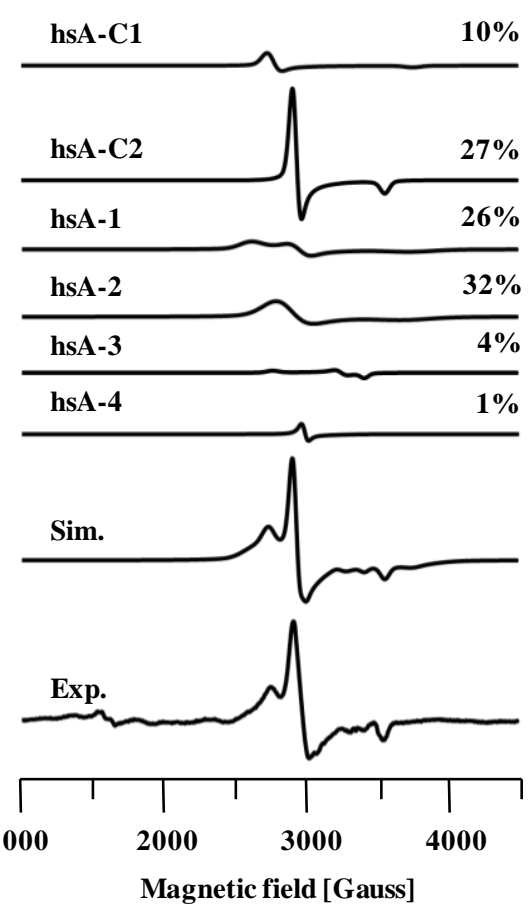

Figure S5(b). Deconvolution of EPR spectra of compound Ru-3-FcPyr in PBS with hsA after incubation for 0, 10, 30 and $60 \mathrm{~min}$ at $37{ }^{\circ} \mathrm{C}$. Experimental conditions: frequency $=9.38 \mathrm{GHz}$, microwave power $=2.0 \mathrm{~mW}$, time constant $=40.96 \mathrm{~ms}$, modulation amplitude $=6 \mathrm{G}$, average of 5 scans of 2 minutes. Simulation parameters: See Table S4 for g values and line widths. Relative intensities used in the simulations are shown as percentages on the right of the spectra. 


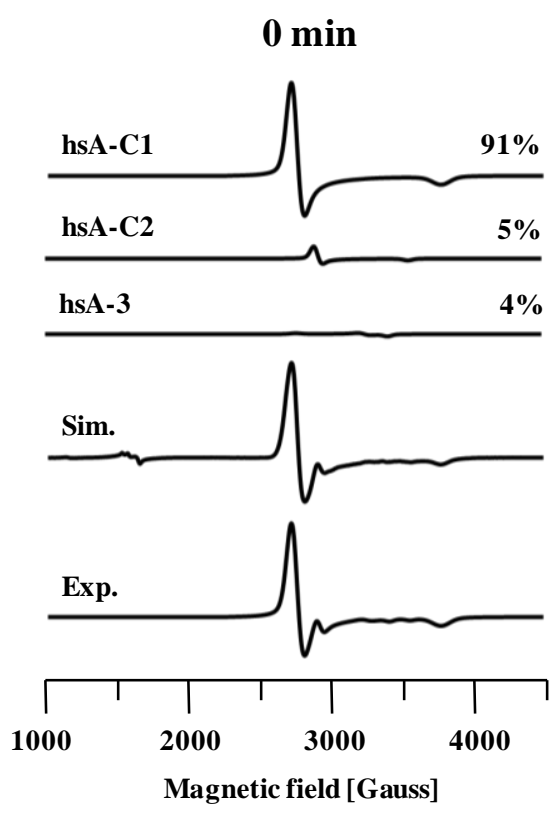

$30 \mathrm{~min}$

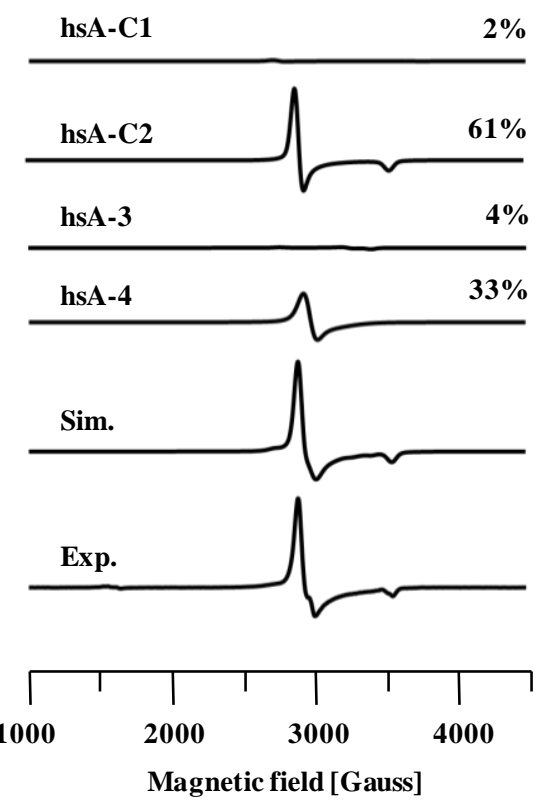

$10 \mathrm{~min}$
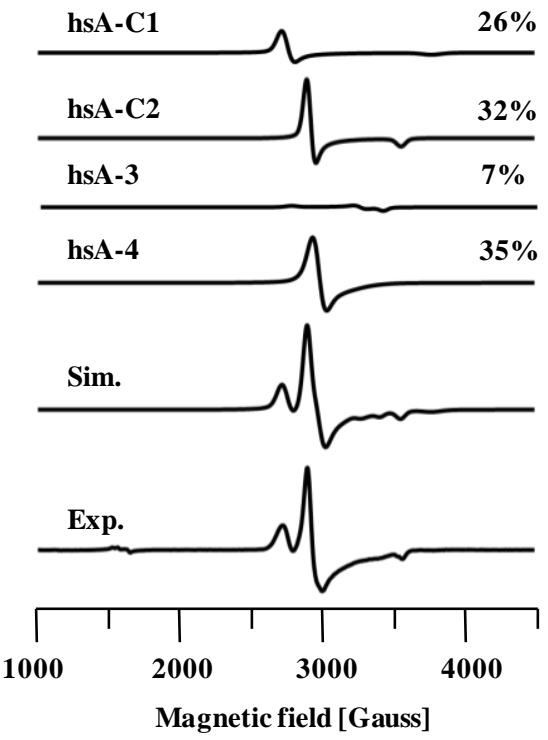

$60 \mathrm{~min}$
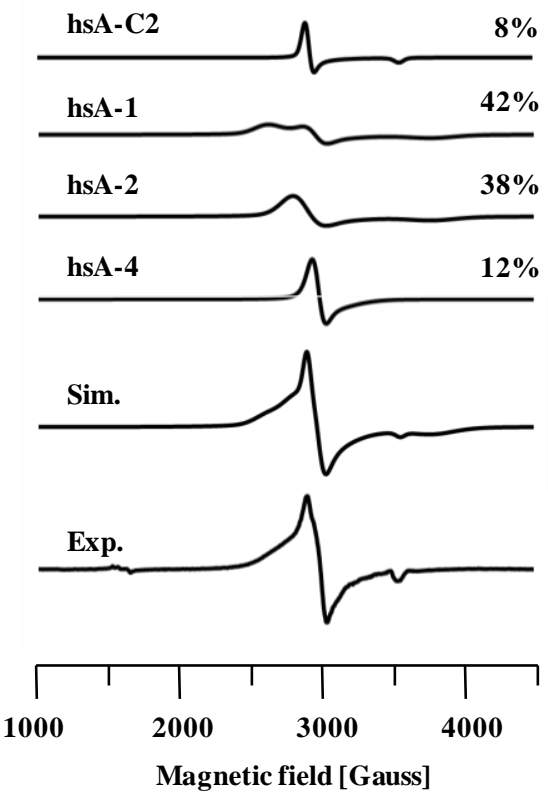

Figure S5(c). Deconvolution of EPR spectra of compound Ru-4-FcVinylPyr in PBS with hsA after incubation for 0, 10, 30 and $60 \mathrm{~min}$ at $37{ }^{\circ} \mathrm{C}$. Experimental conditions: frequency $=9.38 \mathrm{GHz}$, microwave power $=2.0 \mathrm{~mW}$, time constant $=40.96 \mathrm{~ms}$, modulation amplitude $=6 \mathrm{G}$, average of 5 scans of 2 minutes. Simulation parameters: See Table $\mathbf{S 4}$ for g values and line widths. Relative intensities used in the simulations are shown as percentages on the right of the spectra. 

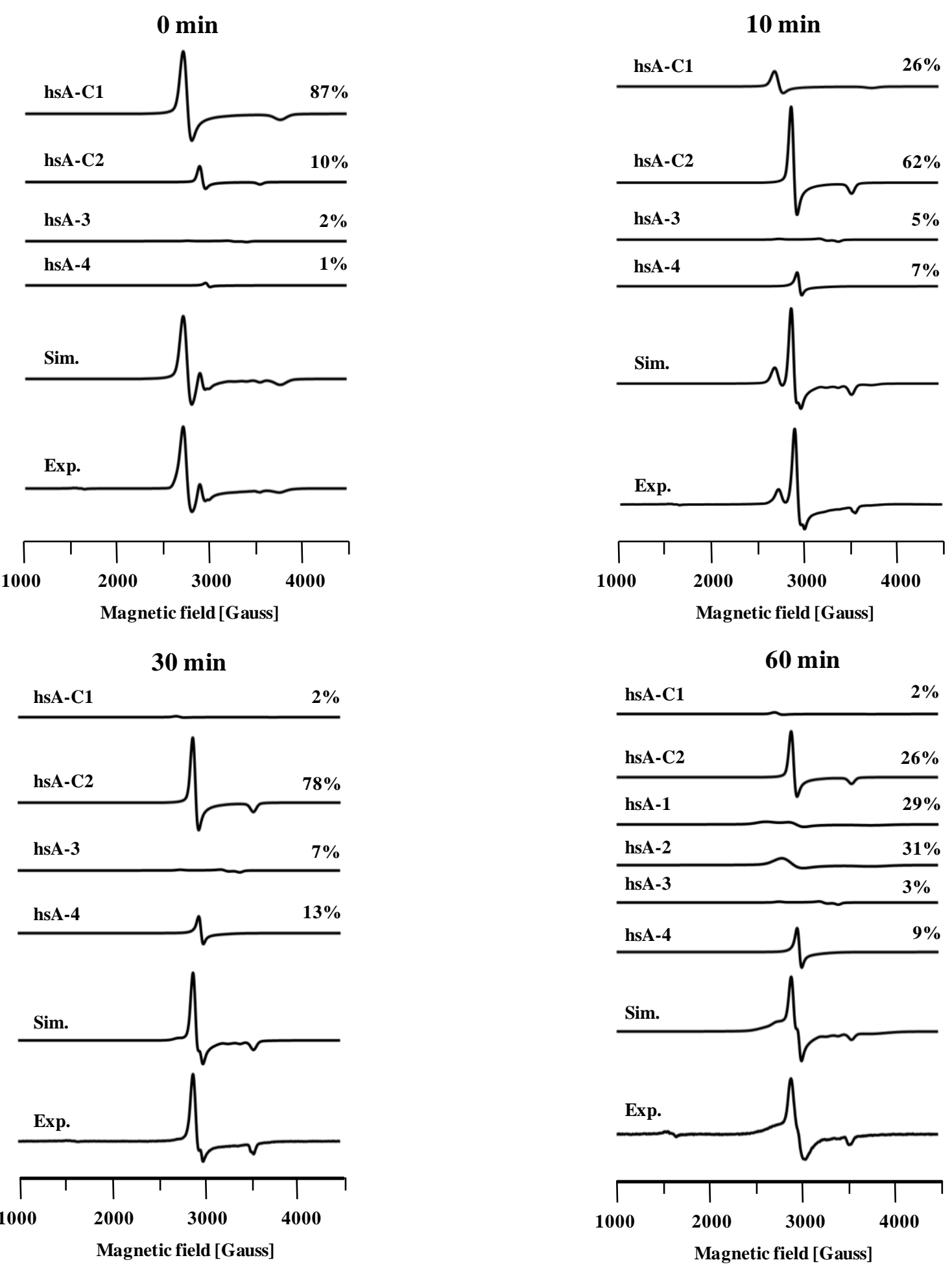

Figure S5(d). Deconvolution of EPR spectra of compound Ru-4-FcEtPyr in PBS with hsA after incubation for 0, 10, 30 and $60 \mathrm{~min}$ at $37^{\circ} \mathrm{C}$. Experimental conditions: frequency $=9.38 \mathrm{GHz}$, microwave power $=2.0 \mathrm{~mW}$, time constant $=40.96 \mathrm{~ms}$, modulation amplitude $=6 \mathrm{G}$, average of 5 scans of 2 minutes. Simulation parameters: See Table $\mathbf{S 4}$ for g values and line widths. Relative intensities used in the simulations are shown as percentages on the right of the spectra. 
Table S4. g values and line widths used in the simulations of the EPR spectra from the complexes in PBS with hsA.

\begin{tabular}{|c|c|c|c|c|c|c|}
\hline \multirow[b]{2}{*}{ Ru(III) species } & \multicolumn{3}{|c|}{ g-values } & \multicolumn{3}{|c|}{ Line widths } \\
\hline & $g_{1}$ & $g_{2}$ & $g_{3}$ & $L_{1}$ & $L_{2}$ & $L_{3}$ \\
\hline Ru-4-FcPyr-C1-hsA & 2.43 & 2.43 & 1.78 & 80 & 80 & 120 \\
\hline Ru-4-FcPyr-C2-hsA & 2.30 & 2.30 & 1.88 & 55 & 55 & 60 \\
\hline Ru-4-FcPyr-hsA-1 & 2.60 & 2.26 & 1.78 & 150 & 125 & 300 \\
\hline Ru-4-FcPyr-hsA-2 & 2.34 & 2.34 & 1.80 & 225 & 225 & 350 \\
\hline Ru-4-FcPyr-hsA-3 & 2.42 & 2.06 & 1.96 & 80 & 70 & 55 \\
\hline Ru-4-FcPyr-hsA-4 & 2.26 & 2.26 & 2.10 & 60 & 60 & 300 \\
\hline Ru-3-FcPyr-C1-hsA & 2.43 & 2.43 & 1.78 & 90 & 90 & 100 \\
\hline Ru-3-FcPyr-C2-hsA & 2.29 & 2.29 & 1.88 & 55 & 55 & 60 \\
\hline Ru-3-FcPyr-hsA-1 & 2.56 & 2.26 & 1.78 & 150 & 125 & 300 \\
\hline Ru-3-FcPyr-hsA-2 & 2.34 & 2.34 & 1.80 & 225 & 225 & 350 \\
\hline Ru-3-FcPyr-hsA-3 & 2.42 & 2.06 & 1.96 & 80 & 70 & 55 \\
\hline Ru-3-FcPyr-hsA-4 & 2.25 & 2.25 & 2.10 & 40 & 40 & 300 \\
\hline Ru-4-FcVinylPyr-C1-hsA & 2.44 & 2.44 & 1.77 & 80 & 80 & 120 \\
\hline Ru-4-FcVinylPyr-C2-hsA & 2.30 & 2.30 & 1.88 & 55 & 55 & 60 \\
\hline Ru-4-FcVinylPyr-hsA-1 & 2.56 & 2.26 & 1.76 & 175 & 125 & 300 \\
\hline Ru-4-FcVinylPyr-hsA-2 & 2.34 & 2.34 & 1.76 & 200 & 200 & 300 \\
\hline Ru-4-FcVinylPyr-hsA-3 & 2.42 & 2.06 & 1.96 & 80 & 70 & 55 \\
\hline Ru-4-FcVinylPyr-hsA-4 & 2.25 & 2.25 & 2.10 & 80 & 80 & 300 \\
\hline Ru-4-FcEtPyr-C1-hsA & 2.44 & 2.44 & 1.77 & 80 & 80 & 120 \\
\hline Ru-4-FcEtPyr-C2-hsA & 2.30 & 2.30 & 1.88 & 55 & 55 & 60 \\
\hline Ru-4-FcEtPyr-hsA-1 & 2.56 & 2.26 & 1.76 & 175 & 125 & 300 \\
\hline Ru-4-FcEtPyr-hsA-2 & 2.34 & 2.34 & 1.76 & 200 & 200 & 300 \\
\hline Ru-4-FcEtPyr-hsA-3 & 2.42 & 2.06 & 1.96 & 80 & 70 & 55 \\
\hline Ru-4-FcEtPyr-hsA-4 & 2.24 & 2.24 & 2.10 & 40 & 40 & 300 \\
\hline
\end{tabular}




\section{Electrochemistry}
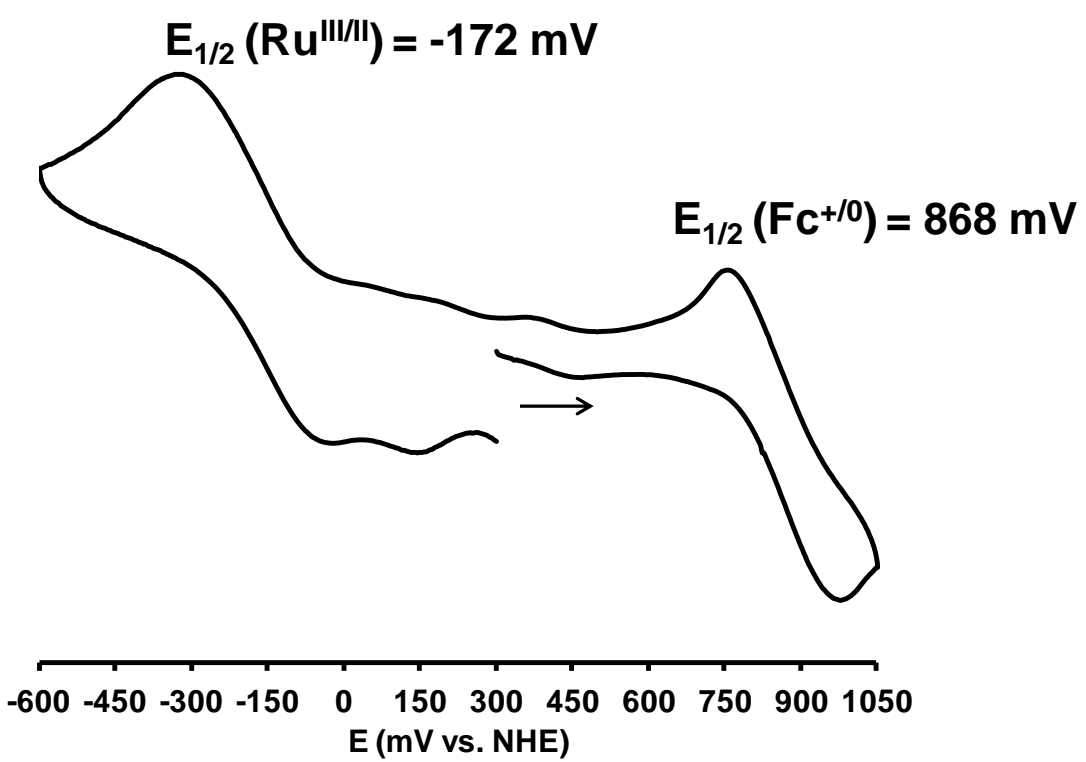

Figure S6(a). Cyclic voltammetry of Ru-4-FcPyr $(5 \mathrm{mM})$ in a solution of $0.1 \mathrm{M}$ tetrabutylammonium perchlorate in $N, N$-dimethylformamide; scan rate $100 \mathrm{mV} / \mathrm{s}, T=25^{\circ} \mathrm{C}$.

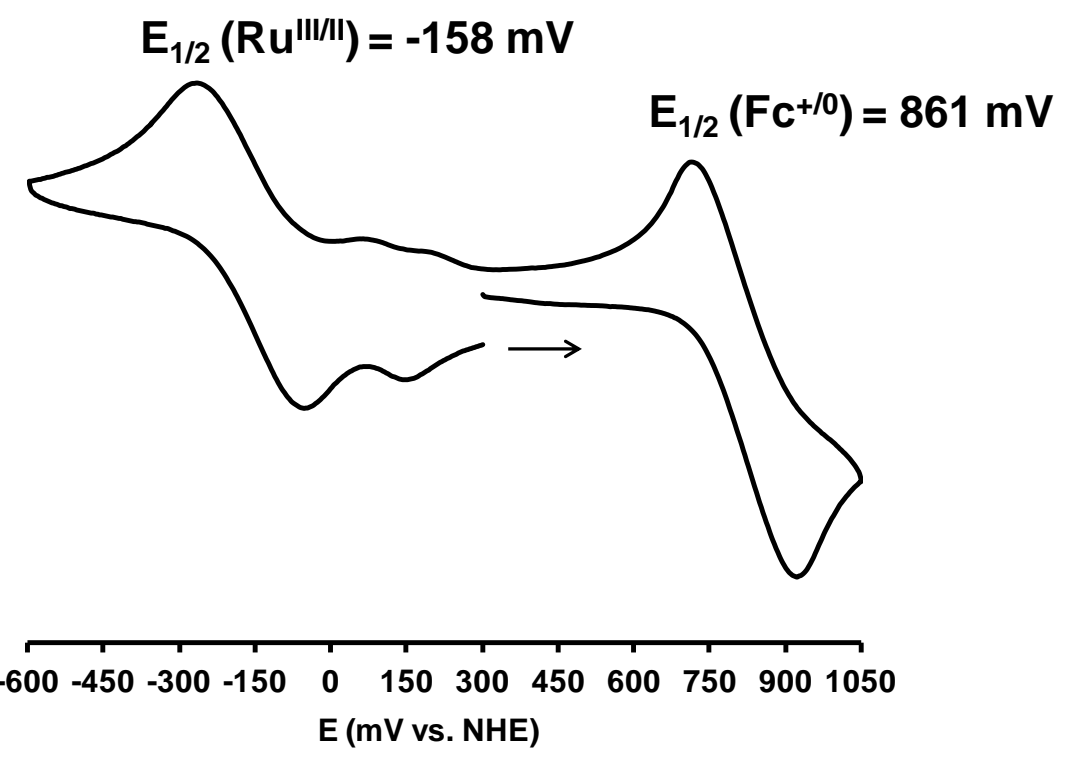

Figure S6(b). Cyclic voltammetry of Ru-3-FcPyr $(5 \mathrm{mM})$ in a solution of $0.1 \mathrm{M}$ tetrabutylammonium perchlorate in $\mathrm{N}, \mathrm{N}$-dimethylformamide; scan rate $100 \mathrm{mV} / \mathrm{s}, T=25^{\circ} \mathrm{C}$. 


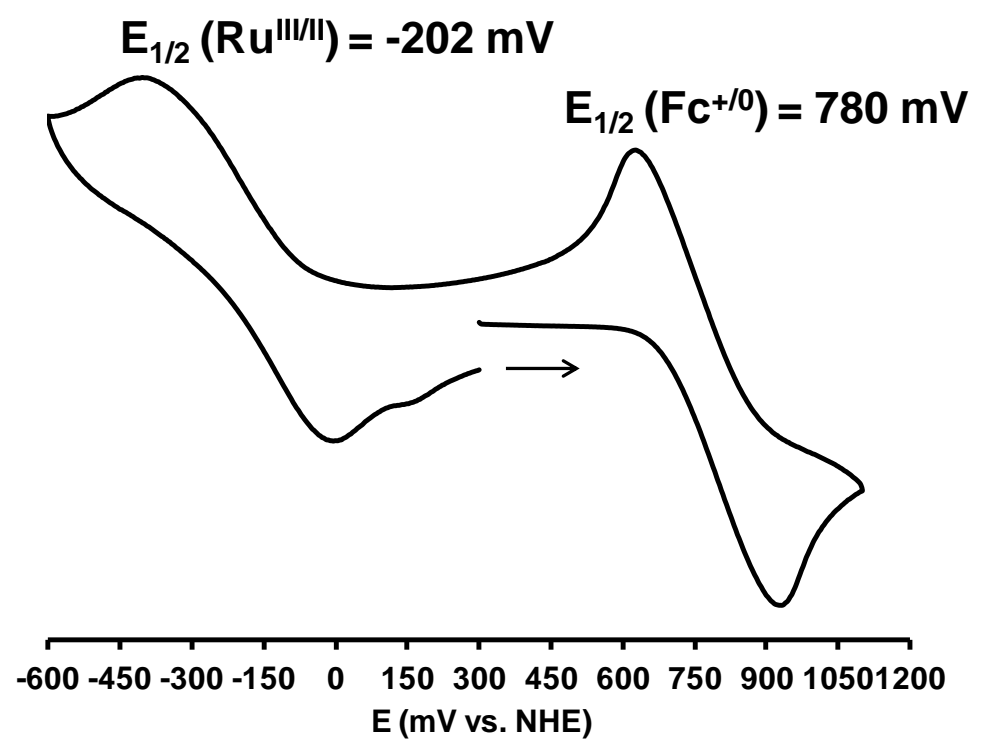

Figure S6(c). Cyclic voltammetry of Ru-4-FcVinylPyr $(5 \mathrm{mM})$ in a solution of $0.1 \mathrm{M}$ tetrabutylammonium perchlorate in $N, N$-dimethylformamide; scan rate $100 \mathrm{mV} / \mathrm{s}, T=25^{\circ} \mathrm{C}$.

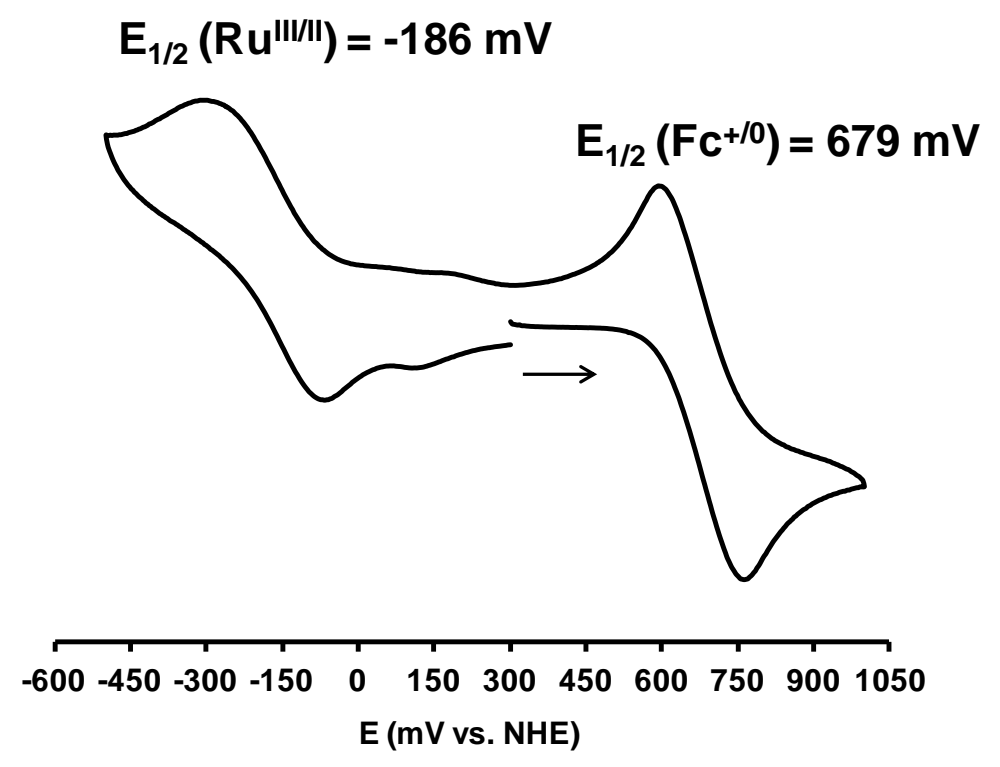

Figure S6(d). Cyclic voltammetry of Ru-4-FcEtPyr $(5 \mathrm{mM})$ in a solution of $0.1 \mathrm{M}$ tetrabutylammonium perchlorate in $N, N$-dimethylformamide; scan rate $100 \mathrm{mV} / \mathrm{s}, T=25{ }^{\circ} \mathrm{C}$. 


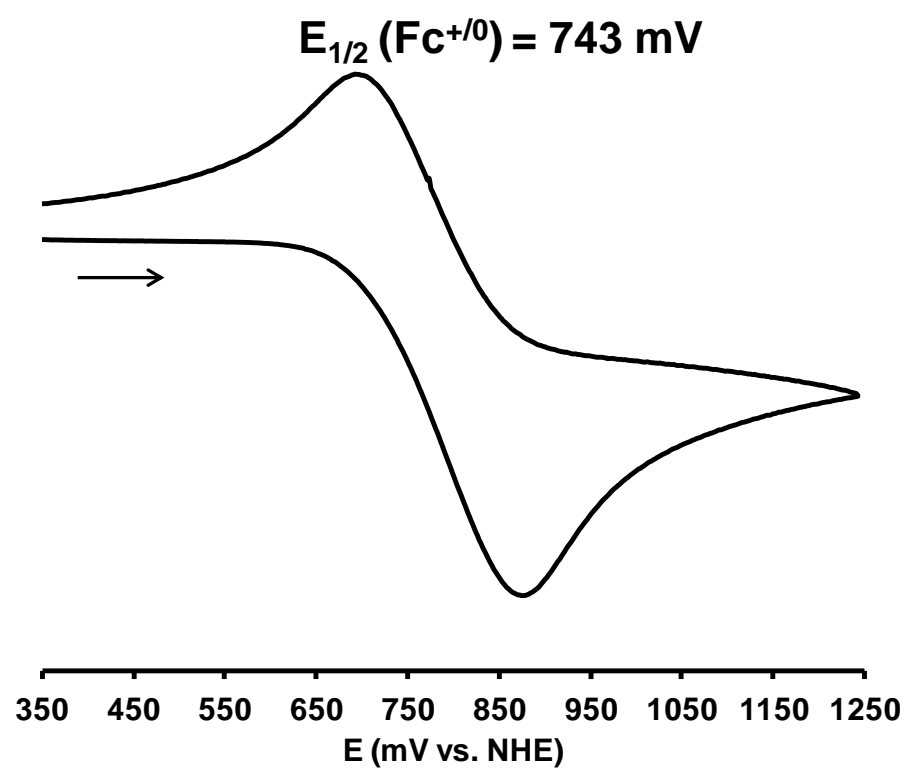

Figure S6(e). Cyclic voltammetry of ferrocene $(5 \mathrm{mM})$ in a solution of $0.1 \mathrm{M}$ tetrabutylammonium perchlorate in $N, N$-dimethylformamide; scan rate $100 \mathrm{mV} / \mathrm{s}, T=25^{\circ} \mathrm{C}$. Due to the overlap of signals of the ferrocene and ferrocenyl ligands of the complexes, the $\mathrm{Fc} / \mathrm{Fc}^{+}$redox couple was used as an external reference under the same conditions with a reported the half reduction potential value 544 $\mathrm{mV}$ vs. $\mathrm{Ag} / \mathrm{AgCl}(\mathrm{KCl} \text {, sat. })^{2}$, which was then converted to $743 \mathrm{mV}$ vs. NHE by adding $199 \mathrm{mV}$.

(2) Noviandri, I.; Brown, K. N.; Fleming, D. S.; Gulyas, P. T.; Lay, P. A.; Masters, A. F.; Phillips, L., J. Phys. Chem. B 1999, 103, 6713-6722.
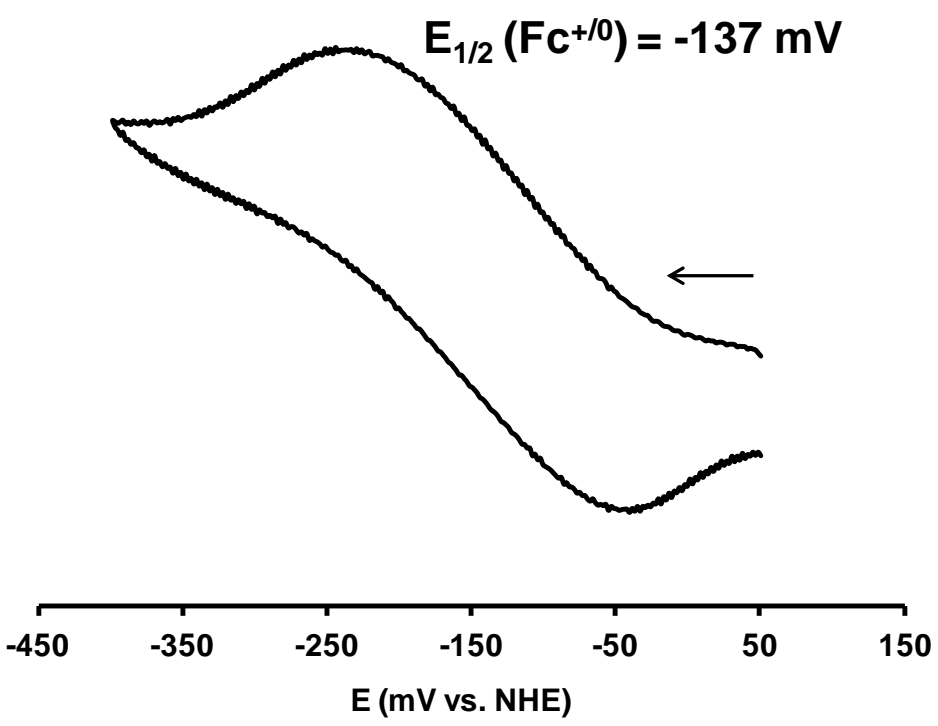

Figure S6(f). Cyclic voltammetry of NAMI-Pyr $(5 \mathrm{mM})$ in a solution of $0.1 \mathrm{M}$ tetrabutylammonium perchlorate in $N, N$-dimethylformamide; scan rate $100 \mathrm{mV} / \mathrm{s}, T=25^{\circ} \mathrm{C}$. 


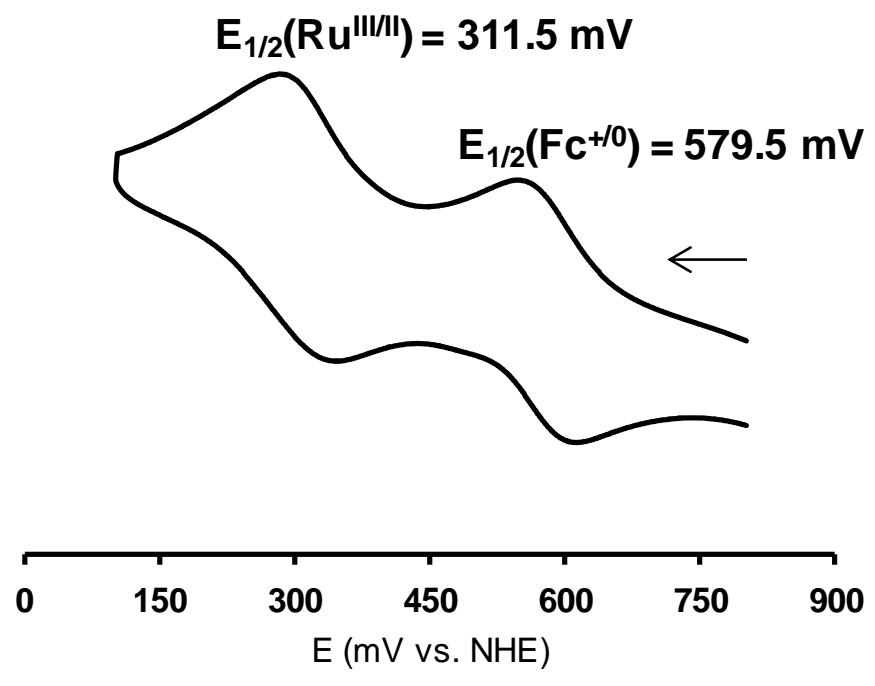

Figure S7(a). Cyclic voltammetry of Ru-4-FcPyr $(200 \mu \mathrm{M})$ in PBS with 1\% DMSO; scan rate 25 $\mathrm{mV} / \mathrm{s} ; T=25^{\circ} \mathrm{C}$.

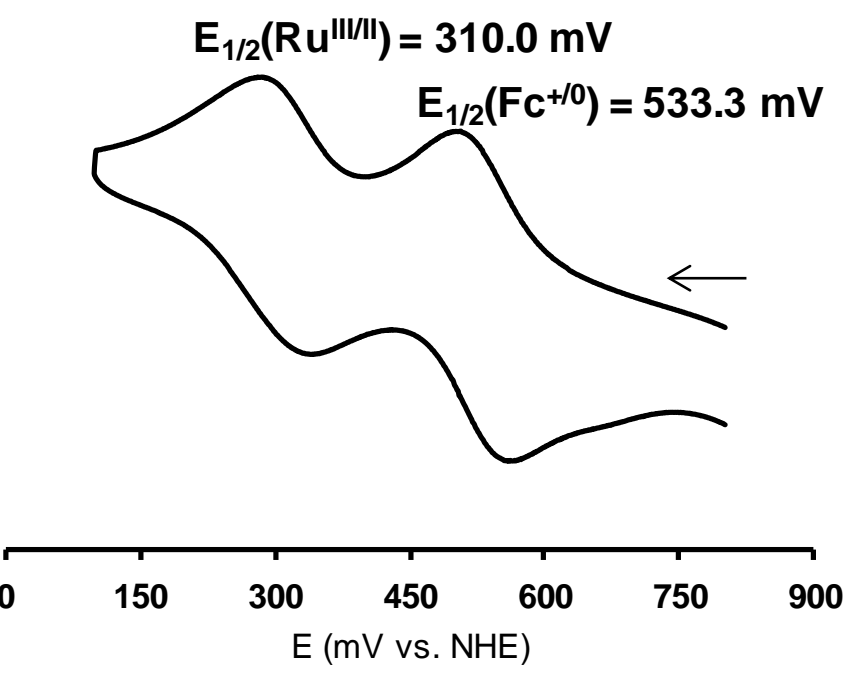

Figure S7(b). Cyclic voltammetry of Ru-3-FcPyr $(200 \mu \mathrm{M})$ in PBS with 1\% DMSO; scan rate 25 $\mathrm{mV} / \mathrm{s} ; T=25^{\circ} \mathrm{C}$. 


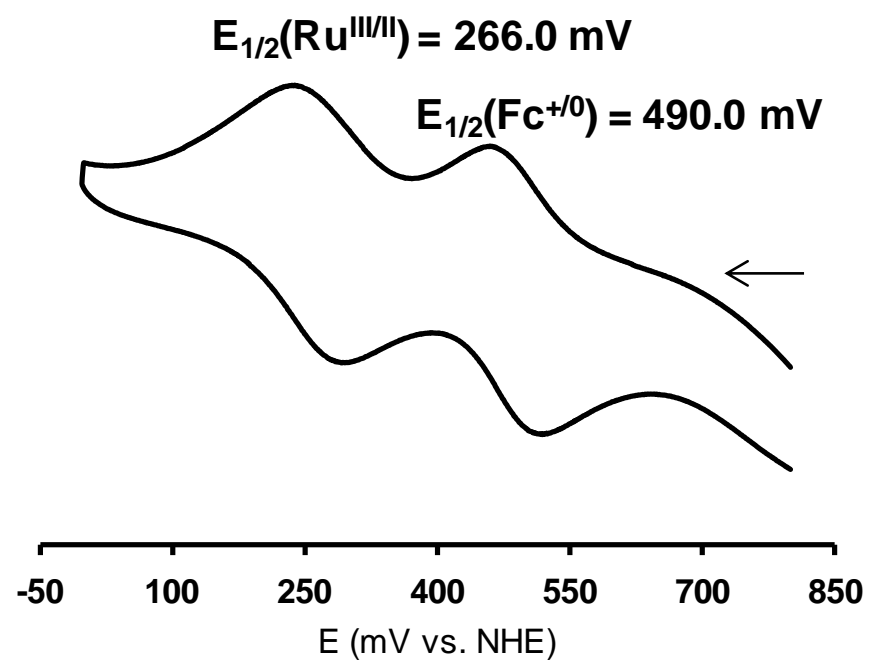

Figure S7(c). Cyclic voltammetry of Ru-4-FcVinylPyr $(200 \mu \mathrm{M})$ in PBS with 1\% DMSO; scan rate $25 \mathrm{mV} / \mathrm{s} ; T=25^{\circ} \mathrm{C}$.

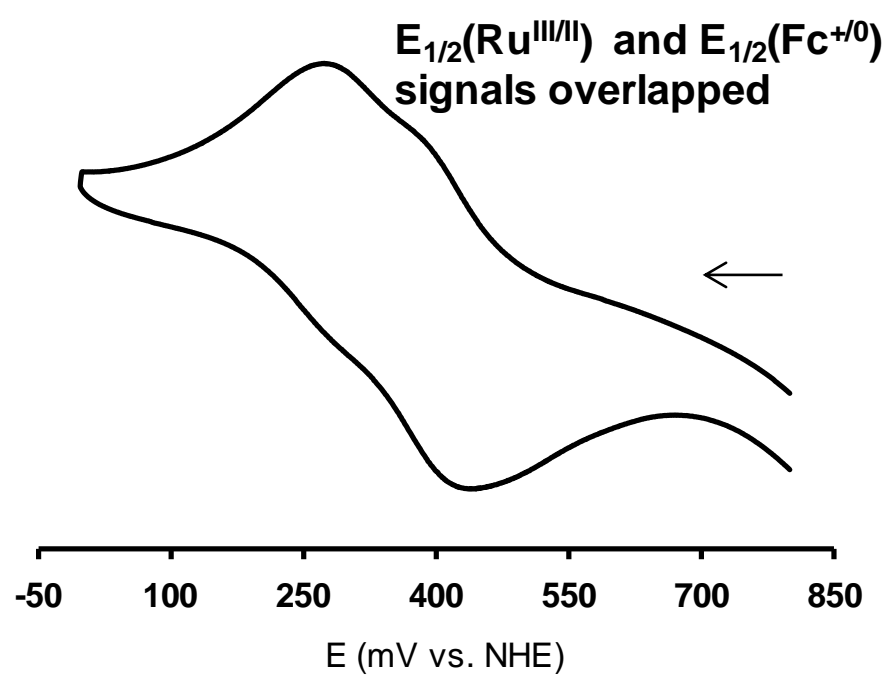

Figure S7(d). Cyclic voltammetry of Ru-4-FcEtPyr $(200 \mu \mathrm{M})$ in PBS with 1\% DMSO; scan rate $25 \mathrm{mV} / \mathrm{s} ; T=25^{\circ} \mathrm{C}$. 


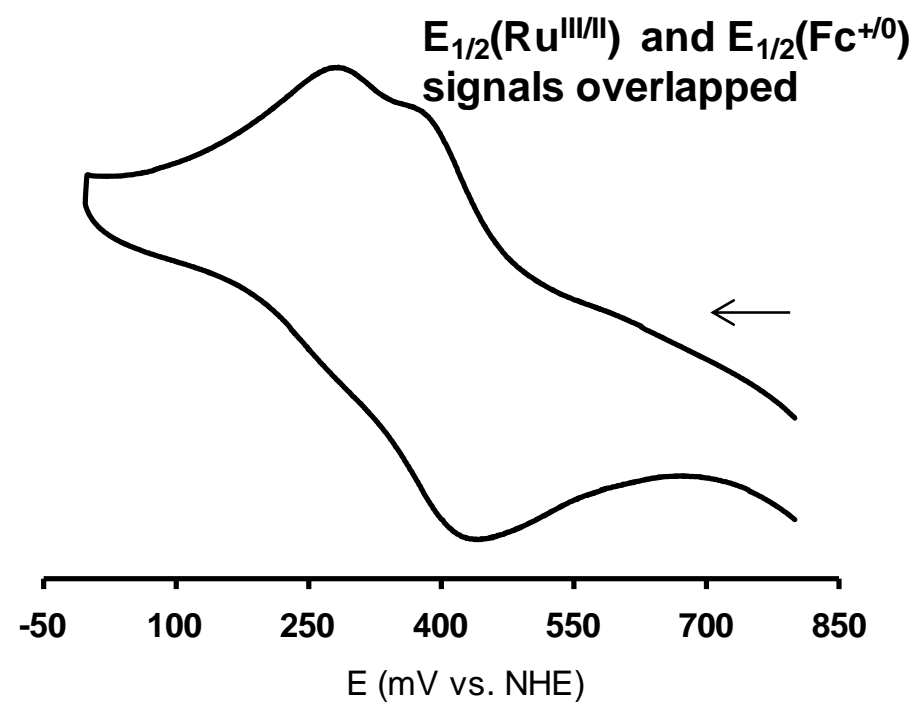

Figure S7(e). Cyclic voltammetry of Ru-4-FcEtPyr $(100 \mu \mathrm{M})$ in PBS with 1\% DMSO; scan rate $25 \mathrm{mV} / \mathrm{s} ; T=25^{\circ} \mathrm{C}$.

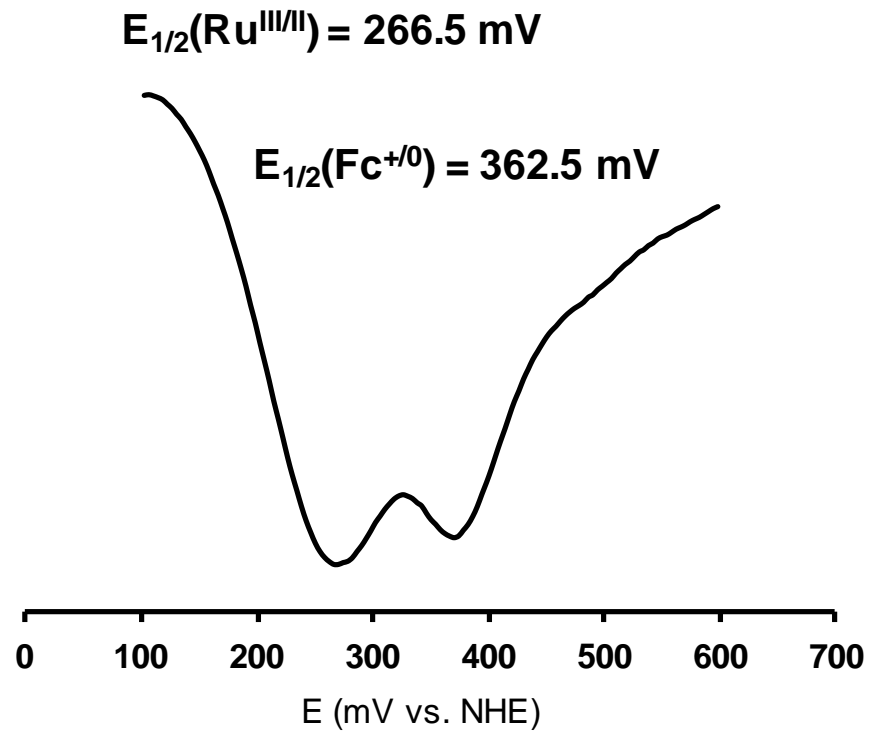

Figure S8. Differential pulse voltammetry of Ru-4-FcEtPyr $(200 \mu \mathrm{M})$ in PBS with 1\% DMSO; scan rate $25 \mathrm{mV} / \mathrm{s} ; T=25^{\circ} \mathrm{C}$. 


\section{Density functional theory calculations}

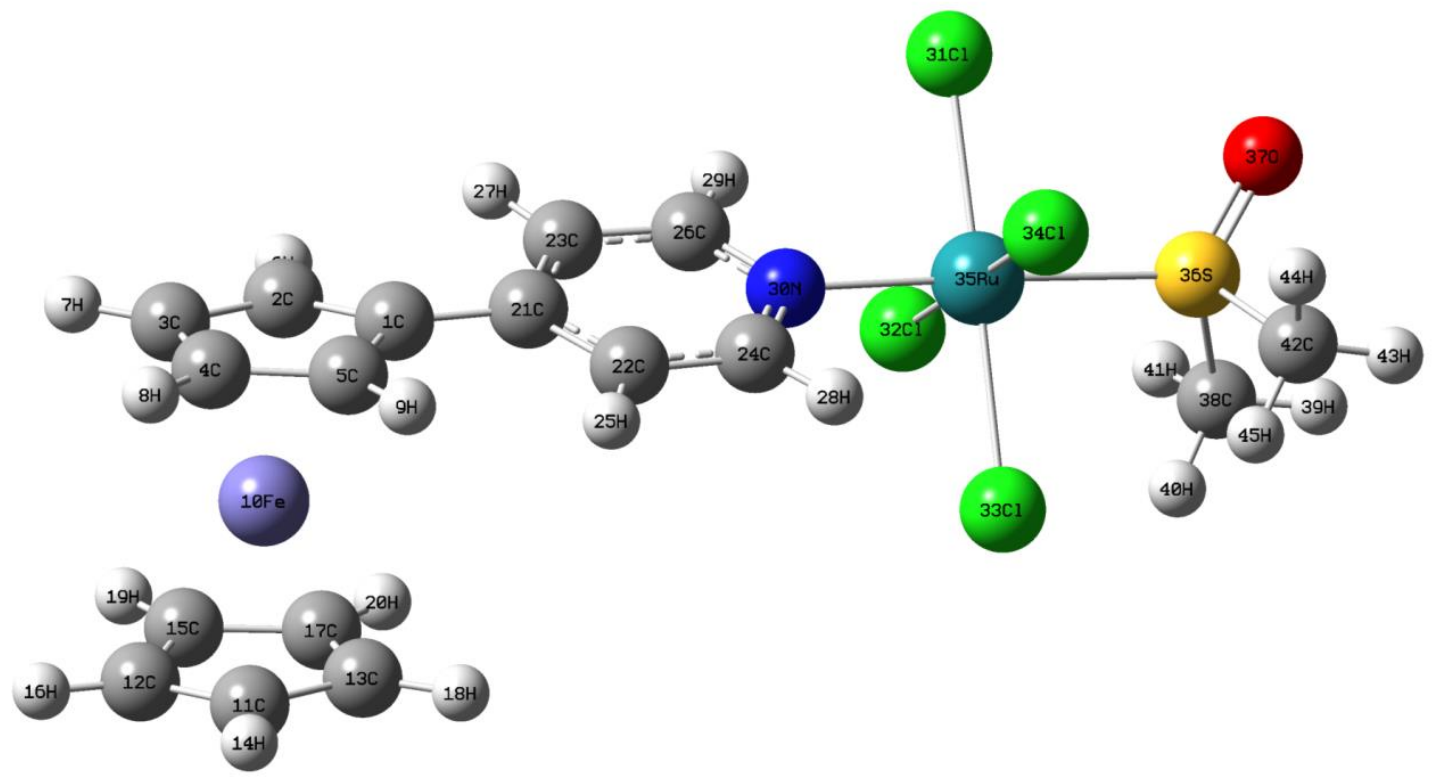

Figure S9(a). DFT optimized structure of Ru-4-FcPyr.

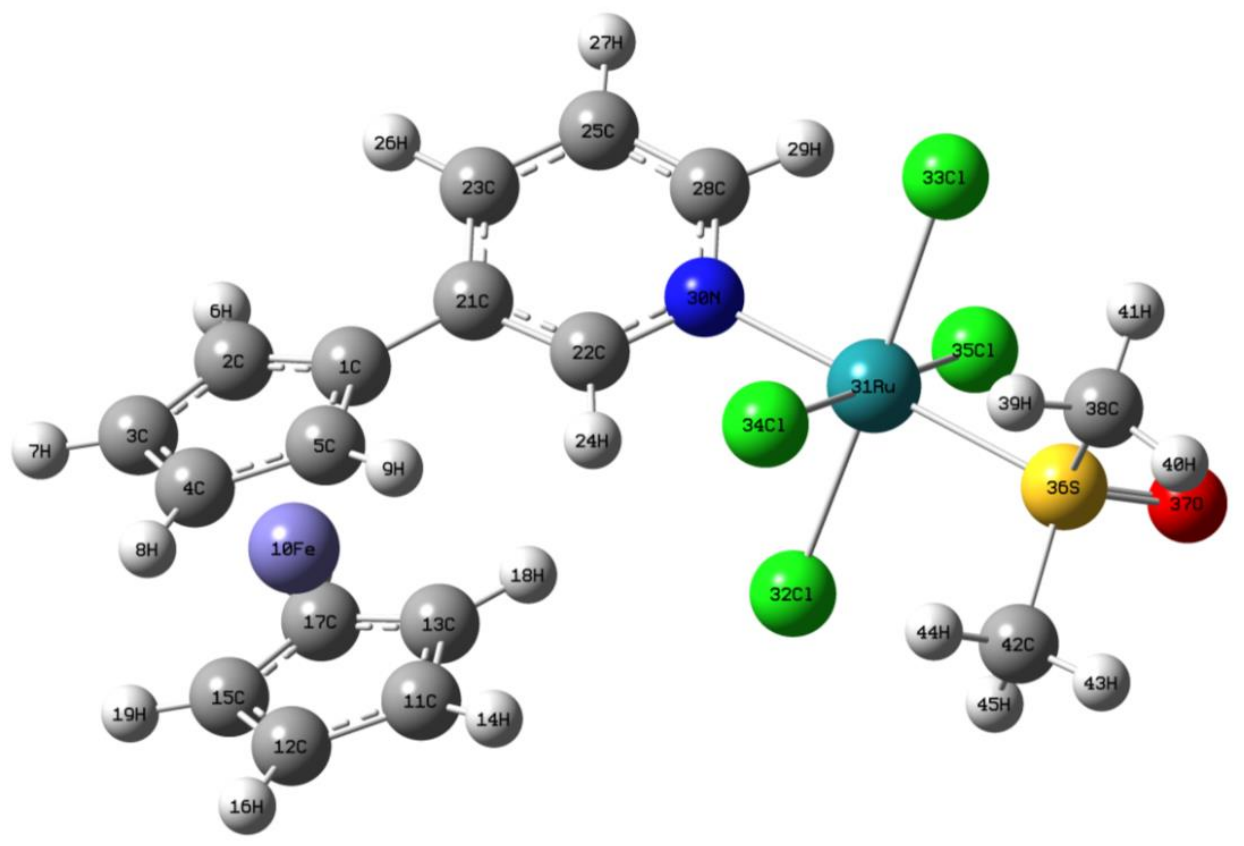

Figure S9(b). DFT optimized structure of Ru-3-FcPyr. 


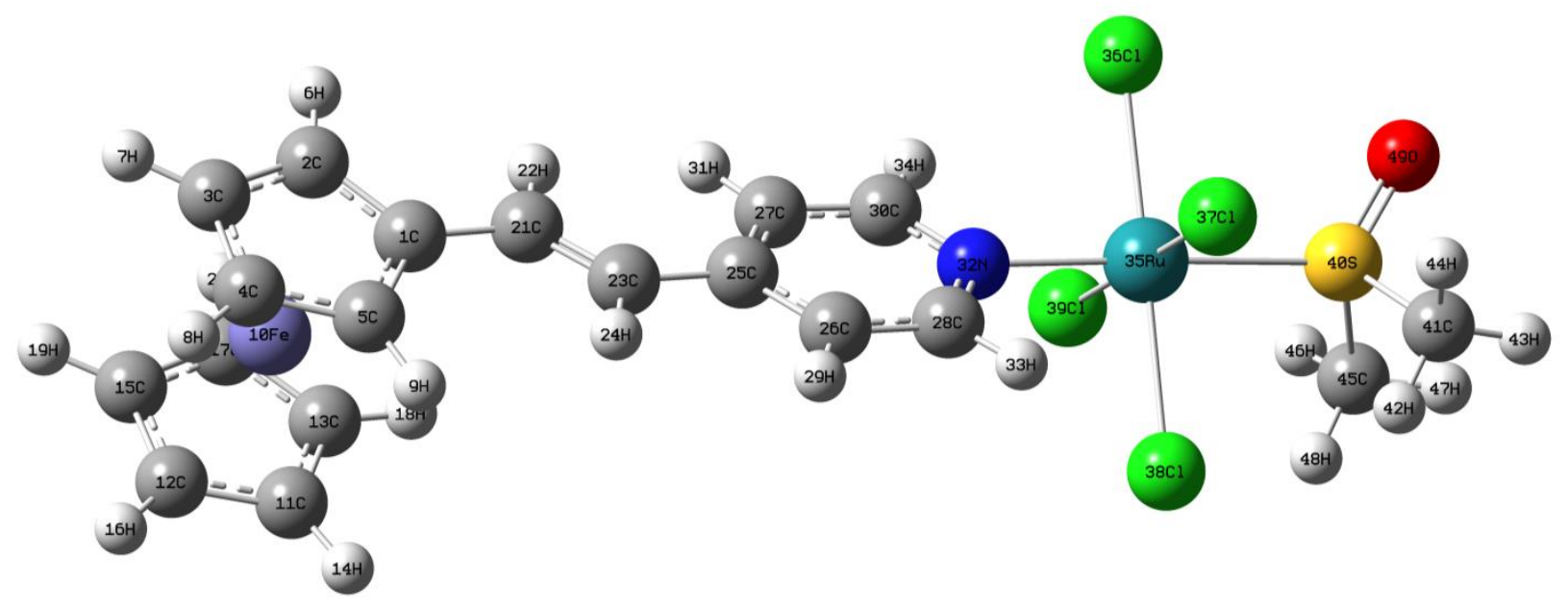

Figure S9(c). DFT optimized structure of Ru-4-FcVinylPyr.

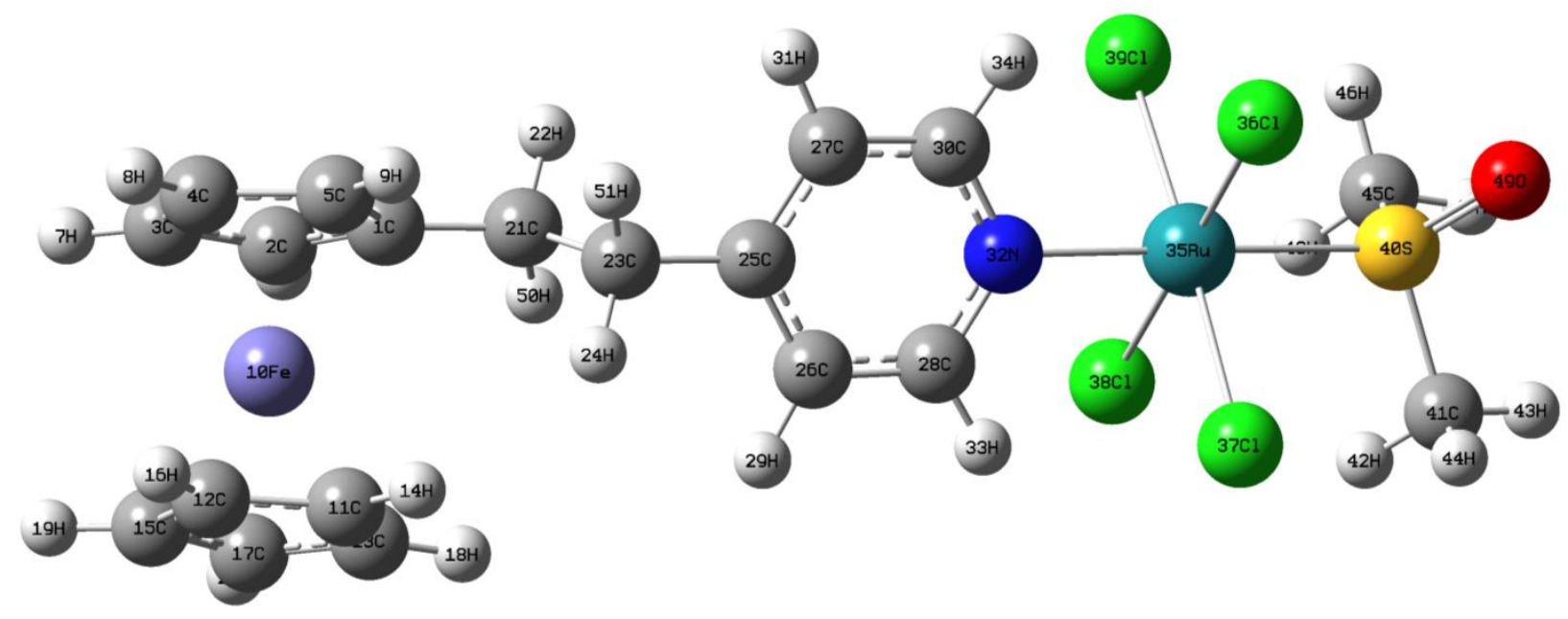

Figure S9(d). DFT optimized structure of Ru-4-FcEtPyr. 


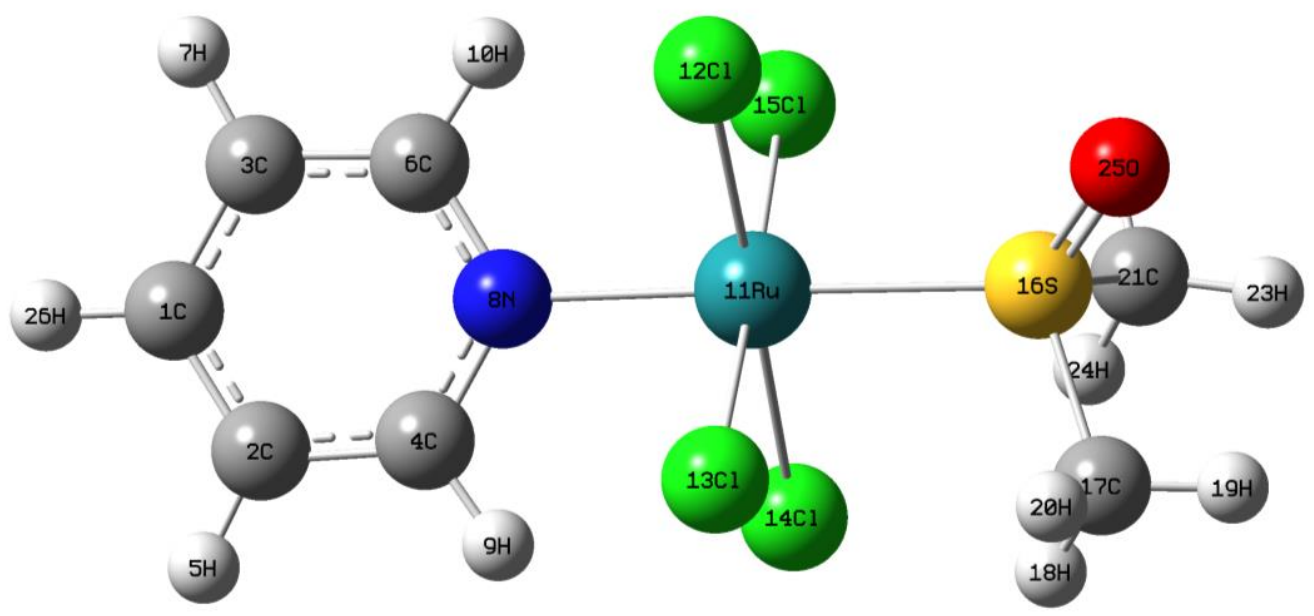

Figure S9(e). DFT optimized structure of NAMI-Pyr. 
Table S6(a). DFT optimized structure coordinates of Ru-4-FcPyr

\begin{tabular}{|c|c|c|c|c|c|c|c|}
\hline & \multicolumn{3}{|c|}{ Coordinates $(\AA)$} & & \multicolumn{3}{|c|}{ Coordinates $(\AA)$} \\
\hline Atoms & $\mathbf{X}$ & $\mathbf{Y}$ & $\mathbf{Z}$ & Atoms & $\mathbf{X}$ & $\mathbf{Y}$ & $\mathbf{Z}$ \\
\hline 1 & 3.641541 & -1.231261 & 0.168434 & 24 & 0.136815 & -0.186501 & 1.133452 \\
\hline 2 & 4.488717 & -1.532926 & -0.952226 & 25 & 2.035875 & -0.084071 & 2.100402 \\
\hline 3 & 5.819993 & -1.725159 & -0.479728 & 26 & 0.043701 & -1.108188 & -0.984136 \\
\hline 4 & 5.814806 & -1.540646 & 0.936493 & 27 & 1.858411 & -1.843296 & -1.836574 \\
\hline 5 & 4.480639 & -1.235545 & 1.335389 & 28 & -0.415083 & 0.271692 & 1.943272 \\
\hline 6 & 4.173029 & -1.584528 & -1.985526 & 29 & -0.581852 & -1.375636 & -1.825024 \\
\hline 7 & 6.683984 & -1.953887 & -1.090311 & 30 & -0.588008 & -0.528297 & 0.051954 \\
\hline 8 & 6.672222 & -1.612733 & 1.593039 & 31 & -3.013468 & -2.327771 & -0.929945 \\
\hline 9 & 4.151773 & -1.049784 & 2.348952 & 32 & -2.362276 & 0.760397 & -2.267514 \\
\hline 10 & 5.154859 & 0.159455 & -0.005531 & 33 & -2.267607 & 2.109482 & 0.91117 \\
\hline 11 & 5.015235 & 2.002626 & 0.892142 & 34 & -2.877545 & -1.010762 & 2.235603 \\
\hline 12 & 6.375077 & 1.709675 & 0.564248 & 35 & -2.666702 & -0.137235 & -0.025713 \\
\hline 13 & 4.254202 & 1.98217 & -0.315598 & 36 & -5.021815 & 0.37737 & -0.099599 \\
\hline 14 & 4.625327 & 2.193021 & 1.88345 & 37 & -6.065878 & -0.572644 & -0.608847 \\
\hline 15 & 6.453773 & 1.508943 & -0.84837 & 38 & -5.232214 & 1.954648 & -0.985137 \\
\hline 16 & 7.198438 & 1.641776 & 1.263644 & 39 & -6.278916 & 2.257304 & -0.885044 \\
\hline 17 & 5.142424 & 1.677679 & -1.390837 & 40 & -4.540135 & 2.685039 & -0.561267 \\
\hline 18 & 3.185752 & 2.135253 & -0.396534 & 41 & -4.970568 & 1.762161 & -2.025801 \\
\hline 19 & 7.347332 & 1.262093 & -1.407409 & 42 & -5.537213 & 0.930503 & 1.557104 \\
\hline 20 & 4.864388 & 1.576985 & -2.431836 & 43 & -6.562695 & 1.304304 & 1.480764 \\
\hline 21 & 2.187893 & -0.992174 & 0.132603 & 44 & -5.478569 & 0.05779 & 2.207673 \\
\hline 22 & 1.506983 & -0.398132 & 1.206429 & 45 & -4.836172 & 1.69368 & 1.90108 \\
\hline 23 & 1.41152 & -1.355082 & -0.976833 & & & & \\
\hline
\end{tabular}

Table S6(b). DFT optimized structure coordinates of Ru-3-FcPyr

\begin{tabular}{|c|c|c|c|c|c|c|c|}
\hline & \multicolumn{3}{|c|}{ Coordinates $(\AA)$} & & \multicolumn{3}{|c|}{ Coordinates $(\AA)$} \\
\hline Atoms & $\mathbf{X}$ & $\mathbf{Y}$ & $\mathbf{Z}$ & Atoms & $\mathbf{X}$ & $\mathbf{Y}$ & $\mathbf{Z}$ \\
\hline 1 & -3.148293 & 1.1749 & 0.756484 & 24 & -0.702397 & -0.021842 & 0.661114 \\
\hline 2 & -4.482727 & 1.527294 & 0.360909 & 25 & -0.590156 & 3.495923 & -0.785012 \\
\hline 3 & -5.403129 & 0.766349 & 1.142823 & 26 & -2.697541 & 3.661208 & -0.345398 \\
\hline 4 & -4.646862 & -0.064022 & 2.026029 & 27 & -0.496373 & 4.490743 & -1.209418 \\
\hline 5 & -3.262564 & 0.184141 & 1.790561 & 28 & 0.532218 & 2.677671 & -0.708418 \\
\hline 6 & -4.74411 & 2.232797 & -0.417419 & 29 & 1.506362 & 2.985813 & -1.062646 \\
\hline 7 & -6.482455 & 0.801268 & 1.066767 & 30 & 0.461977 & 1.438658 & -0.18506 \\
\hline 8 & -5.050909 & -0.766378 & 2.743584 & 31 & 2.168684 & 0.184492 & -0.096082 \\
\hline 9 & -2.431724 & -0.284086 & 2.301995 & 32 & 0.810559 & -1.658769 & -0.958454 \\
\hline 10 & -4.169439 & -0.480369 & 0.075518 & 33 & 3.434312 & 2.052548 & 0.791751 \\
\hline 11 & -3.171926 & -2.181545 & -0.522534 & 34 & 1.545704 & -0.486902 & 2.196663 \\
\hline 12 & -4.540495 & -2.47585 & -0.237076 & 35 & 2.721541 & 0.833941 & -2.332283 \\
\hline 13 & -3.137198 & -1.201758 & -1.557663 & 36 & 4.099378 & -1.254131 & 0.074447 \\
\hline
\end{tabular}




\begin{tabular}{|c|c|c|c|c|c|c|c|}
\hline 14 & -2.300736 & -2.604308 & -0.039697 & 37 & 5.107811 & -1.42643 & -1.023226 \\
\hline 15 & -5.354017 & -1.674657 & -1.097906 & 38 & 5.004097 & -0.812855 & 1.592065 \\
\hline 16 & -4.899969 & -3.172977 & 0.509129 & 39 & 4.292058 & -0.767033 & 2.418437 \\
\hline 17 & -4.483328 & -0.886633 & -1.914124 & 40 & 5.783106 & -1.565162 & 1.748315 \\
\hline 18 & -2.235186 & -0.768842 & -1.970425 & 41 & 5.433374 & 0.174581 & 1.421304 \\
\hline 19 & -6.43646 & -1.660416 & -1.121222 & 42 & 3.533822 & -2.911056 & 0.574218 \\
\hline 20 & -4.790569 & -0.167266 & -2.662421 & 43 & 4.418887 & -3.512673 & 0.801882 \\
\hline 21 & -1.892748 & 1.741816 & 0.233543 & 44 & 2.866899 & -2.80345 & 1.431933 \\
\hline 22 & -0.713543 & 0.986114 & 0.270822 & 45 & 2.98183 & -3.319702 & -0.272344 \\
\hline 23 & -1.813666 & 3.029623 & -0.30968 & & & & \\
\hline
\end{tabular}

Table S6(c). DFT optimized structure coordinates of Ru-4-FcVinylPyr

\begin{tabular}{|c|c|c|c|c|c|c|c|}
\hline \multirow[b]{2}{*}{ Atoms } & \multicolumn{3}{|c|}{ Coordinates $(\AA)$} & \multirow[b]{2}{*}{ Atoms } & \multicolumn{3}{|c|}{ Coordinates $(\AA)$} \\
\hline & $\mathbf{X}$ & $\mathbf{Y}$ & $\mathbf{Z}$ & & $\mathbf{X}$ & $\mathbf{Y}$ & $\mathbf{Z}$ \\
\hline 1 & 5.082947 & -1.164258 & -0.39819 & 26 & 0.382847 & -1.277465 & 1.214957 \\
\hline 2 & 6.058098 & -1.136187 & -1.454824 & 27 & 0.68761 & -0.237438 & -0.911816 \\
\hline 3 & 7.329887 & -1.488041 & -0.915159 & 28 & -0.980413 & -1.033836 & 1.101327 \\
\hline 4 & 7.160537 & -1.726335 & 0.483299 & 29 & 0.757008 & -1.780123 & 2.102599 \\
\hline 5 & 5.786668 & -1.517414 & 0.804445 & 30 & -0.682021 & -0.025794 & -0.959508 \\
\hline 6 & 5.847243 & -0.895828 & -2.489341 & 31 & 1.292939 & 0.110677 & -1.742409 \\
\hline 7 & 8.259582 & -1.552232 & -1.46557 & 32 & -1.509539 & -0.414681 & 0.031454 \\
\hline 8 & 7.94102 & -1.998332 & 1.182163 & 33 & -1.682277 & -1.327509 & 1.870426 \\
\hline 9 & 5.348903 & -1.602328 & 1.790155 & 34 & -1.155704 & 0.46668 & -1.797751 \\
\hline 10 & 6.598192 & 0.189396 & 0.011021 & 35 & -3.58567 & -0.031546 & -0.083495 \\
\hline 11 & 6.354015 & 1.684278 & 1.40041 & 36 & -3.564577 & -0.755901 & -2.367436 \\
\hline 12 & 7.742701 & 1.45975 & 1.149762 & 37 & -4.014188 & -2.308156 & 0.658217 \\
\hline 13 & 5.736151 & 2.051506 & 0.167224 & 38 & -3.573178 & 0.702044 & 2.271332 \\
\hline 14 & 5.853538 & 1.582175 & 2.354394 & 39 & -3.07707 & 2.243257 & -0.782409 \\
\hline 15 & 7.982099 & 1.687065 & -0.240254 & 40 & -5.953757 & 0.437683 & -0.149876 \\
\hline 16 & 8.481184 & 1.159304 & 1.881784 & 41 & -6.745983 & -0.436691 & 1.236875 \\
\hline 17 & 6.741332 & 2.052062 & -0.847281 & 42 & -6.184266 & -0.219178 & 2.147515 \\
\hline 18 & 4.684875 & 2.264887 & 0.024327 & 43 & -7.786105 & -0.101762 & 1.29297 \\
\hline 19 & 8.933928 & 1.589743 & -0.746367 & 44 & -6.681415 & -1.501077 & 1.010746 \\
\hline 20 & 6.587286 & 2.280102 & -1.893977 & 45 & -6.211286 & 2.144225 & 0.431525 \\
\hline 21 & 3.659929 & -0.892753 & -0.570373 & 46 & -5.799577 & 2.799037 & -0.336623 \\
\hline 22 & 3.384954 & -0.470275 & -1.535444 & 47 & -7.287893 & 2.297963 & 0.552395 \\
\hline 23 & 2.69821 & -1.144064 & 0.341237 & 48 & -5.65947 & 2.278325 & 1.364048 \\
\hline 24 & 2.986447 & -1.59982 & 1.288065 & 49 & -6.809484 & 0.236666 & -1.366137 \\
\hline 25 & 1.265049 & -0.880499 & 0.197193 & & & & \\
\hline
\end{tabular}


Table S6(d). DFT optimized structure coordinates of Ru-4-FcEtPyr

\begin{tabular}{|c|c|c|c|c|c|c|c|}
\hline & \multicolumn{3}{|c|}{ Coordinates $(\AA)$} & & \multicolumn{3}{|c|}{ Coordinates $(\AA)$} \\
\hline Atoms & $\mathbf{X}$ & $\mathbf{Y}$ & $\mathbf{Z}$ & Atoms & $\mathbf{X}$ & $\mathbf{Y}$ & $\mathbf{Z}$ \\
\hline 1 & 4.940573 & -1.230159 & -0.469247 & 27 & 0.444143 & -1.54816 & 0.912821 \\
\hline 2 & 5.802678 & -1.138904 & -1.609912 & 28 & -0.660463 & 0.846537 & 0.209338 \\
\hline 3 & 7.130452 & -1.482341 & -1.213143 & 29 & 1.327895 & 1.641443 & 0.206221 \\
\hline 4 & 7.10219 & -1.787728 & 0.181049 & 30 & -0.927053 & -1.38957 & 0.741132 \\
\hline 5 & 5.756564 & -1.635132 & 0.636056 & 31 & 0.830987 & -2.522712 & 1.199114 \\
\hline 6 & 5.490745 & -0.848052 & -2.605477 & 32 & -1.471742 & -0.210586 & 0.390404 \\
\hline 7 & 8.004929 & -1.491494 & -1.851188 & 33 & -1.149309 & 1.772098 & -0.064324 \\
\hline 8 & 7.95078 & -2.070319 & 0.790937 & 34 & -1.623677 & -2.204668 & 0.883658 \\
\hline 9 & 5.416944 & -1.785004 & 1.6525 & 35 & -3.564954 & -0.028555 & 0.106793 \\
\hline 10 & 6.461766 & 0.131978 & -0.141349 & 36 & -3.917513 & -1.296153 & 2.10926 \\
\hline 11 & 6.201212 & 1.609805 & 1.26591 & 37 & -3.520111 & 2.036532 & 1.39304 \\
\hline 12 & 7.59208 & 1.365453 & 1.052944 & 38 & -3.16399 & 1.277428 & -1.947564 \\
\hline 13 & 5.626349 & 2.005851 & 0.019924 & 39 & -3.512967 & -2.079859 & -1.202191 \\
\hline 14 & 5.67348 & 1.504839 & 2.204889 & 40 & -5.932458 & 0.205918 & -0.281145 \\
\hline 15 & 7.876843 & 1.609232 & -0.32558 & 41 & -6.301931 & 1.975019 & -0.503795 \\
\hline 16 & 8.302607 & 1.040554 & 1.801993 & 42 & -5.602032 & 2.384785 & -1.234725 \\
\hline 17 & 6.661751 & 2.00481 & -0.96372 & 43 & -7.344473 & 2.060217 & -0.824605 \\
\hline 18 & 4.588001 & 2.258084 & -0.151648 & 44 & -6.142293 & 2.449879 & 0.464355 \\
\hline 19 & 8.841358 & 1.502326 & -0.805083 & 45 & -6.288791 & -0.35625 & -1.976266 \\
\hline 20 & 6.542406 & 2.250638 & -2.010923 & 46 & -6.130167 & -1.434729 & -1.984275 \\
\hline 21 & 3.444241 & -1.050839 & -0.497761 & 47 & -7.329287 & -0.10328 & -2.201208 \\
\hline 22 & 2.982974 & -1.99985 & -0.807514 & 48 & -5.582094 & 0.123925 & -2.655984 \\
\hline 23 & 2.80511 & -0.615224 & 0.838303 & 49 & -6.985207 & -0.370018 & 0.619861 \\
\hline 24 & 3.253974 & 0.331792 & 1.160449 & 50 & 3.178493 & -0.323565 & -1.274921 \\
\hline 25 & 1.305681 & -0.463768 & 0.71924 & 51 & 3.037074 & -1.358122 & 1.611606 \\
\hline 26 & 0.719011 & 0.754809 & 0.363648 & & & & \\
\hline
\end{tabular}

Table S6(e). DFT optimized structure coordinates of NAMI-Pyr

\begin{tabular}{|c|c|c|c|c|c|c|c|c|}
\hline & \multicolumn{3}{|c|}{ Coordinates $(\mathbf{\AA})$} & & \multicolumn{3}{c|}{ Coordinates $(\mathbf{A})$} \\
\hline Atoms & $\mathbf{X}$ & $\mathbf{Y}$ & $\mathbf{Z}$ & & Atoms & $\mathbf{X}$ & $\mathbf{Y}$ & $\mathbf{Z}$ \\
\hline 1 & 4.741035 & 0.145901 & -0.152133 & & 14 & -0.291877 & 1.607578 & -1.747699 \\
\hline 2 & 3.977806 & 1.311627 & -0.180885 & & 15 & -0.106136 & -1.841855 & -1.587978 \\
\hline 3 & 4.082483 & -1.07853 & -0.057548 & & 16 & -2.566551 & -0.121034 & 0.110019 \\
\hline 4 & 2.590246 & 1.215861 & -0.11413 & & 17 & -3.178094 & 1.5841 & 0.296148 \\
\hline 5 & 4.440167 & 2.29115 & -0.254187 & & 18 & -2.665629 & 2.215423 & -0.432534 \\
\hline 6 & 2.691403 & -1.098152 & 0.004941 & & 19 & -4.26259 & 1.568557 & 0.151479 \\
\hline 7 & 4.628887 & -2.016259 & -0.0312 & & 20 & -2.915346 & 1.900386 & 1.305676 \\
\hline 8 & 1.959808 & 0.030826 & -0.023209 & & 21 & -3.163199 & -0.43098 & -1.582309 \\
\hline 9 & 1.949798 & 2.087521 & -0.132275 & 22 & -2.878219 & -1.453846 & -1.829132 \\
\hline 10 & 2.12907 & -2.018987 & 0.080157 & 23 & -4.250478 & -0.308185 & -1.579498 \\
\hline
\end{tabular}




\begin{tabular}{|c|c|c|c|c|c|c|c|c|}
\hline 11 & -0.157039 & -0.057588 & 0.064961 & & 24 & -2.663092 & 0.264407 & -2.259309 \\
\hline 12 & 0.018683 & -1.665031 & 1.833409 & & 25 & -3.358581 & -0.994903 & 1.037903 \\
\hline 13 & -0.130345 & 1.75777 & 1.686947 & & 26 & 5.826339 & 0.190877 & -0.202552 \\
\hline
\end{tabular}

Table S7(a). DFT optimized structure bond lengths Ru-4-FcPyr

\begin{tabular}{|c|c|c|c|c|c|}
\hline Bonds & Lengths $(\AA)$ & Bonds & Lengths $(\AA)$ & Bonds & Lengths $(\AA)$ \\
\hline $\mathrm{R}(1,2)$ & 1.4369 & $\mathrm{R}(10,17)$ & 2.0553 & $\mathrm{R}(26,29)$ & 1.0816 \\
\hline $\mathrm{R}(1,5)$ & 1.4373 & $\mathrm{R}(11,12)$ & 1.4292 & $\mathrm{R}(26,30)$ & 1.3449 \\
\hline $\mathrm{R}(1,10)$ & 2.0626 & $\mathrm{R}(11,13)$ & 1.4277 & $\mathrm{R}(30,35)$ & 2.1166 \\
\hline $\mathrm{R}(1,21)$ & 1.4736 & $\mathrm{R}(11,14)$ & 1.0821 & $\mathrm{R}(31,35)$ & 2.3951 \\
\hline $\mathrm{R}(2,3)$ & 1.4257 & $\mathrm{R}(12,15)$ & 1.429 & $\mathrm{R}(32,35)$ & 2.4339 \\
\hline $\mathrm{R}(2,6)$ & 1.0817 & $\mathrm{R}(12,16)$ & 1.0824 & $\mathrm{R}(33,35)$ & 2.4667 \\
\hline $\mathrm{R}(2,10)$ & 2.0504 & $\mathrm{R}(13,17)$ & 1.4275 & $\mathrm{R}(34,35)$ & 2.4333 \\
\hline $\mathrm{R}(3,4)$ & 1.4282 & $\mathrm{R}(13,18)$ & 1.0824 & $\mathrm{R}(35,36)$ & 2.4118 \\
\hline $\mathrm{R}(3,7)$ & 1.0824 & $\mathrm{R}(15,17)$ & 1.4291 & $\mathrm{R}(36,37)$ & 1.5006 \\
\hline $\mathrm{R}(3,10)$ & 2.054 & $\mathrm{R}(15,19)$ & 1.0825 & $\mathrm{R}(36,38)$ & 1.8211 \\
\hline $\mathrm{R}(4,5)$ & 1.4256 & $\mathrm{R}(17,20)$ & 1.0822 & $\mathrm{R}(36,42)$ & 1.8211 \\
\hline $\mathrm{R}(4,8)$ & 1.0823 & $\mathrm{R}(21,22)$ & 1.4034 & $\mathrm{R}(38,39)$ & 1.0942 \\
\hline $\mathrm{R}(4,10)$ & 2.0526 & $\mathrm{R}(21,23)$ & 1.4019 & $\mathrm{R}(38,40)$ & 1.0918 \\
\hline $\mathrm{R}(5,9)$ & 1.0817 & $\mathrm{R}(22,24)$ & 1.3883 & $\mathrm{R}(38,41)$ & 1.0902 \\
\hline $\mathrm{R}(5,10)$ & 2.0491 & $\mathrm{R}(22,25)$ & 1.0851 & $\mathrm{R}(42,43)$ & 1.0942 \\
\hline $\mathrm{R}(10,11)$ & 2.0549 & $\mathrm{R}(23,26)$ & 1.3899 & $\mathrm{R}(42,44)$ & 1.0901 \\
\hline $\mathrm{R}(10,12)$ & 2.0535 & $\mathrm{R}(23,27)$ & 1.085 & $\mathrm{R}(42,45)$ & 1.0919 \\
\hline $\mathrm{R}(10,13)$ & 2.0566 & $\mathrm{R}(24,28)$ & 1.0818 & & \\
\hline $\mathrm{R}(10,15)$ & 2.0539 & $\mathrm{R}(24,30)$ & 1.346 & & \\
\hline
\end{tabular}

Table S7(b). DFT optimized structure bond lengths Ru-3-FcPyr

\begin{tabular}{|c|c|c|c|c|c|}
\hline Bonds & Lengths( $(\AA)$ & Bonds & Lengths( $\left({ }^{\AA}\right)$ & Bonds & Lengths( $(\AA)$ \\
\hline $\mathrm{R}(1,2)$ & 1.4357 & $\mathrm{R}(10,17)$ & 2.0548 & $\mathrm{R}(28,29)$ & 1.0814 \\
\hline $\mathrm{R}(1,5)$ & 1.4367 & $\mathrm{R}(11,12)$ & 1.4287 & $\mathrm{R}(28,30)$ & 1.3468 \\
\hline $\mathrm{R}(1,10)$ & 2.0607 & $\mathrm{R}(11,13)$ & 1.4257 & $\mathrm{R}(30,31)$ & 2.1198 \\
\hline $\mathrm{R}(1,21)$ & 1.4735 & $\mathrm{R}(11,14)$ & 1.082 & $\mathrm{R}(31,32)$ & 2.4466 \\
\hline $\mathrm{R}(2,3)$ & 1.4274 & $\mathrm{R}(12,15)$ & 1.43 & $\mathrm{R}(31,33)$ & 2.4248 \\
\hline $\mathrm{R}(2,6)$ & 1.0825 & $\mathrm{R}(12,16)$ & 1.0826 & $\mathrm{R}(31,34)$ & 2.4689 \\
\hline $\mathrm{R}(2,10)$ & 2.0519 & $\mathrm{R}(13,17)$ & 1.4277 & $\mathrm{R}(31,35)$ & 2.3933 \\
\hline $\mathrm{R}(3,4)$ & 1.4288 & $\mathrm{R}(13,18)$ & 1.0823 & $\mathrm{R}(31,36)$ & 2.4138 \\
\hline $\mathrm{R}(3,7)$ & 1.0826 & $\mathrm{R}(15,17)$ & 1.4301 & $\mathrm{R}(36,37)$ & 1.5005 \\
\hline $\mathrm{R}(3,10)$ & 2.0532 & $\mathrm{R}(15,19)$ & 1.0828 & $\mathrm{R}(36,38)$ & 1.8211 \\
\hline $\mathrm{R}(4,5)$ & 1.4259 & $\mathrm{R}(17,20)$ & 1.0825 & $\mathrm{R}(36,42)$ & 1.8207 \\
\hline $\mathrm{R}(4,8)$ & 1.0823 & $\mathrm{R}(21,22)$ & 1.4011 & $\mathrm{R}(38,39)$ & 1.0918 \\
\hline $\mathrm{R}(4,10)$ & 2.0508 & $\mathrm{R}(21,23)$ & 1.3999 & $\mathrm{R}(38,40)$ & 1.0942 \\
\hline $\mathrm{R}(5,9)$ & 1.0822 & $\mathrm{R}(22,24)$ & 1.0809 & $\mathrm{R}(38,41)$ & 1.0902 \\
\hline $\mathrm{R}(5,10)$ & 2.0507 & $\mathrm{R}(22,30)$ & 1.3396 & $\mathrm{R}(42,43)$ & 1.0941 \\
\hline
\end{tabular}




\begin{tabular}{|c|c|c|c|c|c|}
\hline $\mathrm{R}(10,11)$ & 2.0608 & $\mathrm{R}(23,25)$ & 1.393 & $\mathrm{R}(42,44)$ & 1.0918 \\
\hline $\mathrm{R}(10,12)$ & 2.0536 & $R(23,26)$ & 1.0869 & $\mathrm{R}(42,45)$ & 1.0901 \\
\hline $\mathrm{R}(10,13)$ & 2.0623 & $\mathrm{R}(25,27)$ & 1.0856 & & \\
\hline $\mathrm{R}(10,15)$ & 2.051 & $\mathrm{R}(25,28)$ & 1.3911 & & \\
\hline
\end{tabular}

Table S7(c). DFT optimized structure bond lengths Ru-4-FcVinylPyr

\begin{tabular}{|c|c|c|c|c|c|}
\hline Bonds & Lengths( $(\AA)$ & Bonds & Lengths(Å) & Bonds & Lengths( $(\AA)$ \\
\hline $\mathrm{R}(1,2)$ & 1.4381 & $\mathrm{R}(11,12)$ & 1.4289 & $\mathrm{R}(28,32)$ & 1.3446 \\
\hline $\mathrm{R}(1,5)$ & 1.4375 & $\mathrm{R}(11,13)$ & 1.4274 & $\mathrm{R}(28,33)$ & 1.0818 \\
\hline $\mathrm{R}(1,10)$ & 2.0726 & $\mathrm{R}(11,14)$ & 1.0821 & $\mathrm{R}(30,32)$ & 1.3483 \\
\hline $\mathrm{R}(1,21)$ & 1.4589 & $\mathrm{R}(12,15)$ & 1.4287 & $\mathrm{R}(30,34)$ & 1.0815 \\
\hline $\mathrm{R}(2,3)$ & 1.4257 & $\mathrm{R}(12,16)$ & 1.0823 & $\mathrm{R}(32,35)$ & 2.1143 \\
\hline $\mathrm{R}(2,6)$ & 1.0828 & $\mathrm{R}(13,17)$ & 1.4281 & $\mathrm{R}(35,36)$ & 2.3961 \\
\hline $\mathrm{R}(2,10)$ & 2.0488 & $\mathrm{R}(13,18)$ & 1.0822 & $\mathrm{R}(35,37)$ & 2.4324 \\
\hline $\mathrm{R}(3,4)$ & 1.4287 & $\mathrm{R}(15,17)$ & 1.4287 & $\mathrm{R}(35,38)$ & 2.4665 \\
\hline $\mathrm{R}(3,7)$ & 1.0823 & $\mathrm{R}(15,19)$ & 1.0824 & $\mathrm{R}(35,39)$ & 2.4335 \\
\hline $\mathrm{R}(3,10)$ & 2.0511 & $\mathrm{R}(17,20)$ & 1.0823 & $\mathrm{R}(35,40)$ & 2.4150 \\
\hline $\mathrm{R}(4,5)$ & 1.4263 & $\mathrm{R}(21,22)$ & 1.0888 & $\mathrm{R}(40,41)$ & 1.8208 \\
\hline $\mathrm{R}(4,8)$ & 1.0824 & $\mathrm{R}(21,23)$ & 1.3487 & $\mathrm{R}(40,45)$ & 1.8212 \\
\hline $\mathrm{R}(4,10)$ & 2.0517 & $\mathrm{R}(23,24)$ & 1.0896 & $\mathrm{R}(40,49)$ & 1.5007 \\
\hline $\mathrm{R}(5,9)$ & 1.0819 & $\mathrm{R}(23,25)$ & 1.4643 & $\mathrm{R}(41,42)$ & 1.0918 \\
\hline $\mathrm{R}(5,10)$ & 2.0497 & $\mathrm{R}(25,26)$ & 1.4042 & $\mathrm{R}(41,43)$ & 1.0942 \\
\hline $\mathrm{R}(10,11)$ & 2.0554 & $\mathrm{R}(25,27)$ & 1.406 & $\mathrm{R}(41,44)$ & 1.0901 \\
\hline $\mathrm{R}(10,12)$ & 2.0544 & $\mathrm{R}(26,28)$ & 1.3895 & $\mathrm{R}(45,46)$ & 1.0901 \\
\hline $\mathrm{R}(10,13)$ & 2.0579 & $\mathrm{R}(26,29)$ & 1.0865 & $\mathrm{R}(45,47)$ & 1.0942 \\
\hline $\mathrm{R}(10,15)$ & 2.0546 & $\mathrm{R}(27,30)$ & 1.3867 & $\mathrm{R}(45,48)$ & 1.0918 \\
\hline $\mathrm{R}(10,17)$ & 2.0559 & $\mathrm{R}(27,31)$ & 1.0851 & & \\
\hline
\end{tabular}

Table S7(d). DFT optimized structure bond lengths Ru-4-FcEtPyr

\begin{tabular}{|c|c|c|c|c|c|}
\hline Bonds & Lengths $(\AA)$ & Bonds & Lengths $(\AA)$ & Bonds & Lengths $(\AA)$ \\
\hline $\mathrm{R}(1,2)$ & 1.4327 & $\mathrm{R}(11,13)$ & 1.4282 & $\mathrm{R}(28,32)$ & 1.3448 \\
\hline $\mathrm{R}(1,5)$ & 1.4323 & $\mathrm{R}(11,14)$ & 1.0822 & $\mathrm{R}(28,33)$ & 1.0819 \\
\hline $\mathrm{R}(1,10)$ & 2.0681 & $\mathrm{R}(12,15)$ & 1.4286 & $\mathrm{R}(30,32)$ & 1.3453 \\
\hline $\mathrm{R}(1,21)$ & 1.5073 & $\mathrm{R}(12,16)$ & 1.0824 & $\mathrm{R}(30,34)$ & 1.0817 \\
\hline $\mathrm{R}(2,3)$ & 1.4277 & $\mathrm{R}(13,17)$ & 1.4282 & $\mathrm{R}(32,35)$ & 2.1202 \\
\hline $\mathrm{R}(2,6)$ & 1.0831 & $\mathrm{R}(13,18)$ & 1.0822 & $\mathrm{R}(35,36)$ & 2.396 \\
\hline $\mathrm{R}(2,10)$ & 2.0509 & $\mathrm{R}(15,17)$ & 1.4283 & $\mathrm{R}(35,37)$ & 2.4333 \\
\hline $\mathrm{R}(3,4)$ & 1.4275 & $\mathrm{R}(15,19)$ & 1.0824 & $\mathrm{R}(35,38)$ & 2.4671 \\
\hline $\mathrm{R}(3,7)$ & 1.0825 & $\mathrm{R}(17,20)$ & 1.0823 & $\mathrm{R}(35,39)$ & 2.4339 \\
\hline $\mathrm{R}(3,10)$ & 2.0499 & $\mathrm{R}(21,22)$ & 1.0997 & $\mathrm{R}(35,40)$ & 2.4105 \\
\hline $\mathrm{R}(4,5)$ & 1.4286 & $\mathrm{R}(21,23)$ & 1.5438 & $\mathrm{R}(40,41)$ & 1.8209 \\
\hline $\mathrm{R}(4,8)$ & 1.0826 & $\mathrm{R}(21,50)$ & 1.0971 & $\mathrm{R}(40,45)$ & 1.8211 \\
\hline $\mathrm{R}(4,10)$ & 2.0492 & $\mathrm{R}(23,24)$ & 1.0964 & $\mathrm{R}(40,49)$ & 1.5006 \\
\hline
\end{tabular}




\begin{tabular}{|c|c|c|c|c|c|}
\hline $\mathrm{R}(5,9)$ & 1.0821 & $\mathrm{R}(23,25)$ & 1.5118 & $\mathrm{R}(41,42)$ & 1.0918 \\
\hline $\mathrm{R}(5,10)$ & 2.0553 & $\mathrm{R}(23,51)$ & 1.0971 & $\mathrm{R}(41,43)$ & 1.0941 \\
\hline $\mathrm{R}(10,11)$ & 2.0572 & $R(25,26)$ & 1.3984 & $\mathrm{R}(41,44)$ & 1.0901 \\
\hline $\mathrm{R}(10,12)$ & 2.0556 & $\mathrm{R}(25,27)$ & 1.3984 & $\mathrm{R}(45,46)$ & 1.0901 \\
\hline $\mathrm{R}(10,13)$ & 2.058 & $\mathrm{R}(26,28)$ & 1.3911 & $\mathrm{R}(45,47)$ & 1.0942 \\
\hline $\mathrm{R}(10,15)$ & 2.0539 & $R(26,29)$ & 1.087 & $\mathrm{R}(45,48)$ & 1.0918 \\
\hline $\mathrm{R}(10,17)$ & 2.0552 & $\mathrm{R}(27,30)$ & 1.391 & & \\
\hline $\mathrm{R}(11,12)$ & 1.4281 & $\mathrm{R}(27,31)$ & 1.0869 & & \\
\hline
\end{tabular}

Table S7(e). DFT optimized structure bond lengths NAMI-Pyr

\begin{tabular}{|c|c|c|c|c|c|}
\hline Bonds & Lengths(§) & Bonds & Lengths( $(\AA)$ & Bonds & Lengths( $(\AA)$ \\
\hline $\mathrm{R}(1,2)$ & 1.3937 & $\mathrm{R}(6,8)$ & 1.3456 & $\mathrm{R}(16,21)$ & 1.821 \\
\hline $\mathrm{R}(1,3)$ & 1.3935 & $\mathrm{R}(6,10)$ & 1.0816 & $\mathrm{R}(16,25)$ & 1.5006 \\
\hline $\mathrm{R}(1,26)$ & 1.0874 & $\mathrm{R}(8,11)$ & 2.1205 & $\mathrm{R}(17,18)$ & 1.0919 \\
\hline $\mathrm{R}(2,4)$ & 1.3925 & $\mathrm{R}(11,12)$ & 2.3963 & $\mathrm{R}(17,19)$ & 1.0942 \\
\hline $\mathrm{R}(2,5)$ & 1.0856 & $\mathrm{R}(11,13)$ & 2.4346 & $\mathrm{R}(17,20)$ & 1.0901 \\
\hline $\mathrm{R}(3,6)$ & 1.3926 & $\mathrm{R}(11,14)$ & 2.4651 & $\mathrm{R}(21,22)$ & 1.0901 \\
\hline $\mathrm{R}(3,7)$ & 1.0856 & $\mathrm{R}(11,15)$ & 2.4328 & $\mathrm{R}(21,23)$ & 1.0942 \\
\hline $\mathrm{R}(4,8)$ & 1.3454 & $\mathrm{R}(11,16)$ & 2.4108 & $\mathrm{R}(21,24)$ & 1.0918 \\
\hline $\mathrm{R}(4,9)$ & 1.0818 & $\mathrm{R}(16,17)$ & 1.821 & & \\
\hline
\end{tabular}

Table S8(a). DFT optimized structure bond angles of Ru-4-FcPyr

\begin{tabular}{|c|c|c|c|c|c|}
\hline Angles & Degrees & Angles & Degrees & Angles & Degrees \\
\hline $\mathrm{A}(2,1,5)$ & 106.7619 & $\mathrm{~A}(4,10,12)$ & 107.8713 & $\mathrm{~A}(21,23,27)$ & 121.0286 \\
\hline $\mathrm{A}(2,1,21)$ & 126.6346 & $\mathrm{~A}(4,10,13)$ & 160.7442 & $\mathrm{~A}(26,23,27)$ & 118.7566 \\
\hline $\mathrm{A}(5,1,21)$ & 126.5917 & $\mathrm{~A}(4,10,15)$ & 121.9503 & $\mathrm{~A}(22,24,28)$ & 121.9172 \\
\hline $\mathrm{A}(10,1,21)$ & 127.7557 & $\mathrm{~A}(4,10,17)$ & 157.3836 & $\mathrm{~A}(22,24,30)$ & 122.3415 \\
\hline $\mathrm{A}(1,2,3)$ & 108.6863 & $\mathrm{~A}(5,10,11)$ & 107.6031 & $\mathrm{~A}(28,24,30)$ & 115.7399 \\
\hline $\mathrm{A}(1,2,6)$ & 125.6611 & $\mathrm{~A}(5,10,12)$ & 121.8633 & $\mathrm{~A}(23,26,29)$ & 121.958 \\
\hline $\mathrm{A}(3,2,6)$ & 125.6405 & $\mathrm{~A}(5,10,13)$ & 123.9135 & $\mathrm{~A}(23,26,30)$ & 122.3279 \\
\hline $\mathrm{A}(6,2,10)$ & 125.1175 & $\mathrm{~A}(5,10,15)$ & 157.5063 & $\mathrm{~A}(29,26,30)$ & 115.7135 \\
\hline $\mathrm{A}(2,3,4)$ & 107.9287 & $\mathrm{~A}(5,10,17)$ & 160.3885 & $\mathrm{~A}(24,30,26)$ & 118.3937 \\
\hline $\mathrm{A}(2,3,7)$ & 125.9377 & $\mathrm{~A}(11,10,15)$ & 68.4632 & $\mathrm{~A}(24,30,35)$ & 120.7579 \\
\hline $\mathrm{A}(4,3,7)$ & 126.1261 & $\mathrm{~A}(11,10,17)$ & 68.3739 & $\mathrm{~A}(26,30,35)$ & 120.8429 \\
\hline $\mathrm{A}(7,3,10)$ & 125.6329 & $\mathrm{~A}(12,10,13)$ & 68.4688 & $\mathrm{~A}(30,35,31)$ & 89.2587 \\
\hline $\mathrm{A}(3,4,5)$ & 107.9701 & $\mathrm{~A}(12,10,17)$ & 68.4668 & $\mathrm{~A}(30,35,32)$ & 88.8025 \\
\hline $\mathrm{A}(3,4,8)$ & 126.1599 & $\mathrm{~A}(13,10,15)$ & 68.4557 & $\mathrm{~A}(30,35,33)$ & 89.7393 \\
\hline $\mathrm{A}(5,4,8)$ & 125.8689 & $\mathrm{~A}(10,11,14)$ & 125.6259 & $\mathrm{~A}(30,35,34)$ & 89.1216 \\
\hline $\mathrm{A}(8,4,10)$ & 126.034 & $\mathrm{~A}(12,11,13)$ & 108.0701 & $\mathrm{~A}(31,35,32)$ & 90.4399 \\
\hline $\mathrm{A}(1,5,4)$ & 108.6522 & $\mathrm{~A}(12,11,14)$ & 126.0923 & $\mathrm{~A}(31,35,34)$ & 90.5717 \\
\hline $\mathrm{A}(1,5,9)$ & 125.6464 & $\mathrm{~A}(13,11,14)$ & 125.8322 & $\mathrm{~A}(31,35,36)$ & 92.4187 \\
\hline $\mathrm{A}(4,5,9)$ & 125.6977 & $\mathrm{~A}(10,12,16)$ & 125.7267 & $\mathrm{~A}(32,35,33)$ & 89.6382 \\
\hline $\mathrm{A}(9,5,10)$ & 126.6077 & $\mathrm{~A}(11,12,15)$ & 107.9387 & $\mathrm{~A}(32,35,36)$ & 90.8726 \\
\hline
\end{tabular}




\begin{tabular}{|c|c|c|c|c|c|}
\hline $\mathrm{A}(1,10,3)$ & 68.8028 & $\mathrm{~A}(11,12,16)$ & 126.0415 & $\mathrm{~A}(33,35,34)$ & 89.3139 \\
\hline $\mathrm{A}(1,10,4)$ & 68.8222 & $\mathrm{~A}(15,12,16)$ & 126.0171 & $\mathrm{~A}(33,35,36)$ & 88.5838 \\
\hline $\mathrm{A}(1,10,11)$ & 121.2033 & $\mathrm{~A}(10,13,18)$ & 124.6745 & $\mathrm{~A}(34,35,36)$ & 91.172 \\
\hline $\mathrm{A}(1,10,12)$ & 157.1562 & $\mathrm{~A}(11,13,17)$ & 107.9731 & $\mathrm{~A}(35,36,37)$ & 123.6905 \\
\hline $\mathrm{A}(1,10,13)$ & 106.7966 & $\mathrm{~A}(11,13,18)$ & 125.9746 & $\mathrm{~A}(35,36,38)$ & 108.2114 \\
\hline $\mathrm{A}(1,10,15)$ & 160.3189 & $\mathrm{~A}(17,13,18)$ & 126.0186 & $\mathrm{~A}(35,36,42)$ & 108.2586 \\
\hline $\mathrm{A}(1,10,17)$ & 123.3988 & $\mathrm{~A}(10,15,19)$ & 125.7386 & $\mathrm{~A}(37,36,38)$ & 107.6331 \\
\hline $\mathrm{A}(2,10,4)$ & 68.4518 & $\mathrm{~A}(12,15,17)$ & 107.9458 & $\mathrm{~A}(37,36,42)$ & 107.7044 \\
\hline $\mathrm{A}(2,10,5)$ & 68.4892 & $\mathrm{~A}(12,15,19)$ & 126.0144 & $\mathrm{~A}(38,36,42)$ & 98.4304 \\
\hline $\mathrm{A}(2,10,11)$ & 156.9219 & $\mathrm{~A}(17,15,19)$ & 126.0368 & $\mathrm{~A}(36,38,39)$ & 107.7955 \\
\hline $\mathrm{A}(2,10,12)$ & 160.7821 & $\mathrm{~A}(10,17,20)$ & 125.5342 & $\mathrm{~A}(36,38,40)$ & 108.5051 \\
\hline $\mathrm{A}(2,10,13)$ & 121.3078 & $\mathrm{~A}(13,17,15)$ & 108.0722 & $\mathrm{~A}(36,38,41)$ & 106.4712 \\
\hline $\mathrm{A}(2,10,15)$ & 123.9379 & $\mathrm{~A}(13,17,20)$ & 125.7709 & $\mathrm{~A}(39,38,40)$ & 112.6944 \\
\hline $\mathrm{A}(2,10,17)$ & 107.2499 & $\mathrm{~A}(15,17,20)$ & 126.1499 & $\mathrm{~A}(39,38,41)$ & 111.4539 \\
\hline $\mathrm{A}(3,10,5)$ & 68.468 & $\mathrm{~A}(1,21,22)$ & 121.9157 & $\mathrm{~A}(40,38,41)$ & 109.668 \\
\hline $\mathrm{A}(3,10,11)$ & 161.0564 & $\mathrm{~A}(1,21,23)$ & 121.5702 & $\mathrm{~A}(36,42,43)$ & 107.7915 \\
\hline $\mathrm{A}(3,10,12)$ & 124.3534 & $\mathrm{~A}(22,21,23)$ & 116.5132 & $\mathrm{~A}(36,42,44)$ & 106.5313 \\
\hline $\mathrm{A}(3,10,13)$ & 156.9525 & $\mathrm{~A}(21,22,24)$ & 120.2072 & $\mathrm{~A}(36,42,45)$ & 108.4928 \\
\hline $\mathrm{A}(3,10,15)$ & 107.6568 & $\mathrm{~A}(21,22,25)$ & 121.0896 & $\mathrm{~A}(43,42,44)$ & 111.4425 \\
\hline $\mathrm{A}(3,10,17)$ & 121.6088 & $\mathrm{~A}(24,22,25)$ & 118.6985 & $\mathrm{~A}(43,42,45)$ & 112.6402 \\
\hline $\mathrm{A}(4,10,11)$ & 124.3522 & $\mathrm{~A}(21,23,26)$ & 120.2096 & $\mathrm{~A}(44,42,45)$ & 109.6955 \\
\hline
\end{tabular}

Table S8(b). DFT optimized structure bond angles of Ru-3-FcPyr

\begin{tabular}{|c|c|c|c|c|c|}
\hline Angles & Degrees & Angles & Degrees & Angles & Degrees \\
\hline $\mathrm{A}(2,1,5)$ & 107.0766 & $\mathrm{~A}(4,10,12)$ & 107.4564 & $\mathrm{~A}(21,23,26)$ & 120.0894 \\
\hline $\mathrm{A}(2,1,21)$ & 126.8509 & $\mathrm{~A}(4,10,13)$ & 160.1729 & $\mathrm{~A}(25,23,26)$ & 120.5661 \\
\hline $\mathrm{A}(5,1,21)$ & 126.0538 & $\mathrm{~A}(4,10,15)$ & 121.8646 & $\mathrm{~A}(23,25,27)$ & 121.0664 \\
\hline $\mathrm{A}(10,1,21)$ & 127.8797 & $\mathrm{~A}(4,10,17)$ & 157.7456 & $\mathrm{~A}(23,25,28)$ & 119.537 \\
\hline $\mathrm{A}(1,2,3)$ & 108.5136 & $\mathrm{~A}(5,10,11)$ & 107.2264 & $\mathrm{~A}(27,25,28)$ & 119.3956 \\
\hline $\mathrm{A}(1,2,6)$ & 125.6249 & $\mathrm{~A}(5,10,12)$ & 121.4714 & $\mathrm{~A}(25,28,29)$ & 122.7635 \\
\hline $\mathrm{A}(3,2,6)$ & 125.8442 & $\mathrm{~A}(5,10,13)$ & 123.6622 & $\mathrm{~A}(25,28,30)$ & 121.3614 \\
\hline $\mathrm{A}(6,2,10)$ & 125.0671 & $\mathrm{~A}(5,10,15)$ & 157.3082 & $\mathrm{~A}(29,28,30)$ & 115.8748 \\
\hline $\mathrm{A}(2,3,4)$ & 107.8859 & $\mathrm{~A}(5,10,17)$ & 160.291 & $\mathrm{~A}(22,30,28)$ & 119.2607 \\
\hline $\mathrm{A}(2,3,7)$ & 125.9576 & $\mathrm{~A}(11,10,15)$ & 68.4592 & $\mathrm{~A}(22,30,31)$ & 119.4956 \\
\hline $\mathrm{A}(4,3,7)$ & 126.149 & $\mathrm{~A}(11,10,17)$ & 68.2672 & $\mathrm{~A}(28,30,31)$ & 121.2376 \\
\hline $\mathrm{A}(7,3,10)$ & 125.6014 & $\mathrm{~A}(12,10,13)$ & 68.2846 & $\mathrm{~A}(30,31,32)$ & 89.0841 \\
\hline $\mathrm{A}(3,4,5)$ & 108.0968 & $\mathrm{~A}(12,10,17)$ & 68.4628 & $\mathrm{~A}(30,31,33)$ & 88.8429 \\
\hline $\mathrm{A}(3,4,8)$ & 126.1107 & $\mathrm{~A}(13,10,15)$ & 68.4276 & $\mathrm{~A}(30,31,34)$ & 89.8117 \\
\hline $\mathrm{A}(5,4,8)$ & 125.7904 & $\mathrm{~A}(10,11,14)$ & 125.6448 & $\mathrm{~A}(30,31,35)$ & 89.2103 \\
\hline $\mathrm{A}(8,4,10)$ & 125.8534 & $\mathrm{~A}(12,11,13)$ & 108.0574 & $\mathrm{~A}(32,31,34)$ & 88.9903 \\
\hline $\mathrm{A}(1,5,4)$ & 108.4269 & $\mathrm{~A}(12,11,14)$ & 126.9858 & $\mathrm{~A}(32,31,35)$ & 90.191 \\
\hline $\mathrm{A}(1,5,9)$ & 125.2739 & $\mathrm{~A}(13,11,14)$ & 124.9504 & $\mathrm{~A}(32,31,36)$ & 91.1393 \\
\hline $\mathrm{A}(4,5,9)$ & 126.2983 & $\mathrm{~A}(10,12,16)$ & 125.5057 & $\mathrm{~A}(33,31,34)$ & 90.0678 \\
\hline
\end{tabular}




\begin{tabular}{|c|c|c|c|c|c|}
\hline $\mathrm{A}(9,5,10)$ & 126.4814 & $\mathrm{~A}(11,12,15)$ & 108.0159 & $\mathrm{~A}(33,31,35)$ & 90.7153 \\
\hline $\mathrm{A}(1,10,3)$ & 68.79 & $\mathrm{~A}(11,12,16)$ & 126.0472 & $\mathrm{~A}(33,31,36)$ & 90.9054 \\
\hline $\mathrm{A}(1,10,4)$ & 68.776 & $\mathrm{~A}(15,12,16)$ & 125.9322 & $\mathrm{~A}(34,31,36)$ & 88.5185 \\
\hline $\mathrm{A}(1,10,11)$ & 121.2746 & $\mathrm{~A}(10,13,18)$ & 125.3967 & $\mathrm{~A}(35,31,36)$ & 92.4629 \\
\hline $\mathrm{A}(1,10,12)$ & 156.9794 & $\mathrm{~A}(11,13,17)$ & 108.0583 & $\mathrm{~A}(31,36,37)$ & 123.6636 \\
\hline $\mathrm{A}(1,10,13)$ & 107.1361 & $\mathrm{~A}(11,13,18)$ & 124.8946 & $\mathrm{~A}(31,36,38)$ & 108.1694 \\
\hline $\mathrm{A}(1,10,15)$ & 160.5651 & $\mathrm{~A}(17,13,18)$ & 127.0327 & $\mathrm{~A}(31,36,42)$ & 108.2597 \\
\hline $\mathrm{A}(1,10,17)$ & 123.6757 & $\mathrm{~A}(10,15,19)$ & 125.5947 & $\mathrm{~A}(37,36,38)$ & 107.6723 \\
\hline $\mathrm{A}(2,10,4)$ & 68.502 & $\mathrm{~A}(12,15,17)$ & 107.8148 & $\mathrm{~A}(37,36,42)$ & 107.7618 \\
\hline $\mathrm{A}(2,10,5)$ & 68.5398 & $\mathrm{~A}(12,15,19)$ & 126.0908 & $\mathrm{~A}(38,36,42)$ & 98.4 \\
\hline $\mathrm{A}(2,10,11)$ & 157.2178 & $\mathrm{~A}(17,15,19)$ & 126.0921 & $\mathrm{~A}(36,38,39)$ & 108.4776 \\
\hline $\mathrm{A}(2,10,12)$ & 160.791 & $\mathrm{~A}(10,17,20)$ & 125.5423 & $\mathrm{~A}(36,38,40)$ & 107.8243 \\
\hline $\mathrm{A}(2,10,13)$ & 121.9255 & $\mathrm{~A}(13,17,15)$ & 108.0536 & $\mathrm{~A}(36,38,41)$ & 106.5331 \\
\hline $\mathrm{A}(2,10,15)$ & 124.1347 & $\mathrm{~A}(13,17,20)$ & 125.9344 & $\mathrm{~A}(39,38,40)$ & 112.6495 \\
\hline $\mathrm{A}(2,10,17)$ & 107.7462 & $\mathrm{~A}(15,17,20)$ & 126.0075 & $\mathrm{~A}(39,38,41)$ & 109.7157 \\
\hline $\mathrm{A}(3,10,5)$ & 68.5437 & $\mathrm{~A}(1,21,22)$ & 120.0121 & $\mathrm{~A}(40,38,41)$ & 111.3941 \\
\hline $\mathrm{A}(3,10,11)$ & 160.5593 & $\mathrm{~A}(1,21,23)$ & 122.6679 & $\mathrm{~A}(36,42,43)$ & 107.8328 \\
\hline $\mathrm{A}(3,10,12)$ & 124.0966 & $\mathrm{~A}(22,21,23)$ & 117.3198 & $\mathrm{~A}(36,42,44)$ & 108.4024 \\
\hline $\mathrm{A}(3,10,13)$ & 157.6409 & $\mathrm{~A}(21,22,24)$ & 121.4156 & $\mathrm{~A}(36,42,45)$ & 106.5746 \\
\hline $\mathrm{A}(3,10,15)$ & 107.6953 & $\mathrm{~A}(21,22,30)$ & 123.1819 & $\mathrm{~A}(43,42,44)$ & 112.6347 \\
\hline $\mathrm{A}(3,10,17)$ & 122.1148 & $\mathrm{~A}(24,22,30)$ & 115.3944 & $\mathrm{~A}(43,42,45)$ & 111.412 \\
\hline $\mathrm{A}(4,10,11)$ & 123.8002 & $\mathrm{~A}(21,23,25)$ & 119.3389 & $\mathrm{~A}(44,42,45)$ & 109.7377 \\
\hline
\end{tabular}

Table S8(c). DFT optimized structure bond angles of Ru-4-FcVinylPyr

\begin{tabular}{|c|c|c|c|c|c|}
\hline Angles & Degrees & Angles & Degrees & Angles & Degrees \\
\hline $\mathrm{A}(2,1,5)$ & 106.7111 & $\mathrm{~A}(4,10,15)$ & 121.6128 & $\mathrm{~A}(28,26,29)$ & 119.0633 \\
\hline $\mathrm{A}(2,1,21)$ & 124.8239 & $\mathrm{~A}(4,10,17)$ & 157.3696 & $\mathrm{~A}(25,27,30)$ & 120.17 \\
\hline $\mathrm{A}(5,1,21)$ & 128.4617 & $\mathrm{~A}(5,10,11)$ & 107.2732 & $\mathrm{~A}(25,27,31)$ & 121.4244 \\
\hline $\mathrm{A}(10,1,21)$ & 127.9415 & $\mathrm{~A}(5,10,12)$ & 121.3945 & $\mathrm{~A}(30,27,31)$ & 118.4041 \\
\hline $\mathrm{A}(1,2,3)$ & 108.7809 & $\mathrm{~A}(5,10,13)$ & 123.9351 & $\mathrm{~A}(26,28,32)$ & 122.1332 \\
\hline $\mathrm{A}(1,2,6)$ & 125.048 & $\mathrm{~A}(5,10,15)$ & 157.0749 & $\mathrm{~A}(26,28,33)$ & 122.0582 \\
\hline $\mathrm{A}(3,2,6)$ & 126.1683 & $\mathrm{~A}(5,10,17)$ & 160.668 & $\mathrm{~A}(32,28,33)$ & 115.8082 \\
\hline $\mathrm{A}(6,2,10)$ & 126.2475 & $\mathrm{~A}(11,10,15)$ & 68.4408 & $\mathrm{~A}(27,30,32)$ & 122.4713 \\
\hline $\mathrm{A}(2,3,4)$ & 107.8155 & $\mathrm{~A}(11,10,17)$ & 68.3793 & $\mathrm{~A}(27,30,34)$ & 121.9223 \\
\hline $\mathrm{A}(2,3,7)$ & 126.0444 & $\mathrm{~A}(12,10,13)$ & 68.393 & $\mathrm{~A}(32,30,34)$ & 115.6063 \\
\hline $\mathrm{A}(4,3,7)$ & 126.1369 & $\mathrm{~A}(12,10,17)$ & 68.4308 & $\mathrm{~A}(28,32,30)$ & 118.4296 \\
\hline $\mathrm{A}(7,3,10)$ & 125.7728 & $\mathrm{~A}(13,10,15)$ & 68.3985 & $\mathrm{~A}(28,32,35)$ & 120.8714 \\
\hline $\mathrm{A}(3,4,5)$ & 108.068 & $\mathrm{~A}(10,11,14)$ & 125.6085 & $\mathrm{~A}(30,32,35)$ & 120.6922 \\
\hline $\mathrm{A}(3,4,8)$ & 126.0472 & $\mathrm{~A}(12,11,13)$ & 108.0334 & $\mathrm{~A}(32,35,36)$ & 89.3352 \\
\hline $\mathrm{A}(5,4,8)$ & 125.8742 & $\mathrm{~A}(12,11,14)$ & 126.1077 & $\mathrm{~A}(32,35,37)$ & 89.2441 \\
\hline $\mathrm{A}(8,4,10)$ & 125.5152 & $\mathrm{~A}(13,11,14)$ & 125.8547 & $\mathrm{~A}(32,35,38)$ & 89.8291 \\
\hline $\mathrm{A}(1,5,4)$ & 108.6131 & $\mathrm{~A}(10,12,16)$ & 125.6867 & $\mathrm{~A}(32,35,39)$ & 88.8416 \\
\hline $\mathrm{A}(1,5,9)$ & 125.6943 & $\mathrm{~A}(11,12,15)$ & 107.9701 & $\mathrm{~A}(36,35,37)$ & 90.5307 \\
\hline
\end{tabular}




\begin{tabular}{|c|c|c|c|c|c|}
\hline $\mathrm{A}(4,5,9)$ & 125.6908 & $\mathrm{~A}(11,12,16)$ & 126.0213 & $\mathrm{~A}(36,35,39)$ & 90.4005 \\
\hline $\mathrm{A}(9,5,10)$ & 125.3269 & $\mathrm{~A}(15,12,16)$ & 126.0052 & $\mathrm{~A}(36,35,40)$ & 92.3594 \\
\hline $\mathrm{A}(1,10,3)$ & 68.7472 & $\mathrm{~A}(10,13,18)$ & 125.1221 & $\mathrm{~A}(37,35,38)$ & 89.3205 \\
\hline $\mathrm{A}(1,10,4)$ & 68.6534 & $\mathrm{~A}(11,13,17)$ & 108.0084 & $\mathrm{~A}(37,35,40)$ & 91.0019 \\
\hline $\mathrm{A}(1,10,11)$ & 121.4404 & $\mathrm{~A}(11,13,18)$ & 125.8254 & $\mathrm{~A}(38,35,39)$ & 89.7203 \\
\hline $\mathrm{A}(1,10,12)$ & 157.0122 & $\mathrm{~A}(17,13,18)$ & 126.1466 & $\mathrm{~A}(38,35,40)$ & 88.4769 \\
\hline $\mathrm{A}(1,10,13)$ & 107.4405 & $\mathrm{~A}(10,15,19)$ & 125.7293 & $\mathrm{~A}(39,35,40)$ & 90.8834 \\
\hline $\mathrm{A}(1,10,15)$ & 160.7965 & $\mathrm{~A}(12,15,17)$ & 107.9691 & $\mathrm{~A}(35,40,41)$ & 108.2042 \\
\hline $\mathrm{A}(1,10,17)$ & 124.0696 & $\mathrm{~A}(12,15,19)$ & 126.0133 & $\mathrm{~A}(35,40,45)$ & 108.1769 \\
\hline $\mathrm{A}(2,10,4)$ & 68.4577 & $\mathrm{~A}(17,15,19)$ & 126.0147 & $\mathrm{~A}(35,40,49)$ & 123.7383 \\
\hline $\mathrm{A}(2,10,5)$ & 68.5193 & $\mathrm{~A}(10,17,20)$ & 125.7856 & $\mathrm{~A}(41,40,45)$ & 98.3559 \\
\hline $\mathrm{A}(2,10,11)$ & 157.3504 & $\mathrm{~A}(13,17,15)$ & 108.0189 & $\mathrm{~A}(41,40,49)$ & 107.7491 \\
\hline $\mathrm{A}(2,10,12)$ & 160.6537 & $\mathrm{~A}(13,17,20)$ & 125.9385 & $\mathrm{~A}(45,40,49)$ & 107.6758 \\
\hline $\mathrm{A}(2,10,13)$ & 121.96 & $\mathrm{~A}(15,17,20)$ & 126.0403 & $\mathrm{~A}(40,41,42)$ & 108.4039 \\
\hline $\mathrm{A}(2,10,15)$ & 124.1726 & $\mathrm{~A}(1,21,22)$ & 115.0348 & $\mathrm{~A}(40,41,43)$ & 107.7981 \\
\hline $\mathrm{A}(2,10,17)$ & 107.8095 & $\mathrm{~A}(1,21,23)$ & 125.526 & $\mathrm{~A}(40,41,44)$ & 106.5673 \\
\hline $\mathrm{A}(3,10,5)$ & 68.5937 & $\mathrm{~A}(22,21,23)$ & 119.4271 & $\mathrm{~A}(42,41,43)$ & 112.6638 \\
\hline $\mathrm{A}(3,10,11)$ & 160.4611 & $\mathrm{~A}(21,23,24)$ & 118.4659 & $\mathrm{~A}(42,41,44)$ & 109.6987 \\
\hline $\mathrm{A}(3,10,12)$ & 123.8675 & $\mathrm{~A}(21,23,25)$ & 126.7169 & $\mathrm{~A}(43,41,44)$ & 111.4594 \\
\hline $\mathrm{A}(3,10,13)$ & 157.4767 & $\mathrm{~A}(24,23,25)$ & 114.8137 & $\mathrm{~A}(40,45,46)$ & 106.5298 \\
\hline $\mathrm{A}(3,10,15)$ & 107.4957 & $\mathrm{~A}(23,25,26)$ & 119.5199 & $\mathrm{~A}(40,45,47)$ & 107.8216 \\
\hline $\mathrm{A}(3,10,17)$ & 121.8439 & $\mathrm{~A}(23,25,27)$ & 124.1856 & $\mathrm{~A}(40,45,48)$ & 108.4387 \\
\hline $\mathrm{A}(4,10,11)$ & 123.7842 & $\mathrm{~A}(26,25,27)$ & 116.2941 & $\mathrm{~A}(46,45,47)$ & 111.4099 \\
\hline $\mathrm{A}(4,10,12)$ & 107.2837 & $\mathrm{~A}(25,26,28)$ & 120.5014 & $\mathrm{~A}(46,45,48)$ & 109.7053 \\
\hline $\mathrm{A}(4,10,13)$ & 160.4332 & $\mathrm{~A}(25,26,29)$ & 120.4353 & $\mathrm{~A}(47,45,48)$ & 112.6852 \\
\hline
\end{tabular}

Table S8(d). DFT optimized structure bond angles of Ru-4-FcEtPyr

\begin{tabular}{|c|c|c|c|c|c|}
\hline Angles & Degrees & Angles & Degrees & Angles & Degrees \\
\hline $\mathrm{A}(2,1,5)$ & 106.8334 & $\mathrm{~A}(5,10,11)$ & 108.3868 & $\mathrm{~A}(25,26,28)$ & 120.1114 \\
\hline $\mathrm{A}(2,1,21)$ & 125.0792 & $\mathrm{~A}(5,10,12)$ & 119.0012 & $\mathrm{~A}(25,26,29)$ & 120.8364 \\
\hline $\mathrm{A}(5,1,21)$ & 127.8637 & $\mathrm{~A}(5,10,13)$ & 127.8743 & $\mathrm{~A}(28,26,29)$ & 119.052 \\
\hline $\mathrm{A}(10,1,21)$ & 130.9077 & $\mathrm{~A}(5,10,15)$ & 152.7091 & $\mathrm{~A}(25,27,30)$ & 120.1203 \\
\hline $\mathrm{A}(1,2,3)$ & 108.8463 & $\mathrm{~A}(5,10,17)$ & 165.5176 & $\mathrm{~A}(25,27,31)$ & 120.8284 \\
\hline $\mathrm{A}(1,2,6)$ & 125.144 & $\mathrm{~A}(11,10,15)$ & 68.4048 & $\mathrm{~A}(30,27,31)$ & 119.0513 \\
\hline $\mathrm{A}(3,2,6)$ & 126.0079 & $\mathrm{~A}(11,10,17)$ & 68.3724 & $\mathrm{~A}(26,28,32)$ & 122.1042 \\
\hline $\mathrm{A}(6,2,10)$ & 125.757 & $\mathrm{~A}(12,10,13)$ & 68.3651 & $\mathrm{~A}(26,28,33)$ & 122.1764 \\
\hline $\mathrm{A}(2,3,4)$ & 107.726 & $\mathrm{~A}(12,10,17)$ & 68.4174 & $\mathrm{~A}(32,28,33)$ & 115.7194 \\
\hline $\mathrm{A}(2,3,7)$ & 126.1211 & $\mathrm{~A}(13,10,15)$ & 68.3965 & $\mathrm{~A}(27,30,32)$ & 122.0895 \\
\hline $\mathrm{A}(4,3,7)$ & 126.144 & $\mathrm{~A}(10,11,14)$ & 125.8452 & $\mathrm{~A}(27,30,34)$ & 122.1879 \\
\hline $\mathrm{A}(7,3,10)$ & 125.3343 & $\mathrm{~A}(12,11,13)$ & 108.0201 & $\mathrm{~A}(32,30,34)$ & 115.7224 \\
\hline $\mathrm{A}(3,4,5)$ & 107.8694 & $\mathrm{~A}(12,11,14)$ & 125.994 & $\mathrm{~A}(28,32,30)$ & 118.6703 \\
\hline $\mathrm{A}(3,4,8)$ & 126.1958 & $\mathrm{~A}(13,11,14)$ & 125.9838 & $\mathrm{~A}(28,32,35)$ & 120.6707 \\
\hline $\mathrm{A}(5,4,8)$ & 125.9288 & $\mathrm{~A}(10,12,16)$ & 125.6573 & $\mathrm{~A}(30,32,35)$ & 120.6552 \\
\hline
\end{tabular}




\begin{tabular}{|c|c|c|c|c|c|}
\hline $\mathrm{A}(8,4,10)$ & 125.3207 & $\mathrm{~A}(11,12,15)$ & 107.9887 & $\mathrm{~A}(32,35,36)$ & 89.3156 \\
\hline $\mathrm{A}(1,5,4)$ & 108.7246 & $\mathrm{~A}(11,12,16)$ & 125.9795 & $\mathrm{~A}(32,35,37)$ & 89.081 \\
\hline $\mathrm{A}(1,5,9)$ & 125.8185 & $\mathrm{~A}(15,12,16)$ & 126.0277 & $\mathrm{~A}(32,35,38)$ & 89.7926 \\
\hline $\mathrm{A}(4,5,9)$ & 125.4491 & $\mathrm{~A}(10,13,18)$ & 126.1052 & $\mathrm{~A}(32,35,39)$ & 88.7677 \\
\hline $\mathrm{A}(9,5,10)$ & 125.5949 & $\mathrm{~A}(11,13,17)$ & 107.9904 & $\mathrm{~A}(36,35,37)$ & 90.5685 \\
\hline $\mathrm{A}(1,10,3)$ & 68.798 & $\mathrm{~A}(11,13,18)$ & 126.0946 & $\mathrm{~A}(36,35,39)$ & 90.3861 \\
\hline $\mathrm{A}(1,10,4)$ & 68.7649 & $\mathrm{~A}(17,13,18)$ & 125.9144 & $\mathrm{~A}(36,35,40)$ & 92.3753 \\
\hline $\mathrm{A}(1,10,11)$ & 119.2381 & $\mathrm{~A}(10,15,19)$ & 125.6343 & $\mathrm{~A}(37,35,38)$ & 89.3077 \\
\hline $\mathrm{A}(1,10,12)$ & 153.1021 & $\mathrm{~A}(12,15,17)$ & 107.9871 & $\mathrm{~A}(37,35,40)$ & 91.1815 \\
\hline $\mathrm{A}(1,10,13)$ & 108.2737 & $\mathrm{~A}(12,15,19)$ & 126.0317 & $\mathrm{~A}(38,35,39)$ & 89.7042 \\
\hline $\mathrm{A}(1,10,15)$ & 165.0754 & $\mathrm{~A}(17,15,19)$ & 125.9779 & $\mathrm{~A}(38,35,40)$ & 88.5171 \\
\hline $\mathrm{A}(1,10,17)$ & 127.4695 & $\mathrm{~A}(10,17,20)$ & 125.6926 & $\mathrm{~A}(39,35,40)$ & 90.94 \\
\hline $\mathrm{A}(2,10,4)$ & 68.4438 & $\mathrm{~A}(13,17,15)$ & 108.0136 & $\mathrm{~A}(35,40,41)$ & 108.2681 \\
\hline $\mathrm{A}(2,10,5)$ & 68.1488 & $\mathrm{~A}(13,17,20)$ & 125.8966 & $\mathrm{~A}(35,40,45)$ & 108.177 \\
\hline $\mathrm{A}(2,10,11)$ & 153.4134 & $\mathrm{~A}(15,17,20)$ & 126.0868 & $\mathrm{~A}(35,40,49)$ & 123.7157 \\
\hline $\mathrm{A}(2,10,12)$ & 164.7047 & $\mathrm{~A}(1,21,22)$ & 108.6059 & $\mathrm{~A}(41,40,45)$ & 98.418 \\
\hline $\mathrm{A}(2,10,13)$ & 119.3333 & $\mathrm{~A}(1,21,23)$ & 115.3522 & $\mathrm{~A}(41,40,49)$ & 107.6949 \\
\hline $\mathrm{A}(2,10,15)$ & 127.0752 & $\mathrm{~A}(1,21,50)$ & 109.4353 & $\mathrm{~A}(45,40,49)$ & 107.6464 \\
\hline $\mathrm{A}(2,10,17)$ & 108.025 & $\mathrm{~A}(22,21,23)$ & 108.2778 & $\mathrm{~A}(40,41,42)$ & 108.4463 \\
\hline $\mathrm{A}(3,10,5)$ & 68.4446 & $\mathrm{~A}(22,21,50)$ & 105.7209 & $\mathrm{~A}(40,41,43)$ & 107.7489 \\
\hline $\mathrm{A}(3,10,11)$ & 164.732 & $\mathrm{~A}(23,21,50)$ & 109.0102 & $\mathrm{~A}(40,41,44)$ & 106.5533 \\
\hline $\mathrm{A}(3,10,12)$ & 126.6534 & $\mathrm{~A}(21,23,24)$ & 109.1789 & $\mathrm{~A}(42,41,43)$ & 112.6632 \\
\hline $\mathrm{A}(3,10,13)$ & 152.9319 & $\mathrm{~A}(21,23,25)$ & 111.7608 & $\mathrm{~A}(42,41,44)$ & 109.7072 \\
\hline $\mathrm{A}(3,10,15)$ & 107.1437 & $\mathrm{~A}(21,23,51)$ & 109.3537 & $\mathrm{~A}(43,41,44)$ & 111.4715 \\
\hline $\mathrm{A}(3,10,17)$ & 118.4693 & $\mathrm{~A}(24,23,25)$ & 110.0394 & $\mathrm{~A}(40,45,46)$ & 106.4852 \\
\hline $\mathrm{A}(4,10,11)$ & 127.2224 & $\mathrm{~A}(24,23,51)$ & 106.9305 & $\mathrm{~A}(40,45,47)$ & 107.8218 \\
\hline $\mathrm{A}(4,10,12)$ & 107.3904 & $\mathrm{~A}(25,23,51)$ & 109.4543 & $\mathrm{~A}(40,45,48)$ & 108.4866 \\
\hline $\mathrm{A}(4,10,13)$ & 165.3563 & $\mathrm{~A}(23,25,26)$ & 121.5628 & $\mathrm{~A}(46,45,47)$ & 111.444 \\
\hline $\mathrm{A}(4,10,15)$ & 118.2011 & $\mathrm{~A}(23,25,27)$ & 121.4974 & $\mathrm{~A}(46,45,48)$ & 109.6547 \\
\hline $\mathrm{A}(4,10,17)$ & 152.4014 & $\mathrm{~A}(26,25,27)$ & 116.9012 & $\mathrm{~A}(47,45,48)$ & 112.6969 \\
\hline
\end{tabular}

Table S8(e). DFT optimized structure bond angles of NAMI-Pyr

\begin{tabular}{|c|c|c|c|c|c|}
\hline Angles & Degrees & Angles & Degrees & Angles & Degrees \\
\hline $\mathrm{A}(2,1,3)$ & 118.5259 & $\mathrm{~A}(4,8,11)$ & 120.4855 & $\mathrm{~A}(11,16,25)$ & 123.6695 \\
\hline $\mathrm{A}(2,1,26)$ & 120.7328 & $\mathrm{~A}(6,8,11)$ & 120.4577 & $\mathrm{~A}(17,16,21)$ & 98.2986 \\
\hline $\mathrm{A}(3,1,26)$ & 120.7413 & $\mathrm{~A}(8,11,12)$ & 89.1663 & $\mathrm{~A}(17,16,25)$ & 107.7477 \\
\hline $\mathrm{A}(1,2,4)$ & 119.1569 & $\mathrm{~A}(8,11,13)$ & 89.1787 & $\mathrm{~A}(21,16,25)$ & 107.6131 \\
\hline $\mathrm{A}(1,2,5)$ & 121.5237 & $\mathrm{~A}(8,11,14)$ & 89.7631 & $\mathrm{~A}(16,17,18)$ & 108.3958 \\
\hline $\mathrm{A}(4,2,5)$ & 119.3194 & $\mathrm{~A}(8,11,15)$ & 88.9366 & $\mathrm{~A}(16,17,19)$ & 107.82 \\
\hline $\mathrm{A}(1,3,6)$ & 119.1757 & $\mathrm{~A}(12,11,13)$ & 90.4419 & $\mathrm{~A}(16,17,20)$ & 106.583 \\
\hline $\mathrm{A}(1,3,7)$ & 121.5172 & $\mathrm{~A}(12,11,15)$ & 90.4529 & $\mathrm{~A}(18,17,19)$ & 112.6536 \\
\hline $\mathrm{A}(6,3,7)$ & 119.3071 & $\mathrm{~A}(12,11,16)$ & 92.3983 & $\mathrm{~A}(18,17,20)$ & 109.7046 \\
\hline $\mathrm{A}(2,4,8)$ & 122.0572 & $\mathrm{~A}(13,11,14)$ & 89.2442 & $\mathrm{~A}(19,17,20)$ & 111.4364 \\
\hline
\end{tabular}




\begin{tabular}{|c|c|c|c|c|c|}
\hline $\mathrm{A}(2,4,9)$ & 122.2569 & $\mathrm{~A}(13,11,16)$ & 91.0389 & $\mathrm{~A}(16,21,22)$ & 106.527 \\
\hline $\mathrm{A}(8,4,9)$ & 115.6858 & $\mathrm{~A}(14,11,15)$ & 89.8256 & $\mathrm{~A}(16,21,23)$ & 107.7034 \\
\hline $\mathrm{A}(3,6,8)$ & 122.0282 & $\mathrm{~A}(14,11,16)$ & 88.6735 & $\mathrm{~A}(16,21,24)$ & 108.5286 \\
\hline $\mathrm{A}(3,6,10)$ & 122.3073 & $\mathrm{~A}(15,11,16)$ & 90.8199 & $\mathrm{~A}(22,21,23)$ & 111.4474 \\
\hline $\mathrm{A}(8,6,10)$ & 115.6645 & $\mathrm{~A}(11,16,17)$ & 108.2351 & $\mathrm{~A}(22,21,24)$ & 109.7235 \\
\hline $\mathrm{A}(4,8,6)$ & 119.0561 & $\mathrm{~A}(11,16,21)$ & 108.336 & $\mathrm{~A}(23,21,24)$ & 112.6613 \\
\hline
\end{tabular}

Table S9(a). DFT Mulliken atomic spin densities of Ru-4-FcPyr

\begin{tabular}{|c|c|c|c|c|c|c|c|c|}
\hline No. & Atom & Spin Density & No. & Atom & Spin Density & No. & Atom & Spin Density \\
\hline 1 & $\mathrm{C}$ & 0.000665 & 16 & $\mathrm{H}$ & 0.000002 & 31 & $\mathrm{Cl}$ & 0.061868 \\
\hline 2 & $\mathrm{C}$ & -0.000284 & 17 & $\mathrm{C}$ & 0.000114 & 32 & $\mathrm{Cl}$ & 0.039872 \\
\hline 3 & $\mathrm{C}$ & 0.000017 & 18 & $\mathrm{H}$ & 0.000008 & 33 & $\mathrm{Cl}$ & 0.027907 \\
\hline 4 & $\mathrm{C}$ & 0.000044 & 19 & $\mathrm{H}$ & -0.000001 & 34 & $\mathrm{Cl}$ & 0.039965 \\
\hline 5 & $\mathrm{C}$ & -0.000346 & 20 & $\mathrm{H}$ & -0.000005 & 35 & $\mathrm{Ru}$ & 0.86328 \\
\hline 6 & $\mathrm{H}$ & 0.000014 & 21 & $\mathrm{C}$ & -0.003162 & 36 & $\mathrm{~S}$ & -0.009424 \\
\hline 7 & $\mathrm{H}$ & 0.000000 & 22 & $\mathrm{C}$ & 0.001161 & 37 & $\mathrm{O}$ & -0.005023 \\
\hline 8 & $\mathrm{H}$ & -0.000004 & 23 & $\mathrm{C}$ & 0.001264 & 38 & $\mathrm{C}$ & -0.001702 \\
\hline 9 & $\mathrm{H}$ & 0.000017 & 24 & $\mathrm{C}$ & -0.00285 & 39 & $\mathrm{H}$ & -0.000416 \\
\hline 10 & $\mathrm{Fe}$ & -0.000663 & 25 & $\mathrm{H}$ & -0.000131 & 40 & $\mathrm{H}$ & 0.000079 \\
\hline 11 & $\mathrm{C}$ & 0.000125 & 26 & $\mathrm{C}$ & -0.003043 & 41 & $\mathrm{H}$ & 0.000026 \\
\hline 12 & $\mathrm{C}$ & -0.000033 & 27 & $\mathrm{H}$ & -0.000136 & 42 & $\mathrm{C}$ & -0.001715 \\
\hline 13 & $\mathrm{C}$ & -0.000199 & 28 & $\mathrm{H}$ & 0.000409 & 43 & $\mathrm{H}$ & -0.000415 \\
\hline 14 & $\mathrm{H}$ & -0.000005 & 29 & $\mathrm{H}$ & 0.000502 & 44 & $\mathrm{H}$ & 0.000025 \\
\hline 15 & $\mathrm{C}$ & 0.000039 & 30 & $\mathrm{~N}$ & -0.007917 & 45 & $\mathrm{H}$ & 0.000073 \\
\hline \multicolumn{9}{|c|}{ Sum of Mulliken atomic spin densities $=1.00000$} \\
\hline
\end{tabular}

Table S9(b). DFT Mulliken atomic spin densities of Ru-3-FcPyr

\begin{tabular}{|c|c|c|c|c|c|c|c|c|c|}
\hline No. & Atom & Spin Density & No. & Atom & Spin Density & No. & Atom & Spin Density \\
\hline 1 & $\mathrm{C}$ & -0.000215 & 16 & $\mathrm{H}$ & -0.000002 & 31 & $\mathrm{Ru}$ & 0.86451 \\
\hline 2 & $\mathrm{C}$ & 0.000029 & 17 & $\mathrm{C}$ & -0.000022 & 32 & $\mathrm{Cl}$ & 0.033148 \\
\hline 3 & $\mathrm{C}$ & 0.000003 & 18 & $\mathrm{H}$ & -0.000041 & 33 & $\mathrm{Cl}$ & 0.043247 \\
\hline 4 & $\mathrm{C}$ & -0.000011 & 19 & $\mathrm{H}$ & 0.000000 & 34 & $\mathrm{Cl}$ & 0.02808 \\
\hline 5 & $\mathrm{C}$ & 0.000093 & 20 & $\mathrm{H}$ & 0.000001 & 35 & $\mathrm{Cl}$ & 0.063233 \\
\hline 6 & $\mathrm{H}$ & -0.000002 & 21 & $\mathrm{C}$ & 0.000873 & 36 & $\mathrm{~S}$ & -0.00949 \\
\hline 7 & $\mathrm{H}$ & -0.000001 & 22 & $\mathrm{C}$ & -0.00282 & 37 & $\mathrm{O}$ & -0.005103 \\
\hline 8 & $\mathrm{H}$ & 0.000001 & 23 & $\mathrm{C}$ & -0.002802 & 38 & $\mathrm{C}$ & -0.001707 \\
\hline 9 & $\mathrm{H}$ & -0.000016 & 24 & $\mathrm{H}$ & 0.000338 & 39 & $\mathrm{H}$ & 0.000074 \\
\hline 10 & $\mathrm{Fe}$ & 0.000269 & 25 & $\mathrm{C}$ & 0.001032 & 40 & $\mathrm{H}$ & -0.000415 \\
\hline 11 & $\mathrm{C}$ & 0.000013 & 26 & $\mathrm{H}$ & 0.000126 & 41 & $\mathrm{H}$ & 0.000028 \\
\hline 12 & $\mathrm{C}$ & 0.000018 & 27 & $\mathrm{H}$ & -0.000139 & 42 & $\mathrm{C}$ & -0.001722 \\
\hline 13 & $\mathrm{C}$ & 0.000034 & 28 & $\mathrm{C}$ & -0.002726 & 43 & $\mathrm{H}$ & -0.000418 \\
\hline 14 & $\mathrm{H}$ & 0.000082 & 29 & $\mathrm{H}$ & 0.000476 & 44 & $\mathrm{H}$ & 0.000089 \\
\hline 15 & $\mathrm{C}$ & -0.000007 & 30 & $\mathrm{~N}$ & -0.008173 & 45 & $\mathrm{H}$ & 0.000035 \\
\hline
\end{tabular}


Table S9(c). DFT Mulliken atomic spin densities of Ru-4-FcVinylPyr

\begin{tabular}{|c|c|c|c|c|c|c|c|c|}
\hline No. & Atom & Spin Density & No. & Atom & Spin Density & No. & Atom & Spin Density \\
\hline 1 & $\mathrm{C}$ & 0.000602 & 18 & $\mathrm{H}$ & 0.000004 & 35 & $\mathrm{Ru}$ & 0.863863 \\
\hline 2 & $\mathrm{C}$ & -0.000321 & 19 & $\mathrm{H}$ & 0.000001 & 36 & $\mathrm{Cl}$ & 0.061244 \\
\hline 3 & $\mathrm{C}$ & 0.000047 & 20 & $\mathrm{H}$ & -0.000005 & 37 & $\mathrm{Cl}$ & 0.040417 \\
\hline 4 & $\mathrm{C}$ & 0.000002 & 21 & $\mathrm{C}$ & -0.002868 & 38 & $\mathrm{Cl}$ & 0.02817 \\
\hline 5 & $\mathrm{C}$ & -0.000257 & 22 & $\mathrm{H}$ & 0.000139 & 39 & $\mathrm{Cl}$ & 0.040399 \\
\hline 6 & $\mathrm{H}$ & 0.000015 & 23 & $\mathrm{C}$ & 0.001812 & 40 & $\mathrm{~S}$ & -0.009385 \\
\hline 7 & $\mathrm{H}$ & -0.000003 & 24 & $\mathrm{H}$ & -0.000076 & 41 & $\mathrm{C}$ & -0.0017 \\
\hline 8 & $\mathrm{H}$ & 0 & 25 & $\mathrm{C}$ & -0.003596 & 42 & $\mathrm{H}$ & 0.00007 \\
\hline 9 & $\mathrm{H}$ & 0.000012 & 26 & $\mathrm{C}$ & 0.00151 & 43 & $\mathrm{H}$ & -0.000413 \\
\hline 10 & $\mathrm{Fe}$ & -0.000677 & 27 & $\mathrm{C}$ & 0.001619 & 44 & $\mathrm{H}$ & 0.000022 \\
\hline 11 & $\mathrm{C}$ & 0.000125 & 28 & $\mathrm{C}$ & -0.003437 & 45 & $\mathrm{C}$ & -0.001676 \\
\hline 12 & $\mathrm{C}$ & -0.000001 & 29 & $\mathrm{H}$ & -0.000147 & 46 & $\mathrm{H}$ & 0.000026 \\
\hline 13 & $\mathrm{C}$ & -0.000204 & 30 & $\mathrm{C}$ & -0.003132 & 47 & $\mathrm{H}$ & -0.000414 \\
\hline 14 & $\mathrm{H}$ & -0.000006 & 31 & $\mathrm{H}$ & -0.000154 & 48 & $\mathrm{H}$ & 0.000084 \\
\hline 15 & $\mathrm{C}$ & 0.000007 & 32 & $\mathrm{~N}$ & -0.007752 & 49 & $\mathrm{O}$ & -0.005022 \\
\hline 16 & $\mathrm{H}$ & 0.000001 & 33 & $\mathrm{H}$ & 0.000429 & & & \\
\hline 17 & $\mathrm{C}$ & 0.000116 & 34 & $\mathrm{H}$ & 0.00051 & & & \\
\hline \multicolumn{9}{|c|}{ Sum of Mulliken atomic spin densities $=1.00000$} \\
\hline
\end{tabular}

Table S10(d). DFT Mulliken atomic spin densities of Ru-4-FcEtPyr

\begin{tabular}{|c|c|c|c|c|c|c|c|c|}
\hline No. & Atom & Spin Density & No. & Atom & Spin Density & No. & Atom & Spin Density \\
\hline 1 & $\mathrm{C}$ & -0.000027 & 18 & $\mathrm{H}$ & 0.00000 & 35 & $\mathrm{Ru}$ & 0.863381 \\
\hline 2 & $\mathrm{C}$ & -0.000004 & 19 & $\mathrm{H}$ & 0.00000 & 36 & $\mathrm{Cl}$ & 0.060993 \\
\hline 3 & $\mathrm{C}$ & 0.00000 & 20 & $\mathrm{H}$ & 0.00000 & 37 & $\mathrm{Cl}$ & 0.039967 \\
\hline 4 & $\mathrm{C}$ & -0.000001 & 21 & $\mathrm{C}$ & -0.000134 & 38 & $\mathrm{Cl}$ & 0.027861 \\
\hline 5 & $\mathrm{C}$ & 0.00000 & 22 & $\mathrm{H}$ & 0.000003 & 39 & $\mathrm{Cl}$ & 0.04012 \\
\hline 6 & $\mathrm{H}$ & 0.00000 & 23 & $\mathrm{C}$ & 0.00022 & 40 & $\mathrm{~S}$ & -0.009472 \\
\hline 7 & $\mathrm{H}$ & 0.00000 & 24 & $\mathrm{H}$ & -0.000036 & 41 & $\mathrm{C}$ & -0.001729 \\
\hline 8 & $\mathrm{H}$ & 0.00000 & 25 & $\mathrm{C}$ & -0.002857 & 42 & $\mathrm{H}$ & 0.000069 \\
\hline 9 & $\mathrm{H}$ & 0.00000 & 26 & $\mathrm{C}$ & 0.001016 & 43 & $\mathrm{H}$ & -0.000417 \\
\hline 10 & $\mathrm{Fe}$ & -0.000004 & 27 & $\mathrm{C}$ & 0.00109 & 44 & $\mathrm{H}$ & 0.000024 \\
\hline 11 & $\mathrm{C}$ & 0.00000 & 28 & $\mathrm{C}$ & -0.002765 & 45 & $\mathrm{C}$ & -0.001722 \\
\hline 12 & $\mathrm{C}$ & 0.00000 & 29 & $\mathrm{H}$ & -0.000127 & 46 & $\mathrm{H}$ & 0.000028 \\
\hline 13 & $\mathrm{C}$ & -0.000001 & 30 & $\mathrm{C}$ & -0.002833 & 47 & $\mathrm{H}$ & -0.000418 \\
\hline 14 & $\mathrm{H}$ & 0.00000 & 31 & $\mathrm{H}$ & -0.000132 & 48 & $\mathrm{H}$ & 0.000086 \\
\hline 15 & $\mathrm{C}$ & 0.00000 & 32 & $\mathrm{~N}$ & -0.00797 & 49 & $\mathrm{O}$ & -0.005064 \\
\hline 16 & $\mathrm{H}$ & 0.00000 & 33 & $\mathrm{H}$ & 0.000402 & 50 & $\mathrm{H}$ & 0.000003 \\
\hline 17 & $\mathrm{C}$ & 0.00000 & 34 & $\mathrm{H}$ & 0.000495 & 51 & $\mathrm{H}$ & -0.000043 \\
\hline \multicolumn{9}{|c|}{ Sum of Mulliken atomic spin densities $=\mathbf{1 . 0 0 0 0 0}$} \\
\hline
\end{tabular}


Table S10(e). DFT Mulliken atomic spin densities of NAMI-Pyr

\begin{tabular}{|c|c|c|c|c|c|c|c|c|}
\hline No. & Atom & Spin Density & No. & Atom & Spin Density & No. & Atom & Spin Density \\
\hline 1 & $\mathrm{C}$ & -0.002985 & 10 & $\mathrm{H}$ & 0.000496 & 19 & $\mathrm{H}$ & -0.000415 \\
\hline 2 & $\mathrm{C}$ & 0.001013 & 11 & $\mathrm{Ru}$ & 0.863156 & 20 & $\mathrm{H}$ & 0.000027 \\
\hline 3 & $\mathrm{C}$ & 0.001092 & 12 & $\mathrm{Cl}$ & 0.061152 & 21 & $\mathrm{C}$ & -0.001716 \\
\hline 4 & $\mathrm{C}$ & -0.002805 & 13 & $\mathrm{Cl}$ & 0.039163 & 22 & $\mathrm{H}$ & 0.000027 \\
\hline 5 & $\mathrm{H}$ & -0.000127 & 14 & $\mathrm{Cl}$ & 0.028526 & 23 & $\mathrm{H}$ & -0.000415 \\
\hline 6 & $\mathrm{C}$ & -0.002892 & 15 & $\mathrm{Cl}$ & 0.040391 & 24 & $\mathrm{H}$ & 0.000076 \\
\hline 7 & $\mathrm{H}$ & -0.000133 & 16 & $\mathrm{~S}$ & -0.009452 & 25 & $\mathrm{O}$ & -0.005046 \\
\hline 8 & $\mathrm{~N}$ & -0.00804 & 17 & $\mathrm{C}$ & -0.00172 & 26 & $\mathrm{H}$ & 0.000145 \\
\hline 9 & $\mathrm{H}$ & 0.000403 & 18 & $\mathrm{H}$ & 0.00008 & & & \\
\hline
\end{tabular}

